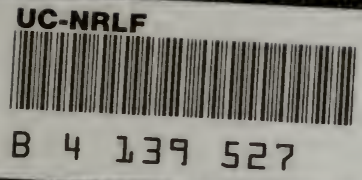



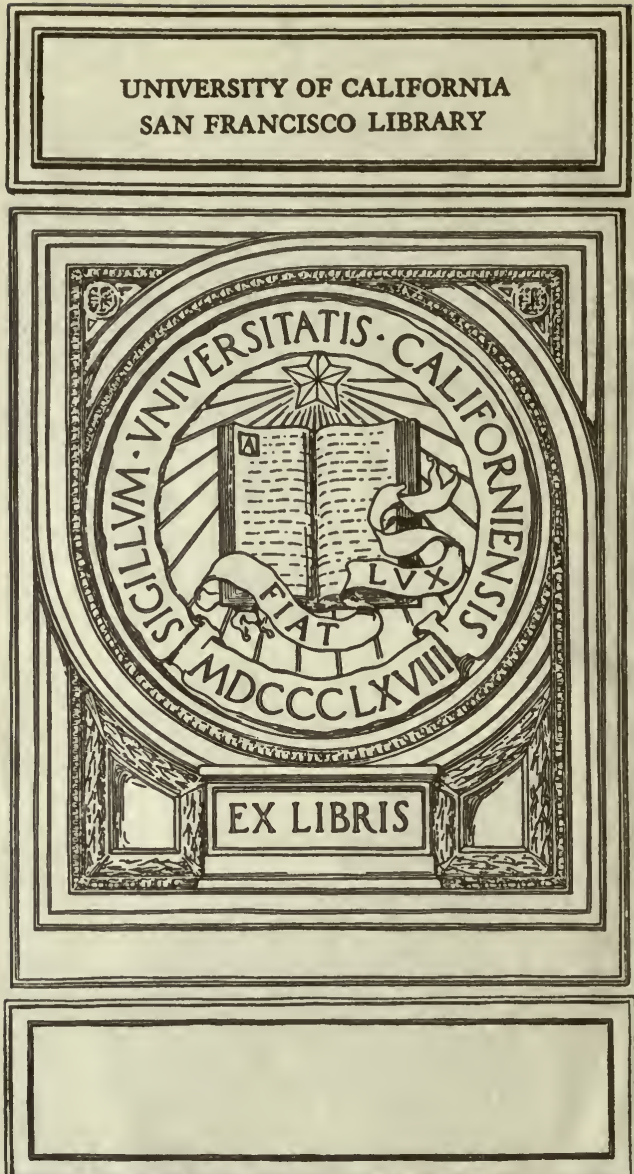


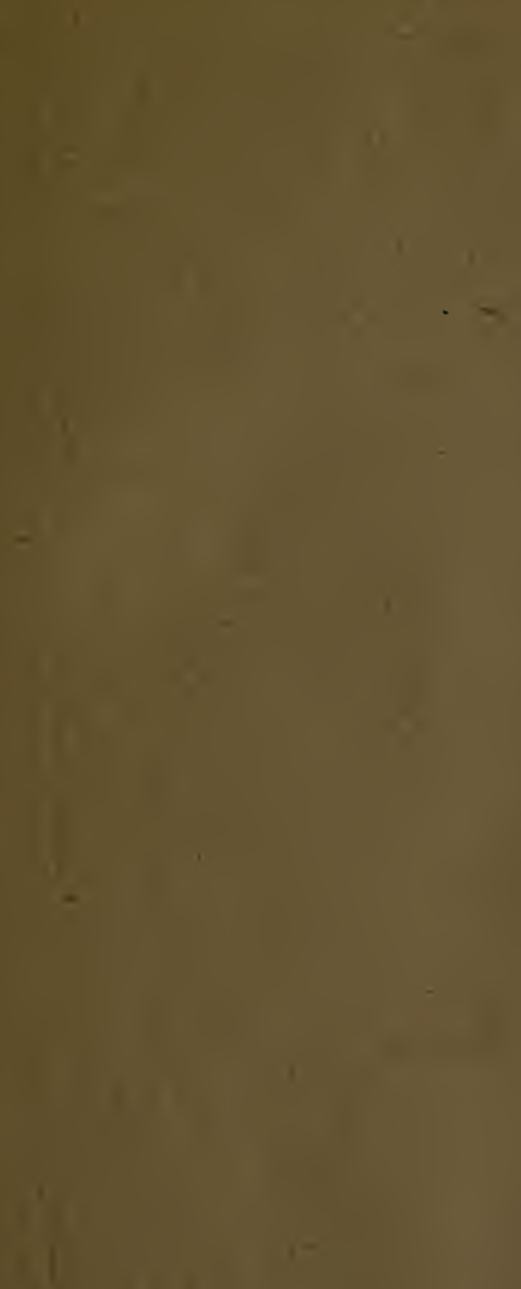


Dialbzed by ilis inieriel Aichne in 2007 wis sumding tram

Miorosoil sarporation 


\section{BACTERIOLOGY FOR NURSES}




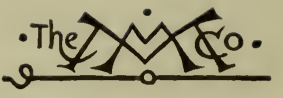

THE MACMILLAN COMPANY

NEW YORK - BOSTON - CHICAGO SAN FRANCISCO

MACMILLAN \& CO., Limited

LONDON - BOMBAY - CALCUTTA

MELBOURNE

THE MACMILLAN CO. OF CANADA, LtD. TORONTO 


\section{BACTERIOLOGY FOR NURSES}

Claraseame Wuiternute R.A
ISABEL [MCISAAC, R.N.

AUTHOR OF "PRIMARY NURSING TECHNIQUE," “HYGIENE FOR NURSES," "HYGIENE FOR THE USE OF PUBLIC SCHOOLS"

SECOND EDITION. REVISED

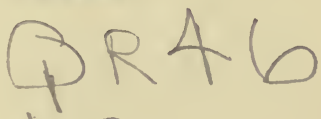

M3

1916

New Mark

THE MACMILLAN COMPANY

1916

All rights reserved 
Copyright, 1909, 1914,

\section{BY THE MACMILLAN COMPANY.}

Set up and electrotyped. Published November, rgog. Reprinted October, rgrx; September, x912; July, r9r3.

Revised Edition, May, October, r9r4; July, r9r5; January, August, October, rgr6. 
To

\section{EUPHEMIA}

SISTER AND COMRADE 



\section{TEACHERS' PREFACE}

IN arranging these chapters on bacteriology for the use of pupil nurses, no attempt has been made to do more than to endeavor to bring the essentials of an enormous subject into a practical arrangement, which will serve to introduce young nurses to one of the most important phases of nursing; viz., the prevention of infection.

The suggested schedule for laboratory work was compiled from several outlines which are in use in different schools for nurses, the courses varying from five exercises of one hour each, to twenty exercises of two hours each ; one seemingly inadequate and the other requiring more time than is feasible in the majority of schools. This work should not be attempted in the classroom, but should be done in a well-equipped laboratory under the direction of a bacteriologist. The class work may easily be done by the nurse teachers, but they should not attempt the laboratory exercises except after extended bacteriological work.

The schedule should not be regarded as inflexible, as numerous opportunities for the observation of material from well-known cases in the wards 
will arise, and their use serve to impress more strongly upon the pupils the manifestations of particular infections. Neither should the arrangement of the chapters be immovable; the laboratory exercises and class work should go hand in hand. 


\section{SCHEDULE FOR TWELVE LABORATORY EXERCISES OF TWO-HOUR PERIODS}

Exercise I. Washing, plugging, and sterilizing glassware.

Exercise II. Making of media.

Exercise III. Technique of :

Inoculation of media.

Preparation of plates.

Hanging drop.

Use of microscope.

Exercise IV. Making and microscopical examination of stained preparations.

Exercise V. Observation of bacilli:

Spore-bearing.

B. subtilis.

B. chromogenic, etc.

Pathogenic:

B. coli communis.

B. typhosus.

B. tuberculosis.

B. diphtherice.

Demonstration of Widal's test.

Exercise VI. Observation of pathogenic micrococci:

Staphylococci.

Streptococci.

Pneumococcus.

Gonococcus.

Spirilla:

S. cholera.

Treponema pallidum.

Exercise VII. Demonstration of anaërobic cultures.

Exercise VIII. Bacteriological examination of water; from five or six sources and after sterilization. 
Exercise IX. Examination of air and dust; from hospital wards, dwellings, and the street.

Exercise X. Examination of cultures from hands, and from rubber gloves; before and after sterilization.

Exercise XI. Examination of milk; from the hospital supply, from outside sources, and after pasteurization.

Exercise XII. Examination of cultures from surgical dressings and suture material.

\section{FOR NURSES' REFERENCE LIBRARY}

Manual of Bacteriology, by Robert Muir, M.A., M.D., F.R.C.P.

Ed., and James Ritchie, M.A., M.D., B.Sc. [Macmillan.]

Practical Bacteriology, by Edwin O. Jordan, Ph.D. [Saunders.] Hygiene of Transmissible Diseases, by A. C. Abbott, M.D. [Saunders.] A Laboratory Guide in Bacteriology, by Paul G. Heinemann, Sc.B. [University of Chicago Press.]

Sources and Modes of Infection, by Charles V. Chapin, M.D., Sc.D. [John Wiley and Sons.] 


\section{TABLE OF CONTENTS}

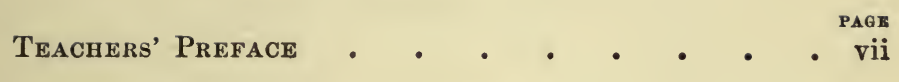
CHAPTER I

INTRODUCTION • • • • • • • • • • 1

\section{CHAPTER II}

Structure, Mode of Development, and Composition of Bacteria.

\section{CHAPTER III}

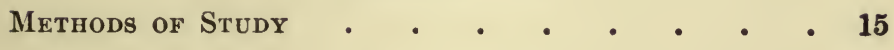

CHAPTER IV

The Effect of Physical and Chemical Agents upon Bacteria, ANd the Effects of Bacterial Growth 27

CHAPTER V

The Relations of Bacteria to Disease

\section{CHAPTER VI}

IMMUNITY

\section{CHAPTER VII}

Inflammation, Suppuration, Pneumonia, Epidemic Cerebro-spinat. Meningitis . 


\section{CHAPTER VIII}

The Venereal Diseases: Gonorrhea, Syphilis • $\quad 76$

CHAPTER IX

Tuberculosis. Leprosy • • • • • • 85

CHAPTER $\mathrm{X}$

Glanders, Actinomycosis, Anthrax

CHAPTER XI

Typhoid Fever (Enteric Fever) • • • • . 108

CHAPTER XII

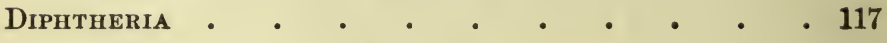

CHAPTER XIII

Tetanus, Influenza, Bubonic Plague • • • • 126

CHAPTER XIV

Asiatic Cholera, Relapsing Fever . • • • 147

CHAPTER XV

Amebic Dysentery, Malarial Fever . • • . 155

\section{CHAPTER XVI}

Infectious Diseases of Unknown Cause: Smallpox (Variola), Hydrophobia (Rabies), Scarlet Fever, Measles, Whooping Cough, Mumps, Yellow Fever 162

CHAPTER XVII

Bacteria in Air, Soll, Water, and Food • • 172 


\section{BACTERIOLOGY FOR NURSES}





\section{BACTERIOLOGY FOR NURSES}

\section{CHAPTER I}

\section{INTRODUCTION}

The Discovery of Bacteria. - Bacteria are the smallest and simplest known form of plant life, although no other class of plants compares with them in importance. The study of bacteria began with the development of the microscope. While several writers of antiquity surmised that such microörganisms existed, and advanced some really marvelous speculations as to their place in nature, yet it was not until a Dutch lens-maker, Leeuwenhoek (1632-1723), perfected a lens of higher power than had been made before, that bacteria, or "animalcules," as he designated them, were seen and described. In 1675 Leeuwenhoek published the fact that he had perfected a lens whereby he could detect in a drop of rainwater, living, moving "animalcules" smaller than anything which had hitherto been seen. He found them in sea-water, in wellwater, in feces, and in the tartar scraped from his 
teeth, and also discovered that they differed in size, shape, and motility; his descriptions and plates leave no doubt but what we now know as bacteria were the "animalcules" which he first saw with his simple lens.

Leeuwenhoek made no attempt to formulate a theory as to the place these microörganisms occupied in nature, but his discovery of their presence in water and in the intestinal evacuations led to the first association of bacteria and disease in the minds of medical scientists. Nothing was done at this time, however, in the way of classifying or separating the organisms, although men did not hesitate to declare them to be the cause of diseases of various kinds.

In 1762 , nearly a century later, Plenciz, a Vienna physician, confirmed Leeuwenhoek's discoveries, and declared that to these "animalcules" was due all of the infectious diseases; that the material of infection must be a living substance, and endeavored to explain upon this ground the period of incubation. Plenciz believed that each disease was due to a special germ, which was capable of multiplication within the human body and could be transmitted to others. That these doctrines of Plenciz should have been lost sight of seems almost incred- 
ible at this time, but they were regarded by many as evidences of an unbalanced mind, most writers at that period doubting the possibility of the microorganisms being living things. In 1786 a Danish zoölogist, Müller, described many structural details of bacteria of which his predecessors were ignorant, and also recognized the extreme difficulties of studying such minute organisms. "The difficulties," he writes, "that beset the investigators of these microscopic animals are countless; the sure and definite determination [of species] requires so much time, so much acumen of eye and judgment, so much perseverance and practice, that there is hardly anything so difficult." (Jordan.)

In 1838 Ehrenberg (1795-1876) made a valuable contribution to the subject in his work on "Infusoria," as the organisms found in infusions of meat, hay, and other substances were called. Ehrenberg was the first to introduce a really systematic method for the study of bacteria.

It was not until Louis Pasteur (1822-1895), about 1850 , began his investigations upon the souring and putrefaction of beer and wine that bacteria were recognized as organisms whose activities were of such significance to the human race.

For two hundred years prior to Pasteur's investi- 
gations, scientists had been discussing whether Leeuwenhoek's " animalcules" generated spontaneously as the result of putrefaction or not, even so great a chemist as Liebig held to the theory of spontaneous generation.

Pasteur proved the utter fallacy of spontaneous generation, and further showed that putrefaction was a chemical change, produced by the activities of the bacteria in their search for food. It was Pasteur who discovered that the souring of milk was due to bacteria, and that certain bacteria are the cause of certain diseases.

Pasteur did not first discover these microörganisms, nor study them first, nor first suggest their connection with disease, but he proved these theories by rigid experiments; proved these and many other theories beyond question, which gave him the title of founder of bacteriology.

The profound importance of Pasteur's work to the world is universally recognized. In 1892 Lord Lister said: "Truly there does not exist in the entire world any individual to whom the medical sciences owe more than they do to Pasteur. . . . Thanks to him, surgery has undergone a complete revolution, which has deprived it of its terrors and has extended almost without limit its efficacious powers." 
In 1876 Robert Koch first demonstrated that anthrax in cattle was due to the Bacillus anthracis.

Until 1882 the methods of study and observation of bacteria were so imperfect that it was almost impossible to isolate a single species, and the process was attended with so much uncertainty that investigators were often not sure whether they were dealing with one or more species.

At this time Koch invented the solid culture media, whereby it became possible to easily isolate a single species, Weigert suggested the use of aniline dyes as a means of differentiation, and the use of animals as a means of obtaining pure cultures began.

From. Koch's series of brilliant investigations, bacteriology is said to have been placed within the reach of men who were not geniuses like Pasteur and himself, and may be justly said to have had its birth.

The development of bacteriology in the last twenty-five years has been marvelously rapid, causing an almost complete revolution in the whole practice of medicine, and opening methods of agriculture and other industries which have proved of infinite benefit to the whole world. The fact that until Pasteur's researches in the middle of 
the nineteenth century the familiar processes of putrefaction and fermentation were not understood, and that the causes of infectious diseases were equally obscure, shows what an important change took place in man's conception of the living world around him, when Pasteur and Koch founded bacteriology.

The part played by bacteria in the causation of disease may be regarded as of surpassing importance, but the work done by them in other directions exerts a mighty influence upon the welfare of mankind. Bacteria not only act as scavengers in destroying dead organic material, but they also change the form of important chemical elements, such as nitrogen and carbon, into substances which are available for the nutrition of the higher plants, thus proving themselves as important in constructive as in destructive processes. 


\section{CHAPTER II}

STRUCTURE, MODE OF DEVELOPMENT, AND COMPOSITION OF BACTERIA

MoRPHOLOGY is the science which deals with the form and structure of organisms.

Bacteria are the smallest and simplest known form of vegetable organisms. They are unicellular (having but one cell) and multiply by fission (splitting into equal parts).

The individual cells differ in size, shape, and structure, which can be determined only by the use of the microscope; but in masses of cells or "colonies," as they are called, which develop in suitable substances, they often present differences in form, color, and consistency which may be detected with the naked eye.

Size. - Different bacteria vary greatly in size, the average of the rod-shaped bacterium being about $0.5 \mu$ in diameter $(1 \mu=1$ micron or micromillimeter $=\frac{1}{1000} \mathrm{~mm} .=$ about $\frac{1}{25000}$ inch). The bacillus of typhoid fever ranges from $1 \mu$ to $3 \mu\left(\frac{1}{25000}\right.$ 
$-\frac{1}{8000}+$ inch) in length; the largest (pathogenic) bacterium known is the spirillum (screw-shaped) of relapsing fever; the bacillus of influenza is one of the smallest of the pathogenic forms, although there are known to be smaller organisms which are too minute to be seen with the present microscopes; the virus of yellow fever will pass through a porcelain filter; the germs of pleuro-pneumonia and foot-and-mouth disease in cattle are too small to be observed (ultramicroscopic).

Shape. - The forms of bacteria are exceedingly simple, comprising three types - the rod, the sphere,
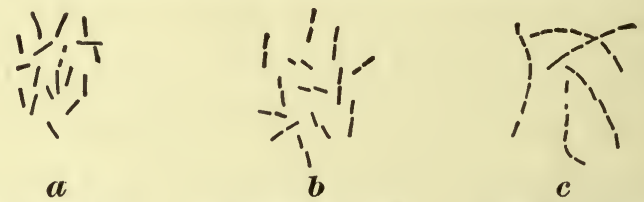

$a$. Single bacilli. $\quad b$. Bacilli in pairs. $\quad c$. Bacilli in threads.

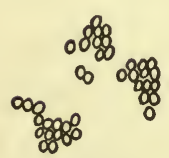

$a$

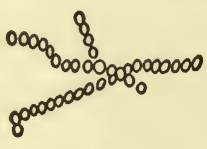

b

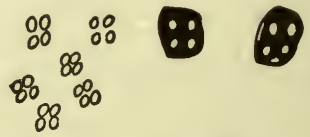

c d

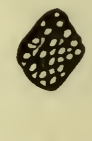

$\boldsymbol{e}$

a. Staphylococci. b. Streptococci. c. Diplococci. $d$. Tetrads. e. Sarcinae.

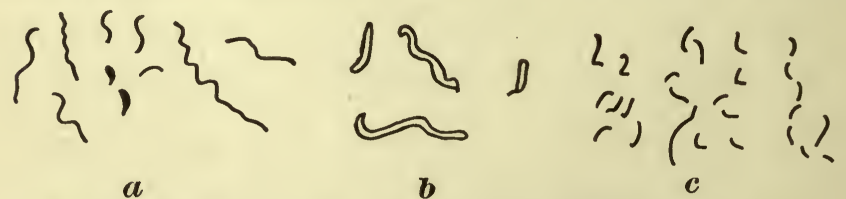

a. and c. Spirilla in comma forms and longer threads known as spirochaeta. $b$. Thick spirals sometimes known as vibrios. 
and the spiral. The rods are known as bacilli (sing. bacillus), the spheres as cocci (sing. coccus), and the spirals as spirilla (sing. spirillum). More baccilli are known than any other form, and cocci are much more numerous than spirilla.

Long-continued growth in artificial media sometimes causes abnormal forms of growth, just as unnatural surroundings and conditions produce deformities in the higher forms of life.

Structure. - The internal structure of bacteria is exceedingly simple: there appears to be a membranous covering, including the protoplasm (germinal matter), which is not always clearly discernible, but in some species (micrococcus of pneumonia) may be seen as a sharply defined capsule inclosing a clear zone.

The nature of the cell-substance is still imperfectly understood; the question of the existence of a nucleus and the significance of the internal structure are still disputed points which present one of the exceeding difficulties of which Müller wrote in 1786.

Motility. - The power of motion in certain species of bacteria is due to hair-like appendages, or flagella, which by a lashing movement enable them to move through fluids. The flagella vary in their position 
upon the cell-body, sometimes occurring at one end, sometimes at both ends, and in others entirely surrounding the bacterium, as in the bacillus of typhoid fever.

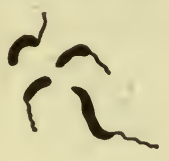

$a$

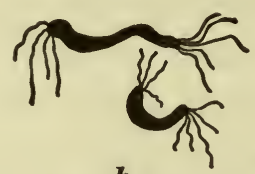

b

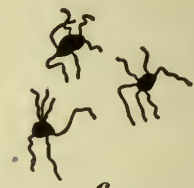

c

Fig. 2. $-a$. Spiral forms with flagellum at one end. $b$. Spirals from water with flagella at both ends. $c$. Bacilli of typhoid fever with flagella on all sides.

The majority of bacteria having motility are bacilli or spirilla.

- Mode of Multiplication. - When bacteria have reached their maximum size, cell-division occurs, which divides the cells into two equal parts. Bacilli and spirilla divide by transverse fission; while among the cocci division may occur in one plane, which results in chains (streptococci), or in two planes, resulting in groups (staphylococci), or in three planes, resulting in packets (sarcinæ).

Under favorable conditions fission occurs rapidly (the hay bacillus in thirty minutes), from which may be readily estimated the enormous multiplication which would result, should nothing occur to check the reproduction. In a single twenty-four hours the increase would reach hundreds of millions, 
DEVELOPMENT AND COMPOSITION OF BACTERIA 11

but, as is the case with all organisms, mathematical increase never continues without check or hindrance.

In the case of bacteria the check arises largely from the products of the bacteria themselves; the organisms in their activity upon food substances produce acids and other injurious materials which check further multiplication. Lack of proper food, or moisture, or favorable temperature, and conflict with other species of organisms, are also checks upon growth and multiplication.

Spore-formation. - Following a period favorable to reproduction, certain bacteria (notably bacilli) enter into a stage known as spore-formation; this usually occurs when food nears exhaustion, or injurious substances have been formed, or unfavorable temperature conditions arise, and is characterized by the development of round or oval glistening bodies (spores) within the cell which are of dense compact structure and possess an extraordinary resistance to heat $\left(70^{\circ}-100^{\circ} \mathrm{C}\right.$, or $158^{\circ}$ $212^{\circ}$ F.), chemicals, and other injurious substances.

A single cell produces but one spore, as a rule, although there are said to be rare exceptions.

Spore-forming bacteria are said to be in the vegetative stage while growth and reproduction 
are taking place. The spore-stage is considered a resting state in which the organisms are able to resist harmful influences to a much greater degree than when in the vegetative state. As soon as fav-

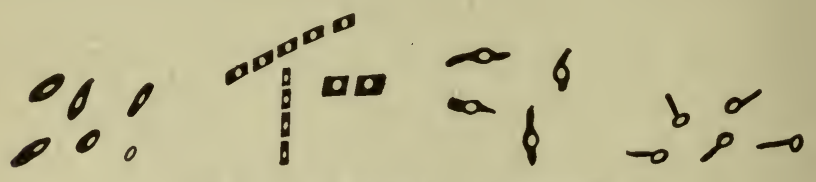

FIG. 3.-Showing spore-formation.

orable conditions of moisture, temperature, and food return, the spores develop again into the same kind of cells from which they originated.

Spore-formation is not common, occurring most frequently in bacilli, less so in spirilla, and rarely in micrococci; however, it is supposed that sporeformation may take place in species growing under natural conditions, but which are impossible to cultivate under artificial surroundings.

The vitality of the spore may remain dormant for months or years, perhaps indefinitely, a fact which is of peculiar significance in the consideration of certain infectious diseases،

Masses of Cells or Colohies. - By implanting upon suitable medium one or more cells of a species of bacteria, and subjecting the culture to favorable conditions of moisture and temperature for a few 
DEVELOPMENT AND COMPOSITION OF BACTERIA 13

hours or days, a mass of cells, or colony, will often be seen with the naked eye. In different species these colonies are often strongly characteristic, varying with the culture media and the conditions under which they are grown.

Besides shape, size, and general appearance, color is often a characteristic difference; but while these differences are important, bacteriologists do not rely upon observations made. with the naked eye (macroscopic).

"The attempt to determine species of bacteria by ordinary macroscopic methods leads to difficulties of the same kind as would be met if we tried to differentiate species from the marks presented by masses of trees in forests from a distancesay, in a balloon. A forest of a given species of tree would appear different at different seasons, and according to its age, the kind of soil, climate, and so on, and the treatment it had received previous to planting." (Marshall Ward.)

The Chemical Composition of Bacteria. - The bodies of bacteria are made up of about 80 per cent of water, the amount varying with the species and the nature of the culture medium; the usual analysis being: 


$$
\begin{aligned}
& \text { Water . . . . . } 85.45 \% \\
& \text { Proteins . . . . . . } 10.33 \% \\
& \text { Fatty substances . . . . . .7\% } \\
& \text { Ash . . . . . . } 1.75 \% \\
& \text { Residue . . . . . } 1.57+\%
\end{aligned}
$$

Sulphur, potassium, calcium, magnesium, phosphoric acid, iron, and silica are found in varying amounts.

Cellulose, the predominant element in the higher forms of plants, is absent from bacteria, and the nature of the protein substances of bacteria are little understood. 


\section{CHAPTER III}

\section{METHODS OF STUDY ${ }^{1}$}

THe slow development of bacteriology was largely due to the lack of method in the study; and not until Pasteur, Koch, and others demonstrated that methods of scientific exactness must be employed was any real progress made. Until this was done the mere fact that bacteria existed stood for very little, as no one could say what effects they produced nor what part they filled in the scheme of nature.

"The technique of bacteriology is one of its greatest contributions to both science and art, and the use of so valuable and simple a tool should be mastered not only by the biological teacher, but by practical workers in medicine, hygiene, and many other fields." (Jordan.)

While bacteriological work in the laboratory will be no part of a graduate nurse's duty, a short course when she is a pupil is necessary to prepare ${ }^{2}$ For reference: A Laboratory Guide in Bacteriology, Heinemann 
her for the various departments of nursing; for she cannot protect herself nor others from contagious matter, if she does not thoroughly understand the sources of infection, the methods of transmission, and the means employed to prevent it. Without a working knowledge of the technique of bacteriology she can neither grasp nor practice aseptic surgical technique, which in its elaborate detail appears nothing short of an absurdity to the ignorant, but to a nurse well trained in first principles and daily routine, becomes an instinct as much a part of her life as the instinctive avoidance of fire or any other dangerous element.

The schedule of exercises in the laboratory outlined in this little book should prepare the pupilnurse not only for her duties in operating and dressing rooms, contagious and maternity wards, but for a better understanding of every nursing requirement from dusting the ward upward. She must know why sputum cups and bedpans need disinfection as well as scrubbing, why certain dishes are separated from others and sterilized, why catheters and douche points require such minute care, why in certain cases the excreta as well as the bed linen must be disinfected, etc. It is not enough to give a nurse the merely mechani- 
cal part of her training without teaching her the principles which should guide the performance of her duties, for without this knowledge she holds in her hands a capacity for doing infinite harm; she cannot avoid dangers which she does not recognize.

To the medical student the study of bacteriology has an entirely different meaning; his application of the knowledge gained is for other purposes, viz. as a means of diagnosis and treatment, - two objects which do not in any way concern the nurse, whose sole interest is for the purpose of enabling her to intelligently execute her nursing and housekeeping technique, the two departments being too closely related to be separated.

In the recent development of bacteriology as related to disease, a tendency has been observed to work along two lines, pathologic and hygienic; the first, considering chiefly the effects produced upon the body by the presence of bacteria and their toxins, and the defenses of the body; while in hygienic bacteriology especial attention is given to the channels by which bacteria leave the body and how they may again infect healthy persons.

Where Bacteria are Found. - Before beginning the study of bacteria it is necessary to have firmly fixed in the mind the fact that bacteria are found every- 
where; wherever air and dust find their way bacteria are present. In the minutest crevices, too small to be seen with the naked eye, like those in the skin, upon the hair, upon all fabrics, furniture, walls, floors, plants; in the earth, water, and food they may be found; in fact, we may truthfully say they are everywhere.

The first and probably the greatest difficulty which beset the early investigators was the presence of numberless kinds together, which effectually prevented any opportunity to isolate a single species for observation. It was early discovered that bacteria would grow in groups (colonies) which were sometimes visible to the naked eye, but the microscope would reveal not one species which might be studied, but a dozen or more, and thus for years scientists labored to devise some method whereby they might isolate a single kind and study its habits.

Bacteria were first grown artificially in bouillon (beef broth), which was called the culture medium, but the multiplicity of species and the fluid medium were serious obstacles which blocked the way of systematic observation, and not until Robert Koch found that gelatin was not unfavorable to bacterial growth, and would solidify the broth, besides being transparent, was it possible for pure cultures to be 
obtained. Meanwhile, investigators found that to secure pure cultures, all utensils, media, or anything coming in contact with them must be freed of bacteria; i.e. the bacteria must be destroyed, or, as we now say, these articles must be "sterilized," or the cultures would not be pure, but a mixture of many species.

It was found that cotton used as a cork for flasks and culture tubes would allow the passage of air which was necessary for the growth of the aërobic bacteria, but would exclude the entrance of bacteria in the air.

Later Weigert Fig. 4.-Culture tube. Tubes of media.

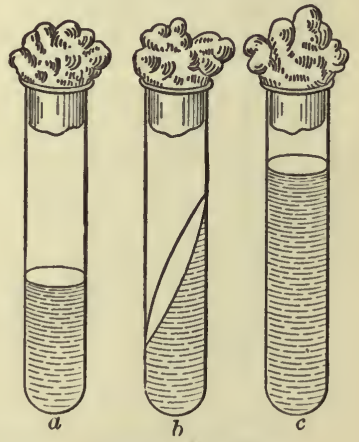
suggested the use $a$. Ordinary upright tube. b. Sloped tube. c. "Deep" of aniline dyes tube for cultures of anaërobes.

for staining bacteria, which were found to take the dyes each in its characteristic way, thus enabling the observer to identify certain species, and from these simple beginnings the elaborate minutiæ of the technique of bacteriology has grown - practically all within thirty-five years. 
Sterilization. - Properly, sterilization means the complete destruction of bacteria, by whatever means; but by custom in the laboratory sterilization is used when heat is the agent employed, and disinfection is used to designate sterilization by chemicals.

Sterilization by heat may be accomplished by dry heat, as by baking or passing an object through a

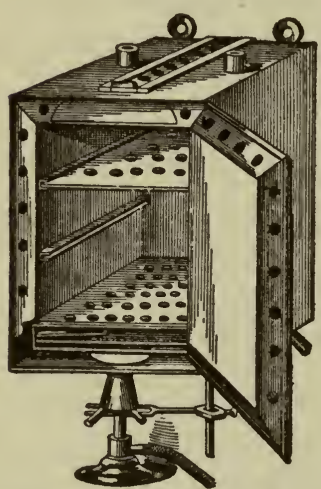

FIG. 5. - Laboratory hotair sterilizer. flame, or by moist heat, such as boiling, or by steam, with or without pressure. Sterilization by heat is commonly employed for the sterilization of utensils, instruments, and culture media, as the action of chemicals would be unfavorable to the cultivation of bacteria; but chemicals are used for disinfecting the hands, old cultures, and all useless infective materials.

It is estimated that bacteria and spores exposed to a temperature of $170^{\circ} \mathrm{C}$. $\left(338^{\circ} \mathrm{F}\right.$.) for one hour will be completely destroyed.

There are a number of hot-air sterilizers in common use which give a uniform heat in all parts of the oven.

Sterilization by steam under pressure is accom- 
plished by means of an autoclave, which is a strong iron cylinder standing upright, closed at the bottom and furnished with a tightfitting lid, and provided with a thermometer, a steam valve, a safety valve, and a gauge whereby the temperature and pressure may be regulated, heat being furnished by Bunsen gas burners or by indirect steam from a central boiler. For culture media in tubes an exposure of five minutes at $120^{\circ}$ C. $\left(248^{\circ} \mathrm{F}\right.$.) is sufficient to destroy all bacteria, but for media in bulk an exposure of fifteen minutes is necessary.

Certain culture media are injured

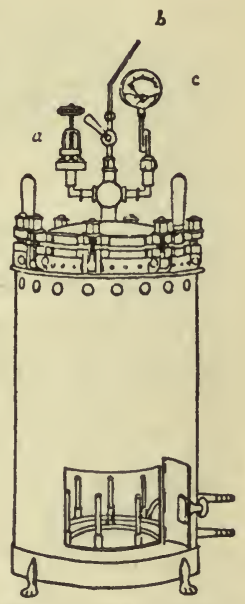

Fig. 6. - Autoclave.

a. Safety-valve.

b. Blow-off pipe.

c. Gauge.

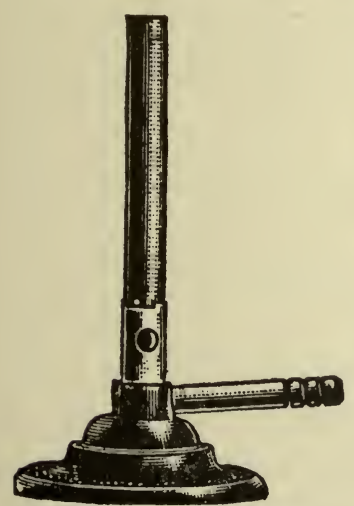

Fig. 7. - Bunsen burner.

by exposure to great heat under pressure, and this fact, together with the extraordinary resistance of the spores of certain species of bacteria, led to the employment of fractional or discontinuous sterilization. The ordinary Arnold steam sterilizer used in the kitchen for the sterilization of 
milk is usually employed, the culture tubes being exposed to $100^{\circ} \mathrm{C}$. $\left(212^{\circ} \mathrm{F}\right.$.) for fifteen minutes on

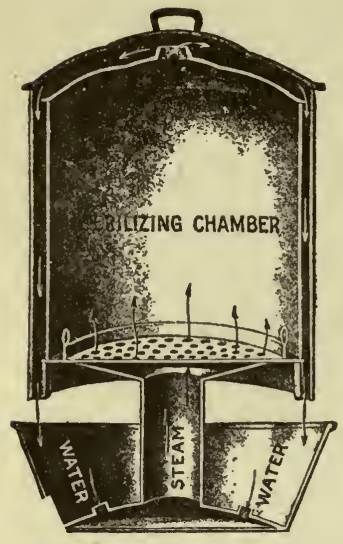

Fig. 8. - Arnold steam sterilizer. three successive days and in the intervals kept at ordinary room temperature; in this way spores which develop after the first sterilization may be destroyed after the second or third.

Filtration of fluids through filter paper or absorbent cotton is employed as an important adjunct of sterilization.

Instruments, such as forceps, scissors, knives, metal syringes, and hypodermic needles, are usually sterilized by boiling in a 2 per cent soda solution for ten minutes, before and after using, the addition of soda preventing rust. Platinum wires used for transferring bacteria are sterilized by passing

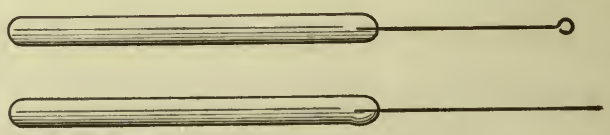
FIG. 9. - Platinum wires.

slowly through a gas flame until red hot and allowing them to cool before using. These wires must be sterilized both before and after using, never being laid 
upon the table before sterilizing, as the purpose for which they are used makes them a constant source of danger.

Cleaning Glassware. - The glassware used in the laboratory consists of flasks, culture tubes, and dishes of various sizes and shapes, with and with-

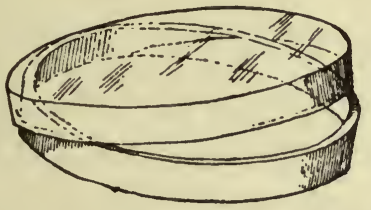

Petri dish.

FIG. 10.

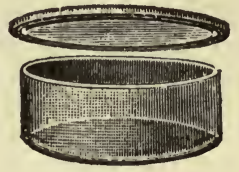

Stender dish.

(Cover shown partially raised.)

out covers, small oblong $(1 \times 2$ inches $)$ pieces of glass called slides, small round cover glasses, glass rods, and glass pencils.

When new or after using, glassware should be put into a strong soapsuds, which should be brought to the boiling point and continued for ten minutes, followed by vigorous

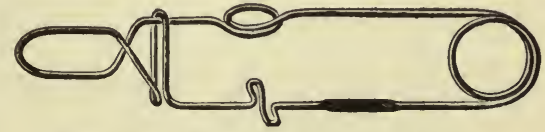

Fig. 11. - Novy's cover-glass forceps. brushing with a tube-brush, rinsed with running water until every particle of soap has been removed, turned upside down to drain in a wire basket, and put into the hot-air sterilizer for twenty minutes. 
If the soapsuds is not effective and the glass has become cloudy with use, a cleaning mixture may be used which contains -

Potassium dichromate . . . . . 60 parts Water . . . . . . . . . 300 parts Concentrated sulphuric acid . . . . 460 parts the sulphuric acid being added slowly with constant stirring. Especial care must be given to remove all traces of the acid by generous rinsing.

Plugging Culture Tubes and Flasks. - The plugging of culture tubes and flasks is done by inserting a suitable quantity of good cotton into the neck of the tube or flask about three quarters of an inch with a glass rod. 'The plug should be rolled smoothly, but not so tightlyas to entirely exclude the passage of air. If not rolled smoothly, bacteria will gain access to the tube in the crevices between the plug and the glass. Neither should the plug be so loose that parts of the cotton will separate when the plug is removed, nor so large that the entrance end rubs the outer rim of the tube when it is inserted. These details may seem exceedingly trivial, but the observance of these minutiæ is what distinguishes good technique from haphazard methods which fail utterly to accomplish the desired results. The plugged culture tubes are then placed 
in the hot-air sterilizer at $150^{\circ} \mathrm{C}$. $\left(302^{\circ} \mathrm{F}\right.$.) for sixty minutes, when the cotton plugs will be charred to a light brown color and will retain their shape.

Culture Media. - Certain food substances are necessary for the cultivation of bacteria, which are known as culture media, and by the behavior of different species upon the various media it is possible for the observer to recognize their kind.

The most common media are bouillon, gelatin, agar, potato, and blood-serum, besides a multitude of special media for more advanced work.

Formulæ for making culture media are a part of the equipment of every laboratory, and must be so closely followed that no attempt will be made to embody them here.

The making of culture media is excellent practice, as the most accurate measurements and management are required; otherewise failure is a sure result.

Staining. - As before mentioned, the staining of bacteria is an important method of distinguishing a species, as various kinds stain in a fixed and characteristic manner. The aniline dyes used most commonly are gentian-violet, methylene-blue, and fuchsin (reddish pink).

A sterilized slide has placed upon it a drop of water to which is added a small amount of bacterial 
growth, the two being mixed and spread evenly upon the glass. This film is allowed to dry in the air and is then passed through the flame of a spirit lamp or Bunsen burner three or four times to fix the film, which is then covered with the stain and allowed to stand twenty or thirty seconds, followed by washing in clear water, when it may be observed with a microscope, and different kinds of bacteria are often easily recognized even by very inexperienced observers. This is a bare outline of how bacteria are stained, the method being greatly elaborated for different species and conditions.

The microscope is an indispensable adjunct to work in the laboratory, the use of which requires practice and delicate care.

Animal Inoculation. - Animal inoculations are employed to observe the virulence of bacteria, to secure pure cultures, and for continuing the life of such organisms as cannot be grown outside of the animal body, such as the virus of smallpox and hydrophobia.

Rabbits, guinea pigs, white rats, and white mice are most commonly used. 


\section{CHAPTER IV}

THE EFFECT OF PHYSICAL AND CHEMICAL AGENTS UPON BACTERIA, AND THE EFFECTS OF BACTERIAL GROWTH

LIKE the higher forms of vegetation, bacteria are susceptible to many influences, the physical and chemical conditions which surround them determining whether they shall live and multiply, or lie dormant, or perish.

Temperature. - Three points of temperature are considered in the growth of different bacteria: a minimum being the lowest point at which growth occurs, an optimum being the temperature of most luxuriant growth, and the maximum being the highest degree at which growth can take place.

The extremes of temperature between which the majority of bacteria are known to grow are $5.5^{\circ} \mathrm{C}$. $\left(41.9^{\circ} \mathrm{F}.\right)$ and $43^{\circ} \mathrm{C}$. (109.4 $4^{\circ} \mathrm{F}$.), although species exist which may multiply at $70^{\circ} \mathrm{C}$. $\left(158^{\circ} \mathrm{F}\right.$.) and others as low as $0^{\circ} \mathrm{C}$. $\left(32^{\circ} \mathrm{F}\right.$.).

The bacteria commonly found in soil and water 
and the bacilli of diphtheria and typhoid fever are much less sensitive to low degrees of temperature than to extremes of heat, sometimes surviving weeks of freezing. A certain species of bacteria commonly found in sewage shows no signs of growth in a temperature below $60^{\circ}$ C. $\left(140^{\circ} \mathrm{F}\right.$.). The favorable degree of temperature for the development of most pathogenic bacteria is that of the human body, $37^{\circ} \mathrm{C}$. (98.6 $6^{\circ} \mathrm{F}$.).

The range between the minimum and maximum degrees of temperature in bacterial resistance is equally great, spores being much more resistant than the vegetative forms; some spores withstanding boiling for sixteen hours, while the vegetative forms are usually killed by ten minutes' exposure to $60^{\circ} \mathrm{C}$. $\left(140^{\circ} \mathrm{F}\right.$.) with moisture.

By thermal death point is meant the degree of temperature necessary to kill the organisms, in a given time; and as this varies with different species, it is used as a means of identification, the thermal death point of all of the common species being well known.

Light. - That light affects the activities of living cells has long been known; the effects of light upon the higher forms of life have been the subject of much investigation during recent years. Sunlight has a 
germicidal effect upon bacteria, many species being killed within a few seconds upon exposure to the direct rays of the sun, and all showing different degrees of sensitiveness to light. The electric light exerts a similar effect to sunlight, but is less powerful.

Moisture. - The absence of moisture may cause the death of bacteria or cause a suspension of development. Certain species are deprived of the power of reproduction without moisture, which under favorable conditions will again grow and multiply.

Desiccation (drying) destroys nearly all of the pathogenic bacteria, the tubercle bacillus being one of the most resistant to drying and the cholera spirillum one of the most sensitive. The spores, however, are extremely resistant to drying. It is said that the spores of the anthrax bacillus will survive drying for ten or more years.

This sensitiveness to drying, shown by a large majority of disease-germs, would indicate that infection through the air, cannot be so common as had been supposed.

Oxygen. - In their relation to oxygen bacteria are divided into three classes: (1) those which require free oxygen for the maintenance of their activities, called obligatory aërobes; (2) those which do not grow except in the almost entire absence of 
free oxygen, called obligatory anaërobes; and (3) the facultative anaërobes, which may exist with or without oxygen.

The obligatory anaërobes derive the small amount of oxygen necessary to them from the oxygen compounds of the material in which they are growing.

Food. - Bacteria obtain their food from many diverse substances, organic compounds of all kinds serving them. Nitrogenous substances especially are quickly attacked by many species, as may be witnessed in the rapid decomposition of meats.

Carbon, nitrogen, and water are essential for the growth of both bacteria and the higher plants, but in the case of the latter both carbon and nitrogen must be resolved into simpler forms before absorption can take place; while bacteria obtain these elements as already prepared in complex organic material, either animal or vegetable.

Bacteria differ greatly in their food requirements, some species thriving best upon a concentrated form of nourishment, and others requiring only a limited amount of protein substances.

The greater number of bacteria belong to the class known as saprophytes, which find their food in dead organic matter and cannot exist in living tissues; parasites, on the contrary, as the name indicates, 
exist in living tissues, certain species being adaptable to either condition, which are known as facultative bacteria. Nearly all of the disease-producing (pathogenic) bacteria belong to the latter class.

Some parasitic species are unable to live except in the living tissues of certain hosts, as the leprosy bacillus, which does not grow outside of the human body; also, the ordinary bacteria found in the soil and water cannot be grown in animal tissues.

The activities of bacteria are so rapid and complex that profound changes are produced in the materials upon which they grow and find their food. The changes which we know as fermentation and putrefaction are due to the saprophytic bacteria, while the parasitic forms found in the living tissues produce the changes which we call disease, and are frequently the cause of death.

The saprophytes, acting upon the highly organized tissues of dead animals and vegetables, resolve them into the simpler elements, water, carbon dioxide, and ammonia, in which form they are appropriated as nourishment by the higher plants. The higher plants in turn furnish food for the animal kingdom, and thus the food supply is used over and over again in different forms, making what is known as the food cycle. Were it not for bacterial activity, vege- 
tation would be robbed of its supply of carbon and nitrogen, and plant life would be speedily ended, which in turn would deprive the animal kingdom of food and thus life would no longer be possible.

A highly important group of saprophytes comprises the nitrifying and denitrifying bacteria which play so important a part in renewing the fertility of the soil.

In the process of decomposition which goes on through bacterial activity, there is a loss of considerable nitrogen into the air where it is no longer available for plant food; there is in consequence a constant diminishing of nitrogen food for vegetation. Also there is a loss of plant food by drainage into streams and the sea, which, if continued without check, would so deplete the soil of nitrogen compounds that plants could no longer live.

It is this loss of nitrogen from the soil which forces the farmer to apply fertilizers of various kinds to renew the exhausted soil.

It has been discovered, however, that the presence of certain bacteria in the soil insures a slow but sure gain in the amount of nitrogen compounds, and sterile fields are inoculated by the application of soil containing these bacteria, which are of two or three species working together. The exact process 
whereby these bacteria restore the free nitrogen to the soil is not clearly understood, but it is thought that the process requires the combined efforts of several species. It has also been learned that the combined action of certain higher plants and some species of bacteria arrests or reclaims the free nitrogen. Ordinary plants do not absorb the free nitrogen from the atmosphere, but a class known as legumes - to which clover, peas, and beans belong - together with certain soil bacteria is able to extract the free nitrogen from the air which permeates the soil; the evidences of which are small tubercles or nodules growing upon the roots, which contain nitrifying bacteria and nitrogen compounds. From the knowledge of this nitrifying process has grown the practice of planting sterile fields with legumes, chiefly clover or peas, and plowing the crop under while green, which restores the lost nitrogen to the exhausted soil.

The saprophytes may therefore be regarded as benefactors, while the parasites, to which belong the pathogenic bacteria, exist at the expense of both animal and vegetable life.

The Effect of Chemicals upon Bacteria. - Many species of bacteria in the course of their growth produce acids and other injurious substances which 
arrest further multiplication. The chemical products of the various species may be favorable or injurious to each other.

Chemical Antiseptics and Disinfectants. - An antiseptic retards the growth but does not kill bacteria, and a disinfectant, or germicide, destroys the organisms.

By sterilization is meant the complete destruction of all bacteria, and all processes ${ }^{1}$ which sterilize necessarily disinfect, but all disinfecting processes do not sterilize, the difference being that in sterilization the spores are also destroyed.

An enormous number of proprietary disinfectants are constantly advocated for many purposes, but complete disinfection may be obtained from simple chemical compounds at a very slight comparative expense, whereas the composition, strength, and effectiveness of patented mixtures are unknown and consequently unreliable, while the expense is great.

Lime is one of the oldest disinfectants known; mixed with water to the consistency of cream, it is an excellent disinfectant for excreta and privy vaults. By the addition of more water it is known as whitewash, and is the best practical disinfectant for cellars or rough walls of any kind, in houses, barracks, stables, and other outbuildings.

${ }^{1}$ Sterilization by steam, etc., is spoken of elsewhere. 
Lime which is to be used for disinfecting purposes should be freshly slaked, as " air-slaked" lime has no antiseptic value. It is said that a 20 per cent solution of freshly slaked lime mixed with half its bulk of typhoid excreta, will bring about complete disinfection within an hour.

Chlorinated Lime (Chlorid of lime) has also long been used as a disinfectant, and is especially valuable for the disinfection of sewage and water. For cellars and privies it is used as a dry powder, but for disinfecting the excreta from communicable diseases a solution (6 ounces to a gallon of water) is used; the same solution is also excellent for disinfecting floors and other woodwork. An easy method of disinfecting drinking water is to add 1 gram (15 grains) of chlorinated lime to 1 liter of water, and after thorough mixing use this solution in the proportion of 1 part to 200,000 parts of water, mix well, allow to stand 20 minutes and the water may be regarded as safe.

Sulphur is another disinfectant which has long been in use. Sulphur dioxide is produced by burning the sulphur, the process being known as sulphur fumigation.

The value of sulphur fumigation depends upon the presence of moisture, ${ }^{1}$ dry fumigation being practically

${ }^{1}$ One fifth pound of water to each pound of sulphur should be allowed to each 250 cubic feet of air space. 
useless except for the destruction of mosquitoes and bedbugs, which may be carriers of disease germs.

Sulphur fumigation with moisture will not destroy spore-bearing bacteria of any kind.

Sulphur fumes tarnish all metals and discolor most fabrics.

Permanganate of potassium is used for disinfecting the hands in surgical work.

Copper sulphate is used $(1: 1,000,000)$ for the destruction of the microscopic algæ in large water supplies.

Bichloride of mercury (corrosive sublimate) is probably the most important chemical disinfectant known, although for some purposes it cannot be used. It corrodes all metals and therefore cannot be used upon surgical instruments nor plumbing fixtures. Neither can bichloride of mercury be used for the disinfection of excreta or other organic matter, as it combines with the albuminous substances and produces an inert compound which has no effect upon the bacteria. The standard solution $1: 1000 \mathrm{bi}$ chloride of mercury is used for disinfecting the skin and for washing floors and other woodwork and furniture after an infectious illness.

Carbolic acid (phenol) one of the best-known disinfectants, is a substance derived from coal tar, 
the crude acid being considered a more effectual disinfectant than the more refined grades. Carbolic acid does not corrode metals, and "in a 5 per cent solution will destroy all vegetative bacteria and most spores even in the presence of considerable organic matter." (Jordan.) Its germicidal power is greatly increased by heat, experiment showing that at room temperature a 5 per cent solution was not effective against anthrax spores in thirty-six days, while at $55^{\circ}$ C. $\left(131^{\circ}\right.$ F.) it was successful in two hours, and at $75^{\circ} \mathrm{C}$. $\left(167^{\circ} \mathrm{F}\right.$.) in three minutes.

The cresols are substances contained in crude carbolic acid which are used very satisfactorily in surgical work, the best-known preparations being creolin, crenosol, and lysol.

Alcohol is much used as a disinfectant in surgical work, although of doubtful value, and is also used for the preservation of organic substances.

Soaps of all kinds are disinfectant and antiseptic. It has been demonstrated that a 10 per cent solution of good soap would destroy the bacilli of typhoid fever, a stronger solution being necessary for cholera bacilli; but for pus germs, streptococci and staphylococci, a 20 per cent solution was entirely ineffective.

For practical purposes, however, a soap solution could not be the sole disinfectant used for the bed 
and body linen of patients suffering from contagious diseases, as the procedure in ordinary laundries would not insure certain results, and, again, such linen must be wet with some chemical disinfectant immediately upon its removal from the bed, as a protection to the nurses and laundresses who must handle it, and to prevent any contagious matter from blowing about as dust. The tincture of green soap is used almost exclusively in all hospitals for the cleaning of hands and the field of operation, it being conceded to be the best soap known for the purpose.

The value of soap in the process of room or household disinfection is not wholly realized.

Corrosive sublimate, carbolic acid, and many other disinfectants used upon fine furniture and woodwork, in solutions strong enough to be good disinfectants, are destructive to the finish, but a 20 per cent solution of warm soapsuds to which has been added 1 ounce of petroleum to each gallon, may be used upon the finest mahogany surfaces with no injury; which would appear to be a much more effective disinfection than merely wiping the furniture with a cloth damp with corrosive sublimate or other chemical disinfectant. The addition of an ounce of washing soda to each gallon of hot soapsuds, used upon floors after an infectious illness or in case of 
very dirty wooden floors will not only remove but disinfect the filth.

The commercial medicated soaps are said to be of little value. Abbott gives a formula for carbolsoap which has the same disinfectant value as pure carbolic acid, is easily made, and particularly valuable for the disinfection of washable clothing:Dissolve 3 parts green soap in

100 parts of warm water, add

5 parts commercial carbolic acid, stirring slowly.

Formaldehyde is a gas which, dissolved in water, gives a solution of about 40 per cent formaldehyde, called formalin. Formalin is the preparation commonly used for disinfecting purposes.

Formaldehyde is considered the most valuable known disinfectant for room disinfection following all infectious diseases; it is also a deodorizer; it does not tarnish metals nor discolor fabrics, and the gas is not poisonous, although extremely irritating.

In fumigating with formalin all cracks and crevices must be tightly packed. There are several especially designed lamps and generators in use, the principle of all being to liberate the gas by heat, but except for hospitals or other large institutions they are too expensive for general use and the simple method of 
pouring formalin over permanganate of potassium in an open vessel, which causes the liberation of an immense volume of gas, is more commonly employed.

For each 1000 cubic feet of space at $15.5^{\circ} \mathrm{C}$. $\left(60^{\circ}\right.$ F.) use :-

Formaldehyde, 40 per cent, 16 ounces,

Potassium permanganate, $6 \frac{3}{4}$ ounces.

The vessel should allow not less than 12 quarts for this amount. This process has the advantage of being easily multiplied for large spaces, which is not the case with single lamps or generators.

The formaldehyde should not be added until the last moment before leaving and sealing the room. When it is impossible to leave a room open for twenty-four hours after fumigation with formaldehyde, the odor may be quickly removed by placing a shallow vessel (platter) filled with aqua ammonia in the room.

\section{Disinfection of Infective Materials.}

Excreta: Carbolic acid, 5 per cent;

or Chloride of lime, 2 per cent;

or Milk of lime (lime and water, consistency of cream) ;

or Bichloride of mercury, 1 ounce,

Hydrochloric acid, 10 ounces,

Water, 1 gallon.


In all cases the disinfecting solution should be double the excreta in bulk, and the mixture, closely covered, be allowed to stand some time before emptying.

All vessels used for stools, sputum, and vomit should be washed in carbolic acid 5 per cent, followed by scrubbing in hot soapsuds and by boiling in soda solution 3 per cent.

Clothing. - Bed and body linen, towels, napkins, wash curtains, bureau and stand covers, soak in cold carbol-soap solution (p. 39) for two hours, rinse in clear cold water, and put into the laundry.

Woolen garments, unless badly infected, may be fumigated with formaldehyde followed by exposure to sunlight. Otherwise, heavy garments, carpets, rugs, furs, woolen curtains, together with children's playthings and books, should be put into compact bundles wrapped in cloths wet in carbolic acid 5 per cent, or bichloride of mercury $1: 1000$, and burned in a furnace. ${ }^{1}$

Utensils. - Dishes and silver may be boiled for 20 minutes in soda solution 5 per cent, also washbasins and other toilet dishes, besides all surgical instruments, nail files, and manicure scissors.

${ }^{1}$ In the light of more recent experiments the necessity for the complete destruction of such articles is disputed. 
Toothbrushes should not be used during infectious illness, but the mouth and teeth cleaned with small mouth sponges and toothpicks wrapped with absorbent cotton, both to be burned immediately.

Furniture. - 1. Fumigation with formaldehyde.

2. Wipe with cloth wet in carbolic acid 5 per cent, followed by washing with 20 per cent warm soapsuds containing 1 ounce of petroleum to each gallon.

3. Expose to sunlight for several days in succession if possible, turning all sides to the sun; turn upside down as well.

Walls. - 1. If papered, wet thoroughly with bichloride of mercury solution, $1: 1000$, remove paper, being very careful to keep the paper wet.

2. Fumigate the room and follow by opening all windows and doors for twenty-four hours.

Floors. - 1. Wet with bichloride of mercury solution $1: 1000$ before fumigation.

2. After fumigation, scrub with 20 per cent hot soapsuds to which has been added 1 ounce of washing soda to each gallon. This first cleaning should be done with a broom and mop, that the water may be as near boiling as is possible.

Woodwork. - 1. Wet with bichloride of mercury $1: 1000$ before fumigation.

2. After fumigation, wash as directed for furniture. 
THE EFFECTS OF BACTERIAL GROWTH

As before stated, bacterial growth is so rapid and complex that profound changes always result in the structure and composition of the materials upon which the bacteria are developing. The putrefactive change which takes place in the body soon after death, due to the invasion of bacteria, is a familiar example.

Physical Effects. Heat. - The temperature of organic substances undergoing the process of decomposition is often very much higher than the surrounding atmosphere, as in the heating of damp hay or in manure heaps, both of which are attributed to heat-producing (thermogenic) bacteria.

Light-producing (photogenic) bacteria cause the phosphorescence sometimes observed upon decaying fish, meat, or wood and more commonly in sea water.

Chemical Products. - The chemical products of bacteria may arise from their secretions or excretions or from the products resulting from their action upon food substances, the character of which depends upon the chemical contents of the food itself and the species of bacteria concerned. It is believed that most of the chemical changes wrought by bacterial activity are not the direct action of the organisms 
themselves, but arise from the enzymes or ferments produced by them. A single organism may secrete more than one enzyme, depending upon different conditions of food and temperature.

By usage the term putrefaction is used to designate the disintegration (breaking up) of proteid substances, while fermentation is used to denote the disintegration of the carbohydrates. The bacteria which produce putrefaction are known as saprogenic, and those concerned in fermentations, as in the lactic and butyric acids in milk, butter, cheese, and vinegars, are known as zymogenic. Bacterial activity produces both acids and alkalies; the fermentation of carbohydrates producing an acid reaction, and the putrefaction of proteid substances causing an alkaline reaction. In the putrefaction of nitrogenous substances there is not only a complete change in the form of the material but the production of many gases of peculiarly offensive odor, which are believed to be due to the action of the obligatory anaërobes.

Chromogenic bacteria are those which produce color, the significance of the pigment being little understood.

Ptomains and Toxins. - The poisonous products of bacteria are known as ptomains and toxins; 
ptomains being the poisonous products resulting from the action of bacteria in the decomposition of organic matter, and toxins are the poisonous substances produced by the bacteria themselves.

Many epidemics of food poisoning which were formerly attributed to ptomains are now believed to be due to the presence of some special organism.

Pathogenic bacteria produce disease by their action upon the animal tissues in which they find lodgment; this poisonous action may be due to the toxins produced by the bacteria, or to the poisonous material of which the germs are composed (endotoxins). Some species produce soluble poisons which are easily separated from the organisms themselves, while others are found to contain proteid matters in their own bodies which are highly toxic, and these we know as endotoxins.

The potency (strength) of some of the bacterial toxins far exceeds that of any other known poisons ; for instance, the toxin produced by the bacillus of tetanus (lockjaw) is more than a thousand times as powerful as strychnine. 


\section{CHAPTER V}

\section{THE RELATIONS OF BACTERIA TO DISEASE}

Among the earliest records of history theories regarding the causes of disease may be found. The belief that the sick man was possessed of the devil seems to have been the first and most lasting belief, for it is still held by the savage races, and may be found among the ignorant classes of civilized nations, who hold it to be the cause of insanity.

During the middle ages, when men began to study the structure and composition of the body, the Hippocratic theory that the body contained four humors, viz. blood, phlegm, and black and yellow bile, which worked in harmony in health, but lost their proportion in disease, was the generally accepted belief as the cause of disease; but the reasons for the loss of proper proportion were not stated.

Later many vague speculations, based more upon imagination than upon facts, prevailed, until Pasteur's investigations into bacteria as a cause for fermentations led to his discoveries and proofs that the infectious diseases owed their origin to bacteria. 
At the present time the principal diseases known to be due to specific microörganisms are :

Class I. Septicæmia, gonorrhœa, Asiatic cholera, leprosy, pyæmia, syphilis, influenza, bubonic plague, pneumonia, diphtheria, tetanus, relapsing fever, meningitis, typhoid fever, tuberculosis, glanders, anthrax, malaria, sleeping-sickness.

Class II. To this class belong those diseases caused by organisms which are yet unknown : smallpox, foot-and-mouth disease, yellow fever, chicken pox, hydrophobia (rabies), measles, mumps, scarlet fever, Rocky Mountain spotted fever, typhus fever, epidemic infantile paralysis.

The sources of the communicable diseases in man are man himself and the lower animals; the majority are peculiar to human beings, although we contract anthrax from cattle, plague from rats, tuberculosis in part from cattle, etc. Formerly it was thought that the main sources of infection in man were in water, air, soil, and food; and while these may serve as vehicles for conveying infectious materials, the source is usually in man himself.

No single species of pathogenic bacteria can produce disease in all animals, nor are the diseaseproducing bacteria for animals the cause of disease in plants. A bacterium may produce disease in 
man and be harmless for cattle, and on the contrary, man is not susceptible to all the diseases of cattle.

The tissues of animals and plants which afford favorable soil for the growth and multiplication of bacteria are known as the hosts, and the host may not always favor bacterial activity; thus an adult is usually resistant to the so-called children's diseases, and on the other hand, hunger, thirst, excessive fatigue, and the wasting diseases all lessen the body's resistance and render the individual susceptible to infections of all kinds. The virulence (ability to produce disease) of the microörganisms also varies, and infection may depend upon the number of bacteria introduced into the body, and so it may be said that the virulence and number of the invading bacteria vary quite as much as the susceptibility of the host.

The channels by which infection may enter the body are (a) by the respiratory tract, (b) by the digestive tract, and (c) through the skin. It is thought that 90 per cent of all infections is taken into the body through the nose and mouth, and as we are usually responsible for what goes into our own mouths, it may be seen that it behooves us to observe hygienic personal habits. 
Character of Infections. - "In the production of disease by microörganisms there are two main factors involved, namely, (a) the multiplication of the living organisms after they have entered the body, and $(b)$ the production by them of poisons which may act both upon the tissues around, and upon the body generally. The former corresponds to infection, and the latter is of the nature of intoxication or poisoning. In different diseases one of these is usually the more prominent feature, but both are always more or less concerned." (Muir and Ritchie.)

Infections vary widely in the effects produced in the body, both in the local and general or constitutional symptoms.

Certain diseases are known as toxcemic, that is, the blood contains the poisonous products (toxins) of the invading bacteria. Tetanus is notably a toxæmic disease, the local symptoms being almost entirely absent, and no bacteria are found in the blood, while the constitutional effects are profound and nearly always fatal.

Diphtheria is also a characteristic toxæmic infection, although the local symptoms are pronounced as well.

Septicremia, or bacteremia as it is sometimes called, denotes the presence and multiplication of bacteria 
in the blood. Typhoid fever, pneumonia, and the general pus infections known as "blood-poisoning" belong to this class, the bacteria being found in the blood or in special organs.

Pycmia is a condition following profound infections, as septicæmia, in which many abscesses are formed throughout the body.

Secondary infections are those which gain entrance to the body through the lesions produced by some other organism, as typhoid fever followed by pneumonia, or measles followed by tuberculosis, or scarlet fever followed by diphtheria; diabetes is frequently accompanied by pus infection of a serious character; in fact, all wasting diseases lower the resistance of the body and greatly increase the susceptibility to infections of all kinds.

The Defenses of the Body. ${ }^{1}-$ The unbroken skin is usually impassable to bacteria. Virulent organisms are often found upon the skin of perfectly healthy persons, where they appear to be harmless unless an abrasion occurs, which affords an entrance into the deeper tissues. The mucous membranes would prove favorable sites for the growth of bacteria were it not for the frequent removal of the mucus which they secrete; the mouth of a healthy person ${ }^{1}$ See Immunity, p. 54. 
contains large numbers of bacteria of all kinds, the bacilli of diphtheria, of influenza, and the pneumococci are often present, - but the saliva has a slight germicidal power and serves as a constant wash to the membranes of the mouth; the hairs of the nasal and aural passages and the eyelashes make some obstruction to the entrance of bacteria; and the moist surfaces of the air-passages retain most of the bacteria contained in the air before it reaches the lungs. The hydrochloric acid of the gastric juice is unfavorable for the growth of bacteria, although it does not always kill them; the bacillus of typhoid fever, for instance, passes through the stomach and finds favorable conditions for development in the intestines.

Large numbers of bacteria are found in the intestines of all perfectly healthy persons, but unless resistance is lowered from some cause, no manifestation of disease occurs.

Transmission of Disease. - Infectious diseases are transferred either directly (contact) from a patient to another individual, or indirectly through air, water, food, or carried by insects.

As a rule, the pathogenic bacteria are incapable of living except for a very short time apart from the body, but the fact that they may exist for a con- 
siderable length of time upon the bodies of healthy persons, and by them be transmitted to those who are susceptible to infections, constitutes a serious menace. The bacillus of influenza exists but a very short time apart from its human host, but the bacilli of tuberculosis and of typhoid fever are much more resistant, adapting their existence to other conditions.

Infectious materials are thrown off from the body through the discharges from the nose, the mouth, the intestines, the bladder, and the skin during the course of infectious diseases, and are often found in these tracts and in the excreta long after the patients have seemingly entirely recovered; this condition is notable in diphtheria, scarlet fever, and typhoid fever, and such persons are known as " carriers."

The modes by which infectious materials are carried from one person to another are at the present time subjects for much discussion, and it seems to be the consensus of opinion that " contact " infection is much more frequent than was formerly supposed. Contact does not necessarily imply the actual contact of the sick and the well; for instance, the child with diphtheria may leave infectious material upon the drinking cup, or a clean wound may become infected by contact with hands which carry infectious material. 
Contact infection is the chief source of danger in those communicable diseases in which infectious materials are discharged from the nose and throat, such as tuberculosis, diphtheria, measles, pneumonia, influenza, scarlet fever, whooping cough ; and also in those diseases in which the infectious materials are discharged in the urine and feces, as in typhoid fever, dysentery, and cholera. 


\section{CHAPTER VI}

\section{IMMUNITY}

By immunity is meant non-susceptibility to a given disease or organism; thus a yellow fever immune is a person who is not susceptible to yellow fever.

Immunity may be natural or acquired.

Natural Immunity. - Man is susceptible to infection with many microörganisms, some of which are harmless to the lower animals, and thus it is said that these animals possess a natural immunity to these infections. The bacillus of typhoid fever produces serious disturbances in man, but rarely any in cattle, and the cold-blooded animals are not susceptible to tetanus, which in man and the higher animals is a serious infection.

The physical differences existing between the warm and cold blooded animals, the vertebrates and invertebrates, and many other distinctions in the various groups of animals, may all be taken into account in the consideration of natural immunity.

It was formerly held that certain races of men 
were susceptible and others immune to certain diseases, but the line is now less sharply drawn and differences are attributed more to differences of habits, pursuits, and opportunities for infection than to racial characteristics. Individuals vary greatly in their powers of resistance, and members of the same family subject to the same environment often exhibit marked differences in their susceptibility to disease. Epidemics of typhoid fever afford excellent examples of the natural immunity of certain persons; for while all may use the same polluted water, not all are infected.

It is said that the small animals used in the bacteriological laboratories exhibit the same individual differences to a less degree.

Acquired immunity may be active or passive. Active immunity is due to the direct participation of the organism concerned, as immunity to smallpox is acquired by an attack of the disease.

Passive immunity is acquired by the transfer of protective substances formed in the body of another animal to the body of the person to be protected. The protection afforded by the use of diphtheria antitoxin is an example of immunization by bacterial products; the horse is actively immunized by the repeated injection of increasing doses of diph- 
theria toxin for several weeks, or until the blood contains the diphtheria antitoxin, which, when injected in suitable quantities into the body of a person who has been exposed to diphtheria, affords a protection against the disease. The antitoxin of diphtheria is also used as a curative measure.

The accompanying table from Muir and Ritchie shows the chief methods by which artificial immunity may be produced, the principles underlying all being the same:-

\section{Artificial Immunity}

A. Active Immunity - i.e. produced in an animal by an injection, or by a series of injections, of non-lethal doses of an organism or its toxins.

1. By injection of the living organisms.

(a) Attenuated in various ways. Examples:-

(1) By growing in the presence of oxygen, or in a current of air.

(2) By passing through the tissues of one species of animal (becomes attenuated for another species).

(3) By growing at abnormal temperatures, etc.

(4) By growing in the presence of weak antiseptics, or by injecting the latter along with the organism, etc.

(b) In a virulent condition, in non-lethal doses.

2. By injection of the dead organisms.

3. By injection of filtered bacterial cultures, i.e. toxins; or of chemical substances derived from such filtrates.

These methods may also be combined in various ways. 
B. Passive Immunity, i.e. produced in one animal by injection of the serum of another animal highly immunized by the methods of $\mathrm{A}$.

1. By antitoxic serum, i.e. the serum of an animal highly immunized against a particular toxin.

2. By antibacterial serum, i.e. the serum of an animal highly immunized against a particular bacterium in the living and virulent condition.

The Mechanism of Immunity. - The study of the mechanism of immunity, that is, the process which occurs within the body as a defense against the invading bacteria, has been enormous and presents problems too abstruse and complex for the understanding of any but the scientists themselves. As a result of these researches, which involve such industry, application, patience, and profound learning that we stand amazed at their depth, there has grown to be more or less well-defined theories of the mechanism of immunity, although the most learned among the investigators hesitates the least to admit the limits of this knowledge.

Antitoxins. - In 1890 Behring and Kitasato discovered that if the blood-serum of an immunized animal was combined with an appropriate amount of toxin (in this case tetanus), and the combination injected into a susceptible animal, there was neither death nor infection; in other words, 
the blood-serum of the immune animal contained some substance which neutralized the toxin, rendering it harmless; they named this something antitoxin.

The chemical character of antitoxin is still a matter of conjecture, but it has been proven that the combination of toxin and antitoxin is of a chemical nature, the antitoxin holding the poison of the toxin in abeyance (that is, neutralizing) so long as the combination exists. This fact has been repeatedly proved in the laboratory, where it is possible to control both substances as to amount and environment, but it is easy to appreciate how difficult the study becomes when the body is invaded by an unknown quantity of pathogenic bacteria, and when the reaction of the living tissues cannot be definitely gauged.

It has been found that antitoxin in small amounts occurs in the normal blood of many healthy persons, and that the amount is quickly increased when toxic materials are introduced into the body, thus showing that the presence of the bacteria stimulates the manufacture of antitoxin by the body. It is believed that the body-cells are responsible for the origin of the antitoxin, and the different cells are the origin of the antitoxins for different organisms. 
It is supposed that in active immunity, i.e. when due to virulent organisms, the body-cells continue to maintain the antitoxin above the normal; while in passive immunity, i.e. when due to antitoxin serum taken from an immunized animal, that the antitoxin is eliminated from the body after a certain time, and the body-cells are not stimulated to continued activity. This condition is notable following the administration of diphtheria antitoxin, immunity lasting about three weeks.

It might be supposed the presence of antitoxin, or the ability of the body-cells to produce it, would be sufficient defense against disease-producing bacteria, but there seems to be at times what is known as a chemical affinity (chemiotaxis) between the toxins and the tissues of the body, in which the toxins combine with the body-cells instead of with the antitoxin, which causes the death of the cells.

Bactericidal (ability to destroy) Substances. - The blood can not only neutralize bacterial toxins, but can destroy the bacteria; it is said that a single drop of rabbit blood may destroy over fifty thousand anthrax bacilli.

The natural immunity of animal organisms was thought by Buchner and others to be due to the bactericidal substances in the blood, called by them 
alexines, and the degree of immunity was dependent upon the amount of alexines contained in the blood; but it has been found that in some cases there is no relation between the resistance of the animal and the bactericidal power of its blood-serum. The human blood-serum is strongly bactericidal for the bacillus of typhoid fever, but that fact does not always prevent the multiplication of the organism in the blood during an attack of the disease. The chief difference between an antitoxic serum and a serum which is bactericidal is, that an antitoxin acts only upon a formed poison, while a bactericidal serum may be protective, preventing an infection. The antitoxin of diphtheria affords the best example of an antitoxic serum; it not only neutralizes the diphtheria toxin, but is also curative.

Certain bactericidal sera which are bacteriolytic (dissolving) in their action have been used only in a limited degree in the diseases of man, as they can only be artificially cultivated in the lower animals and have not always proved satisfactory, because of the differences in species, it is supposed. The bloodserum from animals inoculated with typhoid bacilli has been found entirely ineffective when used for treating the disease in man; and on the other hand, the use of the bacterial cells by vaccination as a 
protection against typhoid fever has attained marked success.

Phagocytosis. - In 1884 Metchnikoff ${ }^{1}$ established his celebrated theory of phagocytosis as an explanation of immunity. Metchnikoff believes that the wandering cells of the animal organism - leucocytes - possess the power of digesting or rendering inert the bacteria which they encounter in the tissues; and that the susceptibility to or immunity from infection in an individual is decided by a conflict between the invading bacteria on one side and the leucocytes and tissues on the other, the outcome depending upon the vigor of the invaders or upon the provisions for defense set up by the leucocytes and tissues.

When the vigor of the body cells is sufficient to destroy the bacteria, the tissues are victorious, but when the toxins produced by the bacteria are strong enough to arrest the activity of the phagocytes, an infection follows.

- ". . . the migration of the phagocytes through the vessel wall into the cavities and tissues is one of the principal means of defense possessed by an animal. As soon as the infective agents have penetrated the body, a whole army of white corpuscles (leucocytes) proceeds toward the menaced spot,

${ }^{1}$ The successor of Pasteur in the Pasteur Institute, Paris. 
there entering into a struggle with the microörganisms." (Metchnikoff, 1905.)

Opsonins. - An immense amount of research followed Metchnikoff's discoveries, one of the great problems being to find the reason why the leucocytes do not always attack the bacteria and prevent infection. Among the investigators was Sir A. E. Wright of England, who, with others, discovered that the blood-serum contains substances which are necessary to prepare the bacteria for the leucocytes; these substances he called opsonins. Opsonins are in the blood of normal animals, but are greatly increased by immunization and differ for different bacteria. The process whereby the opsonins change the bacteria and render them liable to phagocytosis is not perfectly understood.

The opsonic index is the mode of expressing the relative amount of opsonins contained in the bloodserum in comparison to the normal.

The technique of this work is extremely compli- cated and delicate.

The opsonic method of treatment aims to maintain the opsonic index at a high level, which insures the phagocytic power of the blood.

"Wright and Douglas and their followers have found it possible to artificially increase the production of opsonins 
in the blood by subcutaneously injecting into the patient a carefully measured quantity of vaccine (sterile bacteria). The increased phagocytosis which results is not due to any direct stimulation of the leucocytes. The newly formed opsonins are in the blood-serum and act in some unknown way on the bacteria, so changing them that the white blood corpuscles, or scavengers of the body, greedily eat them up. Careful experiments have shown that leucocytes washed free of serum and brought into contact with an emulsion of bacteria show no phagocytic action, while if they are brought into contact with the same organisms which have been previously bathed in blood-serum and the serum then carefully washed off, the microbes are rapidly engulfed by the leucocytes.

"A personal vaccine is prepared, when possible, by isolating the organism from the infected individual, but as the preparation of the vaccine requires several days after the organism has been isolated, the first dose is usually given from the "stock bottle." Stock bottles of vaccine made from pure cultures of various kinds of bacteria are kept in an opsonic laboratory, each bottle of course containing only one kind of bacteria, e.g. staphylococcus. Since it requires nearly three months to cultivate the tubercle bacillus on artificial media, it is plainly evident that it is impracticable to treat tuberculous patients with personal vaccines.

"The normal opsonic index is 1.0, that is, there is in the blood of normal individuals practically an equal measure of opsonins. The object of opsonic therapy is to raise and maintain the opsonic index as high as possible above 
normal, for as long a period as possible, thus constantly preparing multiplying bacteria as palatable food for the leucocytes, until the infected individual has become immunized against the infecting organism.

"The blood is examined on the first two or three days to see whether or not there be a negative phase and to determine the maximal rise of the opsonic index. The negative phase consists in the index falling lower than it was when the vaccine was given, and has occurred but rarely in our experience. On the sixth or seventh day the index is again determined, and as soon as it falls to one or below, another injection is given. Although there are many chances for error in the technique, we sincerely feel that the opsonic index is a valuable guide in regulating the time and size of the dosage, and should be carefully followed until we find a better guide." (Vail and Lincoln.)

Ehrlich's "receptor theory" is an explanation of the origin and action of antitoxins and bactericidal substances in the blood of the immune. The subject is too profound and complex to be embodied in a book of this character.

In acquired immunity the blood-serum sometimes acquires the property of agglutinating the bacteria, causing the infection. This agglutination or clumping is brought about by the presence in the bloodserum of an anti-body that has the property of bringing about the clumping of the bacteria and

${ }^{1}$ Paul Ehrlich, Director of the Royal Prussian Institute for Experimental Therapy. Studies in Immunity. 
causes the cessation of the motility of motile bacteria. This form of anti-body is known as "agglutinin." The Widal test as a means of diagnosis of typhoid fever is based upon this agglutination of bacteria by blood-serum. A drop of blood from the patient is added to a specially prepared culture of typhoid bacilli; if the bacilli become motionless and soon clump (agglutinate) in irregular masses, the patient is doubtless infected with the bacillus of typhoid. Other species of bacteria are also agglutinated by their own anti-sera. It is not thought that agglutinins are bactericidal.

"Of the hypotheses ${ }^{1}$ advanced in explanation of acquired immunity, the one worthy of greatest confidence is that which assumes immunity to be due to reactive changes on the part of the tissues that result in the formation in these tissues of antitoxic and other anti-bodies which circulate free in the blood and in a variety of ways serve to protect the tissues from the harmful effect of extraneous intoxicants and irritants, in some cases acting principally as antidotes to a toxin, in others exhibiting more the germicidal (bacteriolytic) than the antitoxic property."

${ }^{1}$ Abbott, Principles of Bacteriology. 


\section{CHAPTER VII}

INFLAMMATION, SUPPURATION, PNEUMONIA, EPIDEMIC CEREBRO-SPINAL MENINGITIS

THE microörganisms which produce inflammation and suppuration, known as pyogenic or pus-forming bacteria, are of especial interest to the nurse, her daily routine being an almost constant combat with these unseen germs, toward whose activities especially is directed the complex surgical technique which prevails in every department of the hospital.

Inflammation and Suppuration may be due to several organisms, no one organism being the cause; and two or more may be present, while the same organism may produce entirely different results under varying conditions, as in different individuals, or in the same person when resistance is lowered, or when the virulence of the bacteria is increased or lessened from any cause; which accounts for the remarkable diversity in the character of infections. For example, a minute pin prick may carry virulent organisms into the blood of a person whose resistance is 
weak, the result being a severe general infection; while in another case an extensive wound which seemed to have had every condition favorable to a grave infection, healed by "first intention" or with no sign of inflammation or suppuration.

In suppuration there is a gathering of the leucocytes to the point of infection, followed by a liquefaction of the tissue with necrosis (death) of the cells, the result being a creamy fluid which we know as pus. There may be inflammation without suppuration.

In septiccemia the organisms develop in the blood, and there may be no local point of infection, but symptoms of profound general poisoning.

In pycemia abscesses occur in all parts of the body, externally as well as in the internal organs.

The bacteria commonly found in boils, carbuncles, abscesses, and many other infections belong to the group called staphylococci, of which there are two types: staphylococcus 'pyogenes) albus, and staphylococcus (pyo-

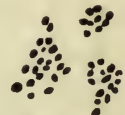

FIG. 12. genes) aureus, the latter distinguished by its production of a bright yellow pigment.

The cells of staphylococcus aureus are arranged in irregular groups not unlike clusters of grapes, and are said to be the most resistant to drying, heat, and chemicals of any of the non-spore-bearing bacteria. 
The staphylococcus aureus is found almost constantly upon the skin, and is supposed to have at times the power to penetrate the skin through the sweat-ducts, several diseases of the skin being attributed to its activities; while suppurative inflammations in all parts of the body are usually found to contain the organisms.

Infections from staphylococci are not unknown among domestic animals; horses, cattle, and rabbits being more susceptible than other animals.

The streptococcus pyogenes is a coccus slightly larger than the staphylococcus, which grows in chains of varying length, it being thought at one time that the length of the chain

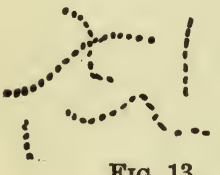

FIG. 13.

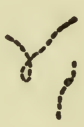
signified the degree of virulence of the germs, but this has not been proven by experiment. There are many so-called strains of the streptococcus, and probably no other diseaseproducing organism causes as many and varied disturbances in man, being not only the primary cause of many infections, but frequently found in mixed and in secondary infections. Erysipelas, puerperal fever, suppurative conditions of all of the organs, pneumonia, ulcerative endocarditis (an affection of the valves of the heart), otitis media (in- 
flammation of the middle ear), and rheumatic fever are all attributed to streptococcus pyogenes.

The mucous membranes frequently harbor streptococci, the tonsils being a favorite resting place. Diphtheria is nearly always accompanied by an abundance of streptococci, which were at one time thought to be the cause of the disease. Streptococcic infections following, or secondary to, other infections occur often in tuberculosis, smallpox, and scarlet fever; and septicæmia, due to streptococci, occurs in many diseases.

In the lower animals, horses, cattle, rabbits, and mice are all susceptible to infections from streptococci.

Immunity following streptococcic infection is of short duration. Efforts have been made to utilize the serum of immunized animals both for the protection and cure of streptococcic infections in man, but the results have been uneven and upon the whole not very satisfactory.

To the two organisms staphylococci and streptococci are due most of the innumerable train of infections liable to occur in hospitals, which are a constant source of anxiety to doctors and nurses. The everyday routine of a hospital ward affords endless opportunities for infection to be carried from 
one patient to another, and the knowledge that staphylococci and streptococci are commonly found upon the skin, in the mouth, and in the nasal passages should be sufficient to prompt the greatest care in taking temperatures by mouth, in giving hypodermic injections, in the use of catheters, rectal tubes, douche points, and medicine glasses.

The nurse's care of her own hands is of vital importance to herself as well as to her patients; in caring for a patient she has no way of knowing what bacteria his body may harbor, which may be a source of danger to the next patient as well as to herself, and for this reason she cannot be too careful about. scrubbing (not simply washing or rinsing) her hands after every bath, enema, douche, catheterization, etc., as well as giving them scrubbing and disinfection before.

At first sight the elaborate technicalities of operating-room work seems a hopeless and inextricable tangle to the beginner; but gradually the reasons and results begin to define themselves, and slowly the whole technique for the prevention of infection unfolds itself, and the conscience which permits no lapses or gaps in the chain which binds the whole together begins to develop, until at last out of the laboratory 
and operating-room drill the nurse awakens to an entirely new. conception of her duties and of all her surroundings.

\section{PNEUMONIA}

The acute inflammation of the lungs known as pneumonia is generally due to a micrococcus known by several names: streptococcus pneumonice, or diplococcus (in pairs) pneumonice, or pneumococcus, or Fränkel's diplococcus pneumonice, after its discoverer; the term pneumococcus being used more commonly than any other, probably on account of its brevity.

The pneumococcus often occurs in pairs (diplococci) or short chains, usually showing a capsule or clear

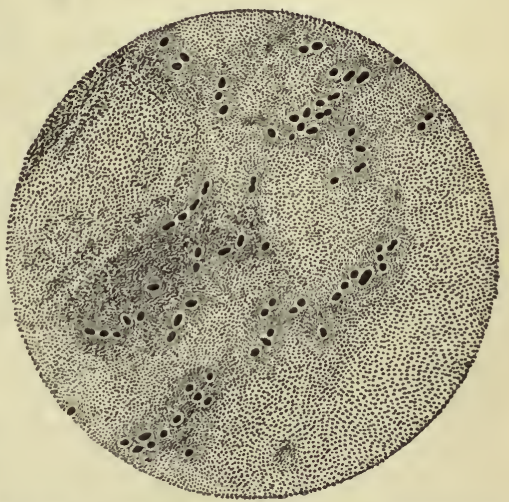

Fig. 14. - Film preparation of pneumonic sputum, showing numerous pneumococci (Fränkel's) with unstained capsules. $\times 1000$.

zone surrounding the cell and bearing a marked resemblance to streptococcus pyogenes.

Pneumonia manifests several different types and is 
not always due to an invasion of pneumococci, neither does the pneumococcus always produce the same results, the variations no doubt being largely due to the condition of the individuals. It was formerly thought that exposure to cold was the sole cause of pneumonia, and it is true that such exposure by lowering resistance opens the way for an invasion of bacteria, while other factors, such as dissipation, loss of sleep, lack of food, and prostration due to other diseases, as typhoid fever, scarlet fever, and measles, may all be contributory to an attack of pneumonia.

There are three types of pneumonia: lobar (acute croupous), broncho-pneumonia, or lobular pneumonia, and capillary bronchitis.

Lobar pneumonia is said to be due almost entirely to the pneumococcus, which is found in the blood, while lobular pneumonia and capillary bronchitis are sometimes due to other organisms, as staphylococcus, or streptococcus, or $B$. diphtherice, or $B$. influenzo, or $B$. typhosus. Pneumococci are not only the cause of lobar and lobular pneumonia, but many other inflammations and suppurative conditions, as inflammation of the middle ear, of the meninges (meningitis), of the pleura (pleurisy), and, in fact, infections due to the pneumococcus have been found in nearly every organ of the body. 
The fact that the pneumococcus may be found in the mouth or nasal passages of nearly all healthy persons renders it an organism to be feared; although the mode of dissemination is still a point in doubt, and all authorities do not entirely agree as to the dangers of infection, although many so-called epidemics have occurred, yet there is enough evidence to warrant careful measures in the nursing of pneumonia patients to protect others from the possibility of contagion.

All cloths used for handkerchiefs and mouth sponges should be burned immediately; nightgowns and bedding should be protected from mouth and nasal discharges and should be frequently changed and disinfected; the hands of both the patient and the nurse should have the closest care; no delirious pneumonia patient can properly use his handkerchief nor sputum cup and will soil his hands constantly with discharges from his mouth and nose, thus requiring the most scrupulous care.

Discharges lodging upon the floor, or bedside table, or nurse's uniform should be wiped away at once with cloths wet in a solution of bichloride of mercury $1: 1000$. No rugs or carpets should be allowed in the sick room of a pneumonia patient.

Immunity following pneumonia is of very short 
duration, a second attack often following the first at a short interval.

Some of the lower animals are susceptible to infection from the pneumococcus, rabbits and mice particularly, guinea pigs being less so, and dogs very resistant.

One of Pasteur's early experiments was the injection of human saliva into rabbits, causing a rapid, fatal general infection which he called sputum septicamia, and which is now known to be due to the pneumococcus.

\section{EPIDEMIC CEREBRO-SPINAL MENINGITIS}

An inflammation of the meninges, or membranes covering the brain and spinal cord, is known as meningitis and may be due to one of several different organisms, which may be primary infections or follow some previous infection occurring in another part of the body.

Meningitis may be caused by streptococcus pyogenes, by pneumococcus, or bybacillus tuberculosis, but these cases are never epidemic, occurring only in scattered instances.

Epidemic cerebro-spinal meningitis is an acute infectious disease due to an organism known as menin- 
gococcus, a small coccus, occurring in pairs, which is sometimes difficult to cultivate in artificial media.

The disease is most common in children and young adults, seldom appearing after thirty-fiveyears of age.

The death rate is very high, averaging 70 per cent, but meningitis due to other bacteria is fatal in nearly all cases.

The portal of entry and mode of dissemination in epidemic cerebro-spinal meningitis are still doubtful subjects. It is thought that the nasal cavity and the middle ear are the avenues of entrance.

The fact that the meningococcus has a very slight resistance to drying would seem to indicate that the disease is spread by germ carriers, whether convalescents, actual patients, or healthy persons. Contact with fresh infective material, as might occur upon handkerchiefs, towels, dishes, thermometers, bedding or hands, is also an avenue for the spread of infection.

An anti-meningitis serum obtained by the immunization of horses has been used with very good results. In one epidemic of meningitis the FlexnerJobling serum was used in forty-seven cases, with thirty-four recoveries and thirteen deaths, a very marked decrease in the average death rate of 70 per cent. 


\section{CHAPTER VIII}

\section{THE VENEREAL DISEASES}

GONORRHGA, SyphILIS ${ }^{1}$

Gonorrhœa is an inflammation of the urethra due to a coccus known as the gonococcus of Neisser, who discovered it, or as micrococcus gonorrhoea, and

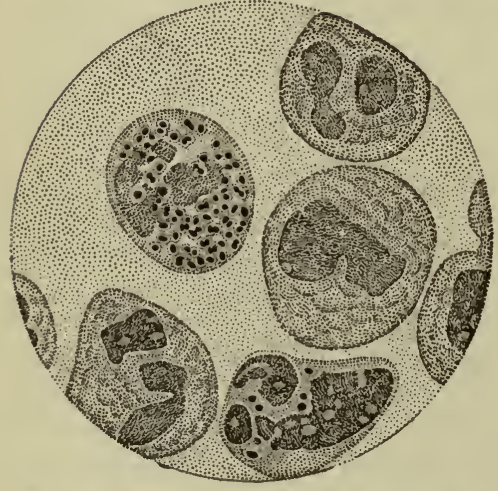

Fig. 15. - Film of pus of gonorrhœea showing gonococci. is said to be one of the most widely distributed diseases in the world, German statistics estimating that 48.5 per cent or more of the male population are thus afflicted.

In appearance the gonococcus bears a striking resemblance to the meningococcus, occurring in pairs with

${ }^{1}$ Read: Hygiene of Transmissibld Diseases. Abbott, p. 166. Also chapters upon gonorrhøea and syphilis, to be found in all standard works on the practice of medicine. 
slightly flattened sides, and like the meningococcus it is found in the pus cells; but the two germs are not often confused, as they are almost never found in the same tissues. Special culture media are required for the artificial growth of the gonococcus, which is sensitive to drying and variations of temperature.

While gonorrhœa is primarily an inflammation of the urethra, the infection is by no means localized, and may cause far-reaching and disastrous results, particularly in women. Stricture of the urethra is the most common result in men; but in women the uterus, Fallopian tubes, and the peritoneum are frequently infected, resulting in a train of serious disorders which necessitate extensive surgical operations, and in nearly, if not quite all cases cause sterility.

Gonorrhoea ophthalmia, which is the cause of 10 per cent of all cases of blindness, occurs in the newborn from infection from the mother, and in later cases the infection may be carried to the eyes by hands, handkerchiefs, towels, or any object which may have been handled or touched by a person suffering from gonorrhœa.

The gonococcus may gain entrance to the blood and be carried in the circulation to all parts of the body; the synovial membranes covering the joints 
are a favorite resting place, resulting in arthritis, or gonorrhœal rheumatism.

"A peculiarly dangerous feature of gonococcus infection is the long period during which an infected man or woman may be capable of infecting others. Gonococci may persist in the genito-urinary secretions for years after apparently complete recovery has taken place. By this means serious inflammations of the genital tract are produced in thousands of innocent wives by their previously infected husbands." (Jordan.)

Epidemics of vulvovaginitis in little girls are not an uncommon occurrence in schools and in institutions, and present almost insurmountable difficulty in stamping them out. Such infections usually originate in unclean, overcrowded tenements where children occupy the same beds with adults, and where baths and clean clothing are infrequent, and are then carried into schools and disseminated by contact with clothing and the water-closet seats. If introduced into children's hospitals or wards, it may be carried by bath tubs, towels, wash cloths, dishes, diapers, bed and body linen, and closet seats.

The most lamentable result of these epidemics of vaginitis among the little girls is the fact that the 
sonsequences to the reproductive organs are quite as grave as when produced in any other manner.

No other epidemic occurring in the hospital is so difficult to control as the cases of vulvovaginitis in little girls. These children should be isolated, and it seems to be the consensus of opinion that all such patients should wear a vulvar pad made of absorbent cotton held in place by a $\mathrm{T}$ bandage, both being changed at least every six hours and burned immediately upon removal, as experiments have proved that the ordinary laundry process supplemented by sterilization will not render diapers safe to use upon a healthy child.

So grave and so persistent are these epidemics in hospitals and other public institutions where large numbers of children are congregated that some hospitals make it an inflexible rule to burn all diapers from non-infected as well as infected children, that there may be no possible danger from that source.

The use of common bath tubs and water-closet seats are two very easy methods of carrying infection unless both are scalded and disinfected with chemicals several times daily.

It often happens that wards where such epidemics have occurred are emptied of patients, fumigated with formalin, and beds, furniture, floors, walls, and wood- 
work painted or varnished, mattresses and pillows discarded, bed and body clothing sterilized, all toys and books destroyed, and the ward may stand empty for a month, open to the sun and air; and when opened, with only new patients and new nurses, a fresh epidemic will occur within a fortnight, and worse than all, this process may have to be repeated three or four times, covering a period of months, while every doctor and nurse in the hospital is exercising every possible precaution which intelligence and ingenuity can contrive, to control it.

A gonococcus vaccine has been employed for gonorrhœal rheumatism, with favorable results.

The lower animals are not susceptible to infection from the gonococcus, although the injection of the poisonous products contained in cultures have caused death in some animals. The gonococci do not invade the tissues of the lower animals.

\section{Syphilis}

Syphilis is a chronic infectious disease characterized by certain lesions of which the chancre, the gumma, and the mucous patch are the most destructive.

Syphilis is liable or may infect any or every tissue of the body. Efforts to identify the microörganism 
which causes syphilis have extended over a long period, and not until very recently has any definite conclusion been agreed upon. Through a series of experiments by Schaudinn and Hoffman, which were confirmed by Metchnikoff and others, it has been decided that syphilis is due to a spirillum known as Treponema pallidum, the reasons for the long delay in arriving
at a decision being the fact that the organism is exceedingly difficult to stain, and, without

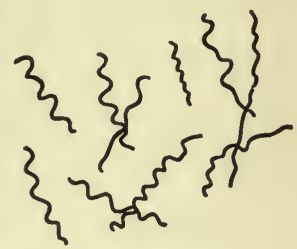
staining, it is almost impossible Frg. 16.-Treponema to see it. pallidum.

For many years all efforts to cultivate Treponema pallidum upon an artificial medium were unsuccessful, although monkeys had been inoculated and from the lesions other monkeys were successfully inoculated, which seemed to be conclusive evidence that Treponema pallidum undoubtedly caused syphilis. Schereschewsky, a German bacteriologist, was the first to bring about the growth of Treponema pallidum on artificial media (1909).

Syphilis is transmitted by sexual congress, may be transmitted by a diseased parent, or may be acquired by inoculation through an abrasion of the skin or mucous membranes. 
Syphilis may be transmitted by the father, the mother being perfectly healthy, or it may be transmitted by a syphilitic mother. Syphilis in a parent may have apparently entirely disappeared, and yet children born subsequently will or may show evidences of the disease. A curious phenomenon regarding the hereditary transmission of syphilis is that shown in Colle's Law, viz. " a child born of a mother who is without obvious venereal symptoms, and which without being exposed to any infection subsequent to its birth shows the disease when a few weeks old, - such a child will infect the most healthy nurse, whether she suckle it or merely handle and dress it; and yet this child will not infect its own mother, even though she suckle it while it has venereal ulcers of the lips and tongue."

The infection upon the lips may be contracted by kissing a syphilitic person or using infected dishes; a wet nurse may infect a healthy child and vice versa. Surgical and dental instruments which are not properly cleaned nor sterilized are grave sources of danger, and doctors and nurses may easily become inoculated while dressing syphilitic ulcers or other lesions upon their patients.

The whole subject of venereal diseases, and especially of their transmission, is of vital impor- 
tance to nurses, who should early inform themselves of the far-reaching consequences of venereal infections. The subject heretofore has been considered almost wholly (outside of the medical profession) from the moral standpoint, and it is very evident that the world at large - women in particular - should have a perfectly clear idea of its physical aspects in order to defend themselves and their children from the ravages of these loathsome infections.

One of the special points of the subject to remember is the fact that the infections of both gonorrhœa and syphilis are chronic, that is, we may truthfully say that the patients almost never recover; the acute symptoms will pass away and there is seeming recovery, but the germs are only latent, and children must bear the burden of their hideous manifestations.

Transmission of gonorrhœa and syphilis is by inoculation - the germs must gain access to the blood - which can occur only by contact. , Sexual congress and heredity will account for a large majority of cases, but there are enough instances of doctors and nurses contracting the diseases in the pursuit of their professional duties to warrant the exercise of the most scrupulous care of all utensils, clothing, and their own hands while working over 
syphilitic patients or those suffering from gonorrhœa.

The use of rubber gloves is one of the best means of protecting every one concerned: no process can be devised for disinfecting the hands which can equal the use of rubber gloves, which should be boiled both before and after using and should never be used for other patients. 


\section{CHAPTER IX}

TUBERCULOSIS. LEPROSY

Tuberculosis is the most widespread disease known. In the United States it was estimated that one ninth of all deaths which occurred in 1900 were due to tuberculosis, and that the cost to the country reached nearly to $\$ 200,000,000$.

Historical. - During 1870-1880 different investigators proved that tuberculosis was an infective disease but did not discover the organism which caused it.

"The announcement of the discovery of the tubercle bacillus was made by Koch in March, 1882, and a full account of his researches appeared in 1884 (Mitth. a. d. K. Gsndhtsamte., Berlin). Koch's work on this subject will remain as a classical masterpiece of bacteriological research, both on account of the great difficulties which he successfully overcame and the completeness with which he demonstrated the relations of the organism to the disease. The two chief difficulties were, first, the demonstration of the bacilli in the tissues, and, secondly, the cultivation of the organism outside the body. For, with regard to the first, the tubercle bacillus cannot be 
demonstrated by a simple watery solution of a basic aniline dye, and it was only after prolonged staining for twenty-four hours, with a solution of methylene-blue with caustic potash added, that he was able to reveal the presence of the organism. Then, in the second place, all attempts to cultivate it on the ordinary media failed, and he only succeeded in obtaining growth on solidified blood-serum, the method of preparing which he himself devised, inoculations being made on this medium from the organs of animals artificially rendered tubercular. The fact that growth did. not appear till the tenth day at the earliest, might easily have led to the hasty conclusion that no growth took place. All difficulties were, however, successfully overcome. He cultivated the organism by the above method from a great variety of sources, and by a large series of inoculation experiments on various animals, performed by different methods, he conclusively proved that bacilli from these different sources produced the same tubercular lesions and were really of the same species. His work was the means of showing conclusively that such conditions as lupus, "white swelling" of joints, scrofulous disease of glands, etc., are really tubercular in nature." (Muir and Ritchie.)

Koch's discovery is considered the most important single discovery in the history of medical science. Tubercle bacilli are minute rods from $2 \mu$ to $3.5 \mu$ or $4 \mu$ in length and about $0.5 \mu$ in breadth, occurring singly or in small groups, and surrounded by a cap- 
sular substance. The tubercle bacillus is non-motile, and is supposed to produce no spores, although some difference of opinion upon this point still exists.

\section{Staining and Culti-} vation. - The tubercle bacillus stains imperfectly or with great difficulty, and when once stained resists all efforts to decolorize it with acids; it is known with a few other organisms

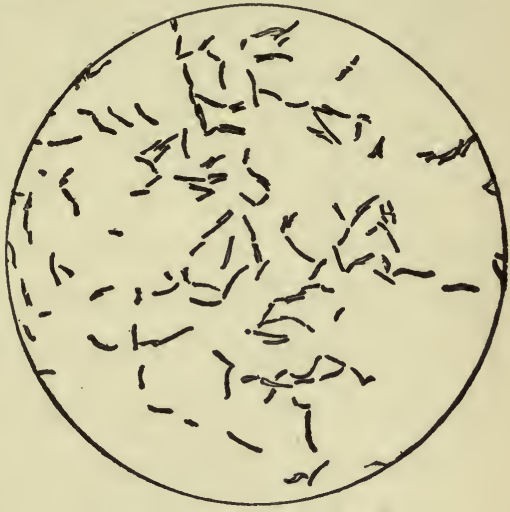

Fig. 17. - Tubercle bacilli. as an "acid-proof bacillus." This characteristic resistance to staining and decolorization constitutes one of the chief means of identifying the organism.

The cultivation of the tubercle bacillus upon artificial media is very slow and uncertain. Koch first succeeded in cultivating it upon blood-serum, which still remains the most satisfactory medium. When cultures have been successfully grown it is less difficult to transfer them to other substances-such as potato, carrot, or macaroni.

No growth is discernible before the end of ten days, which probably accounts for the many failures of early investigators. Cultures from the tissues show 
a more scanty growth than sub-cultures, but are always distinctly characteristic, appearing as dry masses like dry meal spread over the medium and of dull whitish or pale drab color, sometimes emitting a peculiar odor. Growth occurs within a narrow range of temperature, $37^{\circ}-38^{\circ} \mathrm{C}$. $\left(98.6^{\circ} \mathrm{F} .-100.4^{\circ} \mathrm{F}\right.$.), which corresponds to the normal temperature of the human body; but by a series of sub-cultures, growths have been observed in a temperature as low as $23^{\circ} \mathrm{C} .\left(73.4^{\circ}\right.$ F.). The tubercle bacillus is one of the few organisms which grow better upon a slightly acid medium.

Powers of Resistance. - The resistance of the tubercle bacillus is considerable, as it retains its vitality outside of the human body for some time, which constitutes the chief danger in the transmission of the disease. The bacilli in dried sputum will retain their vitality while floating in the air for several days, and if lodged in a cool dark place, may survive for six months. They are highly resistant to dry heat, surviving $100^{\circ} \mathrm{C}$. $\left(212^{\circ} \mathrm{F}\right.$.) for more than an hour, but will be killed by moist heat at $60^{\circ} \mathrm{C}$. $\left(140^{\circ} \mathrm{F}\right.$.) in twenty minutes. Freezing does not always destroy them, but exposure to sunlight will kill them in a few hours.

Of all of the chemicals used for germicidal purposes carbolic acid and its preparations have been found 
to be most effectual in destroying the tubercle bacilli. Lysol, which is a preparation of carbolic acid, has a solvent effect upon mucus, besides being an excellent germicide, which makes it preferable to any other preparation for the disinfection of sputum from patients suffering from phthisis.

Tuberculous Infection in Man. - The tubercle bacillus is one of the few organisms which invades every tissue and organ of the human body. The lungs are the most common seat of infection, but the larynx, the intestines and mesenteric glands, the glands of the neck, the bones and joints, the urinary tract, and the skin are frequently infected.

The lesions caused by the tubercle bacillus are characteristic nodules or tubercles which may be plainly seen with the naked eye in the more advanced stages of some forms of the disease. The general symptoms are wasting, fever, and perspiration, which are due to the toxic products of the bacilli, and in pulmonary tuberculosis (phthisis) the frequent presence of other bacteria may cause various other symptoms.

Tuberculosis in the Lower Animals. - Tuberculosis occurs frequently in cattle and swine. In Europe statistics show that from 15 to 20 per cent of cattle and from 2 to 3 per cent of swine are tuberculous. In the United States the percentage is much 
lower, .134 per cent only being recorded; some allowance is, however, made for the differences in compiling statistics. The appearance of the tubercle bacillus in man and the bovine bacillus is somewhat different, the latter being shorter. The very important question as to man's susceptibility to bovine tuberculosis is still a matter of controversy, although enough evidence has been collected to prove that the bovine bacillus is found in man. Bovine infection occurs much more frequently in children under five years of age than in adults, which is supposed to be due to their diet consisting largely of milk. Tuberculous meat is less dangerous than milk, because cooking will destroy the bacilli.

Tuberculosis is common among fowls, turkeys, and pigeons, but ducks and geese are exempt. Fish also are affected by a disease due to an organism which resembles the tubercle bacillus.

Channels of Infection. - The chief avenue of infection is the respiratory tract. It is estimated that a patient suffering from phthisis may expectorate over 500,000,000 bacilli in twenty-four hours, and even with the most scrupulous care, every act of coughing or sneezing projects large numbers into the air, where they may be inhaled by healthy persons. The action of sunlight and of drying kills the majority 
in the air, but many will find favorable lodging places where they may retain their vitality for weeks.

Infection through the alimentary tract is usually ascribed to butter or milk from tuberculous cows, but tubercle bacilli could easily be taken with food infected by handling, or from common drinking cups, or from dishes or food infected by flies. The phthisical patient often infects his alimentary tract by swallowing his own sputum.

Infection by inoculation - through abrasions of the skin - is not common and is usually localized.

Modes of Dissemination and Methods of Prevention. - To the nurse the modes of dissemination and the methods employed for the prevention of tuberculous infection are of double interest, on her own account as well as that of her patients.

Of first importance, and which should never be forgotten, is the fact that "every tuberculous individual is a source from which the disease may be further disseminated." (Abbott.) The phthisis patient is a source of greater danger to his neighbor than persons suffering from other forms of tuberculosis, but large numbers of bacilli are thrown off from lupus (tuberculosis of the skin), from wound secretions in surgical tuberculosis, from evacuations from the bowels in intestinal tuberculosis, and from 
the urine, when tuberculosis of the genito-urinary tract is present.

In the infectious diseases, as diphtheria, smallpox, scarlet fever, etc., the duration of the disease is short, and isolation is compulsory; but isolation in cases of tuberculosis has never been compulsory in any state, and as the duration of the disease may be for many months and sometimes years, it is easy to understand the ready dissemination and the frightful extent of tuberculous infections.

With intelligent patients of cleanly habits, it is easy to impress upon them how they may control the spread of the disease by the observation of a few simple details, but with the ignorant and persons who are unacquainted with the rudiments of cleanliness, it is an almost hopeless task to expect them to respond to instruction upon these points. The visiting nurses in all large cities, who for years have carried on a systematic campaign of instruction in the tenements, make extremely discouraging reports of the success of their efforts.

If the phthisis patient can be persuaded to use the cheap paper sputum cup, which can be burned, and will use paper napkins or old cloths, which can also be burned, while he is away from home, he can eliminate the chief source of danger; but when such a 
patient continually expectorates upon the floor or pavement, he is a menace not only to his family, but to the whole community in which he lives.

"Cornet states that for the ten years ending with 1897 the death rate from consumption in Germany was 21.5 per 10,000 against 31.4 for a corresponding previous period. He believes the result due to more general efforts at the suppression of indiscriminate spitting and more care in preventing tuberculous sputum from becoming dried and disseminated through the air as dust." (Abbott.)

The prejudice against the establishment of sanatoria for the segregation of tuberculous patients who are unable to have proper care and control for the protection of their families, is gradually dying out as general intelligence upon the subject increases, and many such institutions are being built in the large cities, while camps and cottage hospitals for incipient cases in all parts of the country are restoring health to thousands.

The whole system for the prevention of tuberculosis may be summed up in a very few words, viz. sunlight, fresh air, and cleanliness, but in the last lies the great stumbling block. The practice of cleanliness must begin with the infant; no adult reared in unclean surroundings can ever be taught 
thorough cleanliness; the compiler speaks with conviction, after twenty years of experience in training hundreds of nurses, that no woman who has not been taught the technique of cleanliness in her own home can or will ever be thoroughly, consistently, and safely clean in her nursing technique. If this be true of women of the better class, we should have infinite patience with the poor and ignorant who come from generations of poverty and its accompanying filth.

If the tuberculous patient remains in his own home, he should never occupy a room with any other person, his dishes should be kept apart and any broken food should be burned, his bed and body linen should be changed frequently, and the mattress, blankets, and pillows should be hung out in the air every sunny day, and if he be confined to his bed, enough bedding should be provided to use alternately. Paper sputum cups are preferable, as they may be burned, and if metal cups are used, they should be lined with two thicknesses of rather heavy paper, which can be removed with the sputum and put into the fire, and the cup be boiled for ten minutes in a 5 per cent soda solution, and immersed in a 5 per cent solution of carbolic acid until needed again; there should always be two cups for alternate use. Old soft cotton or linen cloth or cheese cloth should be used for 
handkerchiefs and always burned; these should be small and should never be put into the pocket, but rolled up tightly in paper immediately after using. Kissing, caressing, or shaking hands should be forbidden. - Dry dusting should never be done, but all furniture and woodwork wiped off daily with a dusting cloth wet with a 5 per cent solution of carbolic acid. Floors should be bare and washed every day if possible.

The practice of establishing the tuberculous patient in a tent or upon a broad porch is not only the best possible thing for the patient, but for the safety of the family. Even in the city or large towns such patients may be made comfortable for six or seven months of the year.

The infection of old houses and apartments with the tubercle bacilli must become a recognized fact, the old woodwork, especially floors, and old wall paper probably being the lurking places. In Paris statistics were compiled showing that certain blocks and localities of the city had been furnishing a continuous stream of tuberculous patients for many years, proving, without doubt, that the old buildings were the source of danger.

Clean hands and clean handkerchiefs are the nurse's best protection while caring for tuberculcus patients. 
Predisposing Causes of Tuberculosis. - It is said that in no other known disease do predisposing factors figure so largely as in tuberculosis.

Indoor occupations under unsanitary conditions, such as bad air, insufficient light, dampness, and long hours of work, are especially conducive to all forms of tuberculosis. It was formerly thought that by heredity many persons were tuberculous, but this is now disputed, and it is believed that the intimate relations of parents and children living under the same conditions accounts for the infection. Alcoholism, with all that goes with it, is a predisposing factor, also the wasting diseases, as diabetes and typhoid fever, are often followed by phthisis, but the most important factor of all is uncleanliness combined with poor food and bad air in the homes.

Tuberculin. - In 1890 Robert Koch announced his preparation known as Tuberculin $R$. as a curative agent. Tuberculin is the filtered products of growth from cultures of tubercle bacilli. When injected under the skin of a healthy person, no reaction occurs, but when used upon a tuberculous person or animal, a pronounced reaction occurs, consisting of a sudden elevation of temperature and a marked hyperæmia about the tuberculous focus, followed by disintegration of the tuberculous mass. 
The use of tuberculin did not prove as satisfactory as Koch had expected, and was discontinued almost entirely, except as a means of diagnosis in obscure cases in man and as a test in dairy cows, the latter being practiced extensively in all countries.

Immunity. - An attack of tuberculosis followed by cure does not render the patient immune, but on the contrary, seems to increase his susceptibility to further infections.

\section{LEPROSY}

Leprosy is a chronic, infectious, endemic disease caused by Bacillus leprce, an organism bearing a very strong resemblance to Bacillus tuberculosis.

The leprosy bacillus was discovered by Hansen, a Norwegian scientist, in 1872 ; prior to this, certain peculiar cells had been observed in leprous tissue, and Hansen found large numbers of leprosy bacilli lying within these "lepra cells." The leprosy bacillus is a slender rod, usually straight, occurring in characteristic bundles; it is without motion, does not form spores, and is usually found in the "lepra cells," although sometimes observed in the lymphatic glands and in the blood.

In the tubercular form the bacilli occur in enormous numbers, much greater than in the anæsthetic form. 
In staining the bacilli of leprosy the reaction may be said to be identical with the tubercle bacilli, but this similarity and the strong resemblance in appearance do not cause any confusion of the two organisms, because the leprosy bacillus is found in the characteristic "lepra cells," and the general symptoms of the two diseases are widely different.

Leprosy in Man. - Leprosy is most common in Asia and Africa along the seacoasts, but it also occurs in certain areas of Greece, Russia, Norway, the West Indies, the Pacific islands, and in North America in Nova Scotia, southern California (among the Chinese), and in Minnesota, - being introduced into Minnesota from Norway.

Leprosy is manifested in two forms : "tubercular," which is characterized by nodules of the skin and mucous membranes; and the "anæsthetic" form, in which the sensory nerves are first involved. In the earliest stage the nerves are hypersensitive, followed by the anæsthetic period, which is accompanied by a dry scaly eruption of the skin of the back, shoulders, arms, around the root of the nails, and following the course of the nerves.

The anæsthetic form is more common in the tropics, and a mixture of the two varieties is not infrequent. Both types of the disease are characterized by 
extreme disfigurement: in the tubercular type the nodular growths, especially about the face, often present an oozing, loathsome surface; and in the anæsthetic form necrosis and the separation of the parts occur.

While there seems to be no doubt of the infectiveness of leprosy, no conclusion has been reached regarding the avenue of infection. The disease shows little tendency to extend beyond the areas where it is endemic, and many healthy persons have lived for years among the lepers without contracting the disease.

Negroes are more susceptible to leprosy than whites.

Many authorities believe that the disease is hereditary, but equally good authorities strongly dispute the point.

All efforts to reproduce the disease in man by inoculation have failed entirely, and in only a few instances has the disease been reproduced in any animal.

In most countries the segregation of lepers into colonies has lowered the number of cases, but statistics are somewhat misleading, as it is a wellknown fact that many lepers have concealed the evidences of the disease for years rather than be separated from their own people. 


\section{CHAPTER $\mathrm{X}$}

GLANDERS, ACTINOMYCOSIS, ANTHRAX

Glanders is a disease peculiar to the horse, the mule, and the ass, although other domestic animals and the animals in menageries and zoölogical gardens are sometimes affected. Man is susceptible to the infection of glanders, but the cases are uncommon and usually confined to veterinarians and others caring for horses, who contract the disease by inoculation.

The glanders bacillus was discovered by Löffler in 1882 , and is knownas Bacillus mallei. It is a small rod with rounded ends, somewhat resembling the tubercle bacillus except that it is uniformly thicker; it is nonmotile and does not form spores. In cultures the $B$. mallei occur mostly in pairs or very short chains. The bacillus stains with aniline dyes and grows readily upon ordinary culture media, growth being more abundant in subcultures than in the first transfer from the animal tissues. 
B. malle $i$ is easily destroyed by heat and by chemicals.

Glanders may occur in acute or chronic form, the acute form being ushered in by a chill and high temperature, followed in a few days by an inflammation of the mucous membranes of the nose, and later showing nodules and greatly enlarged glands in different parts of the body. Death usually occurs in a few days. Mules and asses suffer more often with the acute form than horses, the latter usually being afflicted with the chronic form, in which there is a profuse infectious catarrhal discharge from the nose.

The infection of glanders through the skin is known as "farcy," and is characterized by swelling and nodules of the lymphatic glands. The nodules in both forms of glanders become softened and turn into ulcers. The bacilli are found in the young nodules, in the nasal discharges, and in acute general infection may be found in the blood.

Glanders Infection in Man. - Grooms and others working with horses are most liable to contract glaners, and several instances are recorded of the infection of laboratory workers. Man rarely contracts the chronic form, and death usually terminates the acute form in about two weeks. 
Entrance to the body of the horse is probably through an abrasion of the nasal membranes, or by way of the alimentary tract, and more rarely through the broken skin, while in man nearly all cases are the result of entrance through abrasions.

An attack of glanders does not confer immunity upon either man or beast.

The mallein test as a means of diagnosis is used in the same way that tuberculin is employed for the diagnosis of tuberculosis in cows. Mallein is the filtered products of the growth of B. mallei.

\section{ACTINOMYCOSIS}

A disease known as "lumpy jaw," which is common to cattle and occasionally seen in man, is due to a fungus-like organism known as actinomyces.

When growing in colonies the fungus presents a raylike appearance resembling a rosette which is discernible to the naked eye. The outer ends of the films forming the rosette are sometimes blunt or "clubbed."

The staining and cultivation of actinomyces is attended with considerable difficulty.

Much discussion has been spent upon the question as to whether there are two distinct species of 
actinomyces in man and in the lower animals, but it is supposed now that only one exists.

In cattle actinomycosis is characterized by the presence of hard swellings in and about the head, particularly in the tongue and lower jaw, which gradually soften, destroying the bones as well as the soft parts, while the swelling continues to encroach upon the surrounding tissues, usually causing great disfigurement. Death is usually due to the mechanical obstruction caused by the hard tumors, and not to any toxic effect of the bacteria.

In man the infection is more general, with less formation of the hard tumors, and more suppuration, death usually occurring in a few weeks.

Method of Infection. - The actinomyces is found upon grain, barley especially, which would probably account for the infection of cattle; but the manner of transmission from one animal to another or to man has not yet been explained. The cases occurring in man have often been in persons who have had no contact or remote relation to either animals or men suffering with the disease, and neither have they handled any grain which might harbor the organisms. 


\section{ANTHRAX}

Splenic fever or anthrax is a disease of cattle, sheep, horses, and swine, caused by the anthrax bacillus (B. anthracis). Man is also susceptible to anthrax, contracting the disease by inoculation from handling hides, wool, or the carcasses of animals dead from anthrax.

As early as 1850 several investigators declared that in the blood of all animals suffering from anthrax were to be found rodlike organisms, and that healthy animals which were inoculated with this blood speedily manifested the typical symptoms of anthrax.

It was not until 1876, when Robert Koch made his first contribution to bacteriology, that these first theories were proven by Koch's success in obtaining a pure culture from which he made many generations of subcultures, and successfully inoculated animals from the last cultures. It was at this time that Koch made the first observations upon sporeformation in bacteria.

The Bacillus anthracis is one of the largest of the disease producing bacteria; it occurs singly or in short chains, and shows a capsule which in the short chains appears to envelop the whole chain in one capsule. 
Colonies of anthrax bacilli present an extraordinary appearance, not unlike wavy locks of hair. The staining and cultivation of the bacillus is not difficult.

Growth is best at a temperature of $35^{\circ} \mathrm{C}$. (95 $95^{\circ} \mathrm{F}$.). Without spores the anthrax bacillus displays little resistance to heat, drying, or chemicals, but will survive freezing; but the spores are the most resistant of any pathogenic bacteria, it being said that anthrax spores have retained their vitality for thirty years. The bacillus grows without oxygen, but no spore-formation takes place in the absence of oxygen. It is believed that the spores of the anthrax bacillus never form in the body of the animal suffering with anthrax, but develop in the discharges from the body, or in blood drawn from the body, or in the body after death. The last reason is one of especial importance, for with the ordinary burial the spores might retain their vitality in the soil for years. It is customary to cover the carcasses of animals dead from anthrax with large quantities of lime, which effectually prevents spore-formation. Pastures which have been used by infected cattle are declared to be unsafe after ten or fifteen years.

The usual method of infection for cattle is by grazing in infected pastures. Epidemics of anthrax have occurred as the result of pastures being over- 
flowed by drainage from tanneries, hides from foreign countries often being infected.

Cattle may also be infected by inoculation through the broken skin, but this occurs less often than through the alimentary tract.

The Infection of Anthrax in Man. - Butchers, herders, and handlers of hides and wool are most commonly infected with $B$. anthracis, the infection occurring through the broken skin, through the respiratory tract, or through the alimentary tract, the disease in nearly all instances being contracted from the lower animals, and not from one man to another.

The most common form of anthrax in man is the malignant pustule or carbuncle, contracted by handling infected hides or carcasses. This infection is usually localized, and with proper surgical care produces no serious results.

"Wool sorter's disease" is a form of anthrax contracted by inhalation of spores floating in the air from infected wool. This form of anthrax very commonly develops into a general septicæmia resulting in death.

Anthrax contracted through the alimentary tract is of rare occurrence in man, and probably occurs from taking food which has been infected by han- 
dling, or more rarely from under-cooked meat from anthrax-infected cattle.

A vaccine for the immunization of herds and flocks of cattle, horses, and sheep has been very successfully employed in Europe and South America, where anthrax prevails much more than in the United States. 


\section{CHAPTER XI}

TYPHOID FEVER (ENTERIC FEVER)

TyphoID fever is an acute infectious disease characterized by lesions or ulcerations in the small intestines, and by symptoms of profound intoxication often resembling general septicæmia, which is due to the Bacillus typhosus. The bacillus of typhoid was discovered by Eberth in 1880, and isolated first by Gaffky in 1884. The B. typhosus belongs to a group of organisms (colon-typhoid bacilli) bearing a strong resemblance, which makes identification often a matter of great difficulty. In the intestines of all healthy individuals are found the Bacillus coli, which is ordinarily a harmless saprophyte, but closely resembles the $B$. typhosus both in appearance and habits of growth. The other organisms comprising the group are the para-typhoid bacilli, the bacillus of dysentery, the Bacillus enteriditis, the Psittacosis bacillus, the bacillus of hog cholera, and others. 
In size the bacillus of typhoid is about three times as long as it is broad, the rods having rounded ends, but with very little in its appearance to aid in its identification. It is very actively motile, but the

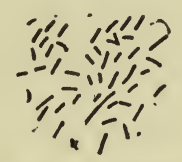

Fig. 18. - Bacillus typhosus.

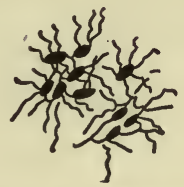

Fra. 19. - Bacillus typhosus, showing flagella.

flagella cannot be seen without special staining (Löffler's method). During life the bacilli may be found in the blood, in the urine, in the rose-spots, and in the feces of patients suffering with typhoid fever; and after death may be found in the tissues of the spleen, of the liver, of the kidneys, and of the intestines. Colonies of typhoid bacilli show nothing especially characteristic, being irregular, with somewhat wrinkled surfaces and a blue white color. Typhoid bacilli grow best at about $35^{\circ} \mathrm{C}$. (95 ${ }^{\circ} \mathrm{F}$.); they are killed by a temperature of $60^{\circ} \mathrm{C}$. $\left(140^{\circ} \mathrm{F}\right.$.), but sometimes survive freezing for weeks or even months. They grow slowly, with or without oxygen, and form no spores; their growth does not liquefy gelatin, nor produce gaseous fermentation, nor coagulate sterilized milk; these points and others are utilized 
to distinguish $B$. typhosus from the allied organisms which so closely resemble it.

While the bacillus of typhoid is frequently found in soil and in water, its presence can always be traced to the discharge of excreta from typhoid fever patients; the origin is often remote and obscure, but careful investigation invariably establishes the fact that such pollution of soil and water always arises from the excreta of typhoid-fever patients.

It was formerly thought that the bacillus of typhoid was capable of reproduction in both soil and water, but this is now acknowledged to be wrong, experiments showing that, while the bacillus may survive in sterile water for three months and in ordinary streams for five or six days, it does not multiply in either case.

In the soil or in privy vaults, the bacilli may survive for months, and may then be washed into streams by heavy rains, or they may infect the soil when the contents of the vault is used for fertilizing purposes, but they do not multiply in the soil.

Typhoid Infection in Animals. - Repeated experiments have failed to produce the typical typhoid fever of the human being in animals, although infections have occasionally occurred.

Prevalence of Typhoid Fever. - Typhoid fever is 
one of the widespread diseases, which has been characterized by appalling epidemics. As the disease is contracted by taking the germs into the mouth, and as the organisms originate only in the feces and urine of typhoid-fever patients, these epidemics are a sad comment upon our private and public cleanliness.

The fever prevails mostly in August, September, and October, favored no doubt by the beginning of decay in vegetation; it is more common in men than women, probably because more men drink water from varied sources than women; it occurs more frequently between the ages of sixteen and thirtyfive than at any other time.

Symptoms of Typhoid Fever. - The symptoms of typhoid fever are widely different in different individuals, in fact so varied that diagnosis is often a matter of great difficulty.

The premonitory symptoms are commonly headache, malaise, loss of appetite, nosebleed, and the gradual increase of temperature. About the tenth day characteristic rose-spots appear upon the abdomen. The onset is usually gradual, but in some instances is as sudden and violent as a typical pneumonia.

During and after the second week, suppurations may occur in various parts of the body, which may 
be attributed to the bacillus of typhoid. Mixed infections also are not uncommon, the pus cocci and the pneumococci frequently causing serious or fatal complications.

Modes of Dissemination. - Typhoid fever may be disseminated by polluted water, food, and soil, each factor carrying the bacilli in an infinite number of ways: which are often so circuitous that to the ignorant they seem to be very "far-fetched." Air-borne infection is rare.

Water pollution in cities and towns is always the result of a close relation between the water supply and the disposal of sewage; the same statement holds good in villages and farms where the water comes from shallow wells in close proximity to privy vaults. For twenty years, ending about 1893, typhoid fever prevailed to an alarming extent in Chicago, where the city sewage was discharged into Lake Michigan and the city water was drawn from the same source from intakes at one half and one mile from shore. The prevalence culminated in a severe epidemic in 1892, when in Cook County Hospital alone there were two hundred and forty typhoidfever patients on August 1.

During the following year a new three-mile intake was opened, and soon after the drainage canal which 
diverted the sewage into the Illinois River was also opened, with the result that with a greatly increased population the number of typhoid-fever patients in Cook County Hospital, August 1, 1894, had dropped to less than forty.

The history of epidemics of typhoid fever due to polluted water - and they are only too numerous - are strikingly similar; somehow, by some way, the water supply and the sewage come into contact, and if the sewage contains the discharges from many typhoid-fever patients, the possibilities of epidemics are enormous.

While freezing kills a majority of typhoid bacilli, enough survive to make the ice made from polluted water a source of danger.

Milk, more than any other article of food, serves as a carrier of typhoid bacilli, because no other article of food is subjected to so much or so careless handling, nor does any other article of food furnish such favorable media for the development of all kinds of bacteria. Although the bacillus of typhoid does not multiply in water, it is reproduced in milk.

The use of polluted water for washing milk cans, bottles, pails, and measures is the common source of milk pollution with typhoid bacilli.

Uncooked food, such as lettuce, celery, cucumbers, 
often the source of infection, either from the use of polluted water in cleaning them, or from fertilizers.

Houseflies are a frequent cause of the contamination of both food and dishes. It has been shown experimentally that living typhoid bacilli may remain in or upon the bodies of houseflies for two or three weeks.

Infection from contact does not result from casual contact, but usually occurs in nurses who are caring for typhoid-fever patients, and for this reason the most careful disinfection must be given to the urine, the fecal discharges, and to the bed and body linen of all typhoid patients. The details of the nursing of typhoid patients are almost countless, requiring an extraordinary amount of handling, which renders infection an easy matter unless the patient and his linen are kept immaculately clean and the nurse gives her own hands the most scrupulous care.

That comparatively few nurses contract typhoid fever from their patients speaks volumes for their observation of cleanliness.

A recent extraordinary discovery regarding the dissemination of typhoid fever is the fact that typhoid bacilli may be found in the excreta of some person for months or years after an attack, which 
no doubt explains some of the hitherto unexplained sources of infection. Attempts have been made to secure an internal disinfection in these cases to prevent further elimination of the bacilli.

Immunity following an attack of typhoid fever is variable, an occasional second or even third attack having been recorded.

Persons coming from a pure water supply to a polluted water are very susceptible to typhoid infection; while persons living permanently in a city having an impure water are almost wholly immune.

The Widal Test is commonly employed as a means of diagnosis, especially in cases lacking the characteristic clinical symptoms. It was discovered by Widal that if living typhoid bacilli were placed in the dilute blood-serum taken from a person suffering with typhoid fever, they would speedily lose their motility and become clumped (agglutinated) in characteristic groups.

Serum-therapy. - Numbers of attempts have been made to treat typhoid fever by a specific serum, but so far the results have not been successful.

Vaccination for protection against typhoid infection has been much more successful. The vaccine contains bacterial cells or substances derived from 
them. In the British army in India and South Africa vaccination against typhoid fever was employed for thousands of soldiers and for many nurses, the results being fairly successful. Wonderful results were obtained in our own Army during the maneuvers of 1911 at San Antonio, and again in Texas City in 1913, where thousands of soldiers were vaccinated. In 1911, 12,800 men were in camp for four months, and only one case of typhoid fever occurred, and at the present time (January, 1914) no cases have thus far occurred among the troops assembled in Texas. 


\section{CHAPTER XII}

\section{DIPHTHERIA}

Diphtheria is an infectious disease caused by the Bacillus diphtherice, which was discovered by Klebs in 1883 and first isolated by Löffler in 1884, hence the name, Klebs-Löffler bacillus of diphtheria.

An enormous amount of research has been applied to the bacillus of diphtheria and its toxins, which led to the discovery and use of an antitoxin serum for the prevention and cure of diphtheria, that may be considered one of the most important contributions of bacteriology to medical science.

Bacillus diphtherice is a slender rod varying in length from $1 \mu$ to $6 \mu$, presenting a beaded or granular appearance and sometimes showing clubbed ends. No other known bacillus shows so great a variety of shapes and sizes, nor in artificial media produces so many involution (abnormal) forms.

The diphtheria bacillus does not form spores and has no power of motion. 
Many special methods of staining the organism are used. The diphtheria bacillus grows best upon a slightly alkaline medium at body heat, $37^{\circ} \mathrm{C}$. $\left(98.6^{\circ}\right.$ F.), often showing minute colonies within twelve or fifteen hours, which are of a grayish white color with granular surfaces and fringed edges.

Resistance. - The resistance of the diphtheria bacillus constitutes one of its chief dangers as an . infective agent. Growths upon ordinary media retain their vitality from six weeks to twelve or fifteen months, and observers have isolated living bacilli from dried diphtheritic membrane after a lapse of eight months. It is said that bacilli in dry membrane will resist dry heat at $98^{\circ} \mathrm{C} .\left(208.4^{\circ} \mathrm{F}\right.$.) for an hour, but will be killed by moist heat at $55^{\circ} \mathrm{C}$. $\left(131^{\circ} \mathrm{F}\right.$.) in forty-five minutes.

This extreme resistance probably explains many instances of outbreaks of diphtheria of unknown origin, as the bacilli could easily be carried in the dry state for long distances by means of clothing and many other articles.

Diphtheria Infection in Man. - The mucous membranes of the human body are the favorite site for the development of the bacilli of diphtheria. The pharynx is most commonly infected, but the larynx or nasal membranes are quite often the site of infec- 
tion, while infection of the conjunctiva (membrane of the eye), and the mucous membranes of the genital organs is not uncommon.

Diphtheria is a typical toxæmia; the bacillus is almost never found anywhere outside of the point of infection, which shows a false membrane accompanied by necrosis of the tissues beneath it and a profuse exudate, while the general symptoms indicate grave lesions of the heart, the nervous system, and the kidneys.

Fatty degeneration of the heart and nervous system causes the extreme weakness and prostration so frequently observed in diphtheria, as well as the attacks of paralysis following. The gravity of a diphtheritic infection cannot be measured by the extent of the false membrane, as many fatal results follow apparently mild cases, showing that a small amount of toxin may do fatal damage to vital organs. McCollom says, "A patch of membrane the size of a thumb-nail on the tonsil may generate sufficient toxin to cause death."

In most instances the Bacillus diphtherice is not alone in causing an infection, but is associated with the pyogenic organisms, the streptococcus pyogenes occurring oftenest, the staphylococcus and pneumococcus being found occasionally. 
Some of the very serious complications of diphtheria, as the extensive swelling and suppuration of the glands of the neck, are due to pus infections; apparently the diphtheritic lesion affords an avenue for the entrance of pyogenic organisms. It is in these complicated cases of diphtheria that the antidiphtheritic serum has little effect.

Diphtheria Infection in the Lower Animals. - By inoculation of the lower animals typical diphtheria with all of the local and general symptoms can be reproduced. Cats, dogs, pigeons, and guinea pigs are the most susceptible, rabbits somewhat less so, and rats and mice the most resistant.

The Toxins of Diphtheria. - The fact that the bacillus of diphtheria is found only at the point of infection and not in the internal organs, although profound changes are wrought in these organs, led to the conclusion that these changes were due to soluble poisons (toxins), produced by the bacilli at the point of infection, which gain access to the general circulation and are carried to the distant organs affected. This poison is known as a toxalbumin, and in its chemical composition is analogous to the venom of poisonous serpents. If kept in the dark at a low temperature, the toxin of diphtheria may retain its activity for months, but its toxicity 
is lost by exposure to sunlight for a few hours or by boiling for five minutes.

Animals inoculated with diphtheria toxin show all of the conditions of typical diphtheria, except the false membrane, which is conclusive evidence that the chief injury arising from diphtheria infection is due to the toxins secreted by the bacilli.

The Antitoxin of Diphtheria. - In 1890 Behring and Kitasato found that the blood-serum of an animal which had been immunized against diphtheria would neutralize the effects of a diphtheria infection in another animal; in other words, the blood-serum of an immunized animal contained an antitoxin which is now known as the antitoxin of diphtheria. By a long series of wonderful experiments it was found practical to manufacture the antitoxin of diphtheria for both protective and curative purposes. Horses are used for this purpose on account of their size and their endurance. For two or three months gradually increasing doses of diphtheria toxin are injected subcutaneously into the horse at intervals of five or six days. When the blood has reached the desired potency, itis drawn from the jugular vein into sterile glasses and allowed to clot, when the serum is drawn off under aseptic conditions, filtered, tested, bottled, and kept in the dark at a low temperature. 
For curative purposes the horse-serum containing the antitoxin of diphtheria, which is commonly known as anti-diphtheritic serum, or still more commonly as diphtheria antitoxin, is injected with a sterilized syringe into the loose subcutaneous tissiue, usually in the back, below the shoulder. Beginning with a dose of 3000 or 4000 units, the dose is repeated about every six hours, the size of the dose and the number of times it is repeated being governed entirely by the condition of the patient.

The administration of diphtheria antitoxin is sometimes followed by temporary pains in the joints, or a rash. A few cases of death from the use of diphtheria antitoxins are reported, the cause being unknown, but is supposed to be due to some individual idiosyncrasy. In proportion to the enormous number of injections constantly made the deaths are of very rare occurrence.

The only argument needed in favor of the use of diphtheria antitoxin is its effect upon the death rates from diphtheria. In New York the death rate fell from 15.19 per 10,000 in 1885 to 6.62 per 10,000 in 1895; in Chicago from 14.29 per 10,000 in 1885 to 5.13 per 10,000 in 1895 .

Modes of Dissemination. - Diphtheria is more common in cold and temperate climates than in the 
tropical regions, prevailing more in the late autumn and winter than at other seasons.

Diphtheria may occur at all ages, but by far the greatest number of cases occur between the third and fifteenth years of life.

The dislodgment of particles of membrane by coughing, sneezing, or labored breathing is the chief source of infection from the patient suffering with diphtheria.

Nurses and doctors are liable to have bits of membrane coughed into their faces, such accidents making attendance upon diphtheria patients peculiarly dangerous.

Epidemics of diphtheria have been traced to the milk-supply, but the pollution of milk does not arise from the cattle, and is always due to outside human sources during its handling.

It is a popular belief that diphtheria is carried by sewer gas, but this has not been proven in any case. Faulty drainage, or leaking plumbing, or accumulations of filth of any kind will always afford means of conveyance to bacteria, and, in the case of the bacillus of diphtheria, is especially dangerous because of its unusual powers of resistance.

The fact that the diphtheria bacillus is so resistant to drying should be kept constantly in the mind of 
the nurse in the execution of all of the details of nursing a diphtheria patient. Scrupulous cleanliness of bed and body linen, of mouth sponges and dishes, and especially of the hands and finger nails of both the patient and the nurse, should be observed at all times.

Prophylaxis. - The use of anti-diphtheritic serum as a means of protection against diphtheria is employed to a considerable extent with well children when diphtheria attacks other members of a family or school; the immunity thus acquired lasts about three weeks. The other measures employed to prevent the further spread of the disease are complete isolation of the patient and nurse, the sterilization by heat and chemicals of all clothing, dishes, utensils, instruments, etc., and the consistent practice of cleanliness in the minutest details.

A common and dangerous mistake in the care of diphtheria patients is to break the quarantine directly the throat shows no sign of membrane. It is found that diphtheria bacilli are present in the throat for days and sometimes weeks after convalescence seems fully established, consequently the patient should be kept in isolation until the throat is entirely free from bacilli. Some boards of health require two negative cultures for release from quarantine. 
Pseudo-diphtheria Bacillus, or Hoffman's Bacillus. - This organism was first described by Hoffman in 1888; it strongly resembles the bacillus of true diphtheria, but is non-virulent. The pseudo-diphtheria bacillus is said to be found in the throats of about 20 per cent of all healthy persons, while only 1 or 2 per cent harbor the Klebs-Löffler bacillus. 


\section{CHAPTER XIII}

TETANUS, INFLUENZA, BUBONIC PLAGUE

Tetanus (lockjaw) is an acute infectious disease, caused by Bacillus tetani, which is characterized by frequent and long-continued spasms of the voluntary muscles, and which is nearly always fatal.

Bacillus tetani belongs to the small group of anaërobes, that is, the class of microörganisms which

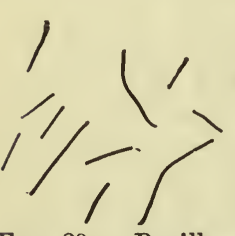

Fig. 20.-Bacillus animals. tetani. grow best in the absence of free oxygen, and is found in abundance in cultivated soil, in street dust, and in the droppings of horses and other

The tetanus bacillus was discovered by Nicolaier in 1884, who first observed it in pus taken from mice which had been inoculated with garden soil. Nicolaier did not succeed in growing it in pure cultures, and it was not until 1889 that Kitasato, by the use of anaërobic methods, obtained cultures which were free from other organisms, and 
was able to reproduce the typical disease in animals.

Bacillus tetani is a rather long, slender rod, and when in the spore stage presents the appearance of a small pin or drumstick, as the spore is always situated at the extreme end of the rod, and is three or four times the size of it. In

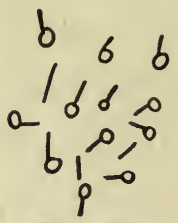

Fig. 21. Bacillus tetani in spore stage. the vegetative state there is nothing characteristic in its appearance, but in the spore stage it is easily discerned among many other organisms, besides being slightly motile.

The tetanus bacillus stains readily with ordinary dyes, but its cultivation is attended with extreme difficulty. Growth is slow; the first colonies not showing before the end of three days. The growth liquefies gelatin and blood-serum, and produces a small amount of gas, giving out a disagreeable characteristic odor. In the vegetative state the bacillus of tetanus possesses no extraordinary amount of resistance, readily succumbing to heat and to chemicals, but the spores of Bacillus tetani possess wonderful powers of resistance. They will survive one hour of dry heat at $80^{\circ} \mathrm{C}$. $\left(176^{\circ} \mathrm{F}\right.$.) but are killed by five minutes' exposure to moist heat at $100^{\circ} \mathrm{C}$. $\left(212^{\circ} \mathrm{F}\right.$.). They will resist the action of 5 per cent carbolic acid 
for ten hours, but are killed in three hours by corrosive sublimate, $1: 1000$.

Tetanus Infection in Man. - Tetanus occurs more commonly in the tropics than in colder climates. In Peru, Brazil, and some of the West Indian islands tetanus has at times become almost epidemic in its frequency.

The negro is particularly susceptible to tetanus, whether from the physical peculiarities of his race or from his unclean habits has not yet been determined.

Among the negroes in hot climates tetanus in the new-born by infection through the navel is very frequent, which may be attributed to habits of uncleanliness.

Though an infectious disease, tetanus is not communicable from one person to another except by direct inoculation. The disease can only be contracted by the introduction of the tetanus bacillus into the tissues of the body through abrasions or wounds.

The bacillus being strictly anaërobic, punctured wounds such as occur by gunshots, or by stepping upon nails, splinters, or other sharp objects which carry the bacilli into the deeper tissues, where they find favorable moisture, temperature, and absence 
of oxygen for their development, are the most common methods of tetanus infections. In wounds of this character the bacillus of tetanus is not alone carried into the tissues, as the soil is filled with many kinds of bacteria, some of which are also infective and by their action create much more favorable conditions for the multiplication of the tetanus bacilli. Some writers, notably Kitasato, believe that the presence of other bacteria or foreign material are necessary for the production of tetanus in man.

Tetanus may follow very trivial injuries, and as the local symptoms are usually slight, the first symptoms may be stiffness of the muscles of the neck with convulsive seizures. Like the bacillus of diphtheria, the tetanus bacillus is found only at the point of infection, the disastrous effects to the nervous system being due to the toxins manufactured by the bacilli.

Hundreds of cases of tetanus occur every year in the United States following the celebration of the Fourth of July with toy pistols, blank cartridges, fire crackers, and other explosives; infection in these instances usually occurs through injuries to the hands from premature explosions which carry shreds of clothing or cartridge paper or soil into the tissues. 
Tetanus in Animals. - The majority of the lower animals are susceptible to infection by the tetanus bacillus, the horse being particularly susceptible. Cases are recorded of epidemics of tetanus in certain stables, although there was no evidence to prove that the disease was contracted in any way than by the inoculation of wounds.

One peculiarity of tetanus infection in animals is the fact that the convulsive seizures begin near the site of infection and gradually become general, while in man the muscles of the jaw and neck are always affected first.

Prophylaxis. - All punctured or lacerated wounds of the feet or in any part of the body which are made by gunshots, nails, splinters, or other objects which have been contaminated by the soil should have immediate surgical care of the most careful kind; all discharges and dressings from the wounds of patients suffering with tetanus should be burned at once, and all utensils and instruments used for such dressings should be kept apart from other surgical supplies and should be sterilized by steam under pressure (autoclave) after each dressing.

The Toxin of Tetanus. - As in diphtheria, the tetanus bacilli are found only at the point of infection, and the profound general disturbances are 
due to the soluble poisons (toxins) produced by them.

Usually the wound shows little or no redness, swelling, or suppuration, and if these conditions are present, they prove the presence of other organisms. This absence of local signs constitutes one of the gravest dangers of tetanus, as there is always a period of incubation of from seven to twelve days before the manifestation of convulsions, and this lapse of time makes treatment at this stage usually fruitless.

Kitasato, who first isolated Bacillus tetani, gives the following statements regarding its toxic peculiarities: "When cultures of this organism are robbed of their bacteria by filtration through porcelain, the filtrate contains the soluble poison, and is capable, when injected into animals, of causing tetanus.

"Inoculations of other animals with bits of the organs of the animal dead from the action of the tetanus poison produce no result; but similar inoculations with the blood or with the serous exudate of the pleural cavity always result in the appearance of tetanus. The poison is therefore largely present in the circulating fluids.

"The greatest amount of poison is produced by cultivation in fresh neutral bouillon of a very slightly alkaline reaction. 
"The activity of the poison is destroyed by an exposure of one and one half hours to $55^{\circ} \mathrm{C} .\left(131^{\circ}\right.$ F.), of twenty minutes to $60^{\circ} \mathrm{C} .\left(140^{\circ} \mathrm{F}\right.$.), and of five minutes to $65^{\circ} \mathrm{C}$. $\left(149^{\circ} \mathrm{F}\right.$.).

"By drying at the temperature of the body under access of air the poison is destroyed, but by drying at the ordinary temperature of the room it is not destroyed.

"Diffuse daylight diminishes the intensity of the poison. Its intensity is preserved for a much longer time when kept in the dark.

: "Direct sunlight robs it of its poisonous properties in from fifteen to eighteen hours.

"Its activity is not diminished by diluting a fixed amount with water or nutrient bouillon.

"Mineral acids and strong alkalies diminish its intensity."

The chemical nature of tetanus toxin is not positively known, but it is one of the most powerful poisons known.

Tetanus Antitoxin or Antitetanic Serum. - The principles involved in the production of an antitoxin in diphtheria are identical in tetanus; in fact, it was through the researches into tetanus that the principles were first worked out.

Animals are immunized from tetanus by the 
repeated injection of gradually increasing doses of tetanus toxin, until the blood contains the required amount of antitoxin; the blood-serum of the immune animal is capable of protecting the susceptible animal or human from the action of the tetanus toxin and also against the effects of the living tetanus bacillus.

The use of the tetanus antitoxin for the treatment of tetanus has been far less successful than the use of diphtheria antitoxin for diphtheria, because in diphtheria the local signs in the throat lead to an early diagnosis and treatment before the bacilli have produced an overwhelming amount of toxin; while in tetanus the first symptoms are the convulsions which are due to the presence of the toxins. Also, the toxins of tetanus have an affinity for the cells of the central nervous system, while the toxins of diphtheria act upon the tissues of less vital importance.

The other pathogenic anaërobes are Bacillus chauvei, the cause of a disease in cattle commonly known as "black leg," "quarter evil," or "symptomatic anthrax"; the Bacillus edematus, which is the cause of malignant edema; the Bacillus Welchii, or gas-producing bacillus, found in cases of emphyse- 
matous gangrene; the Bacillus botulinus, found in raw meat and the cause of many cases of meat poisoning; and the Bacillus fusiformis, found in an affection of the membranes of the mouth and throat.

\section{INFLUENZA}

Influenza (commonly known as La Grippe or Grippe) is an infectious catarrhal disease of the respiratory tract caused by Bacillus influenzo, the constitutional symptoms being due to the toxins produced by the bacilli growing in the mucous membranes, especially in the bronchii.

The influenza bacillus is one of the smallest known pathogenic organisms, usually about $1.5 \mu$ in length and $0.3 \mu$ in thickness; the ends of the rods are rounded, it is strictly aërobic, non-motile, and does

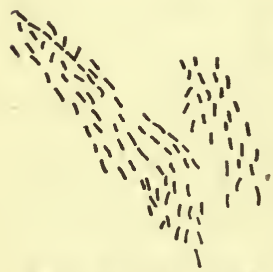

FIG. 22.-Bacillus influenzæ. not form spores. It stains with ordinary dyes and is decolorized by the Gram method. It grows best at body temperature, $37^{\circ} \mathrm{C}$. $\left(98.6^{\circ} \mathrm{F}\right.$ ), but develops only upon media to which blood has been added. Being an aërobic, its growth takes place only upon the surface of the medium employed. The colonies develop as minute 
transparent spots, like tiny drops of dew. The bacillus of influenza possesses little resistance to drying, to heat, or to chemicals.

Influenza Infection in Man. - $B$. influenzce usually invades the air-passages and is found in the sputum and nasal discharges, more largely in the bronchial mucus; but is almost never found in the blood. Influenza bacilli are often found in the bronchial and nasal discharges for weeks after recovery seems complete. The varied symptoms of influenza, which seem to be almost innumerable, are due to the toxins produced by the bacilli and not to their local effects.

Pneumonia, meningitis, inflammation of the middle ear, gastric and kidney disorders, and many nervous manifestations very commonly accompany influenza, and "are probably to be referred to the selective action of the toxin in different individuals rather than to localization of infection." (Jordan.)

Pneumonia, due to $B$. influenzce, and influenza as a secondary infection in pulmonary tuberculosis, are both grave conditions.

Pulmonary tuberculosis is not infrequently a sequence of influenza.

The methods whereby the bacilli of influenza are transmitted in the sudden and appalling epidemics 
of influenza which sometimes sweep over a whole country in a few days, and over almost the whole globe in a season, are still matters of considerable doubt. The fact that $B$. influenzo possesses so little resistance to drying and does not grow outside of the human body does not coincide with the rapidity of the epidemics. The fine droplets of mucus expelled by sneezing and coughing would seem to be the source of infection, but how they are transmitted such distances and develop in so short a time remain to be explained.

Patients suffering with influenza should be isolated from other members of the family. Particular attention should be given to the disinfection of dishes, utensils, and linen. All mouth sponges, handkerchiefs, and old linen used to receive nasal and bronchial discharges should be burned at once.

An attack of influenza is said to impart a transient immunity, but it is of such short duration as to be very insignificant.

Influenza in Animals. - No typical attacks of influenza have been reproduced by the inoculation of animals. Monkeys and rabbits are the only animals showing any significant symptoms.

Pseudo-influenza Bacilli. - Several bacilli have been observed and described which bear a strong 
resemblance to $B$. influenzo, but their place has not yet been fully determined.

An organism which appears to be identical with the bacillus of influenza is found in whooping cough.

The Koch-Weeks Bacillus. - This organism was first observed by Koch in 1883 as the cause of the eye inflammations so common in Egypt, and later was recognized as the cause of the contagious form of conjunctivitis, known all over the world. This organism is slightly longer than the influenza bacillus, and may be cultivated without the hemoglobin medium, which are the only points of difference yet observed.

\section{BUBONIC PLAGUE}

Bubonic plague, also known as Oriental plague, bubonic pest, black death, and several other names, is an acute, specific, transmissible disease which is characterized by high fever and inflammation and suppuration of the lymphatic glands known as buboes, due to an organism known as Bacillus pestis. Bubonic plague is usually attended by high mortality, which varies in different races and in different epidemics.

While the direct cause of bubonic plague is $B$. pestis, the predisposing causes are overcrowding, 
filth, bad air, poor and insufficient food, and intemperance. It may be said that epidemics of plague have never occurred where hygienic conditions exist.

The plague bacillus was simultaneously discovered and described by Yersin and Kitasato from observations made during the epidemic at Hong Kong in 1894. Plague bacilli are small oval rods, somewhat shorter than the typhoid bacillus and of about the same thickness, although considerable variation in size occurs. The rods have rounded ends, and in staining, the middle portion is usually left uncolored, giving the so-called "polar-staining." The bacillus may be described as short, oval, capsulated, nonmotile, non-spore-bearing, and polar-staining. It grows luxuriantly
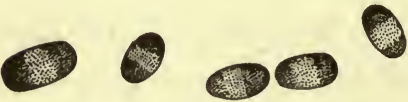

FiG. 23. - Bacillus of bubonic plague, showing polar-staining.

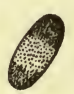

on solidified bloodserum as a yellowish gray deposit, growing in shred-like

films which adhere to the sides or drop to the bottom of the culture tube. Growth is best at a temperature between $36^{\circ} \mathrm{C}$. and $39^{\circ} \mathrm{C}$. (96.8 $8^{\circ} \mathrm{F}$.$102.2^{\circ} \mathrm{F}$.). It is destroyed by drying at room temperature in four days; by exposure to sunlight in four hours; by moist heat at $100^{\circ} \mathrm{C}$. $\left(212^{\circ} \mathrm{F}\right.$.) instantly, and at $80^{\circ} \mathrm{C}$. $\left(176^{\circ} \mathrm{F}\right.$.) in five minutes; 
by 1 per cent carbolic acid in ten minutes; and by corrosive sublimate solution 1:1000 instantly.

Plague Infection in Man. - The first records of plague in history date about the beginning of the Christian era. For centuries it raged in Northern Africa, and during the middle ages extended to Arabia, India, Asia Minor, and throughout Europe.

History relates that during the frightful visitation of plague in the fourteenth century more than one fourth of the population of Europe, about 25,000,000 people, died, ten thousand persons dying in one day in Constantinople. In 1664-1665 London had an epidemic of plague which carried off 68,500 persons out of a population of 460,000 .

It is supposed that in all of these epidemics other infections were present, probably malignant typhus fever and "spotted fever," both of which are favored by the same unsanitary conditions that are so great a factor in epidemics of plague.

Bubonic plague has never been epidemic in America, although a considerable number of cases have occurred in San Francisco, brought by ships from China; but by the enforcement of quarantine regulations and medical inspection there has been no extended dissemination of the disease.

The death rates in different epidemics vary from 
50 per cent to 95 per cent, Yersin reporting the latter after the Hong Kong epidemic in 1894.

Race mortality shows also a wide variation, but it is attributed rather to differences in social conditions than to physical differences of the races. At Hong Kong the mortality was 93.4 per cent among Chinese; 77 per cent among Indians; 60 per cent among Japanese; 100 per cent among Eurasians; and only 18.2 per cent among Europeans.

There are two forms of plague in man: the bubonic and plague pneumonia. The bubonic form often passes into a septicæmic form when the bacilli pass from the buboes into the blood. There are sometimes subcutaneous hemorrhages, causing dark spots, from which the name "black death" no doubt originated. In plague pneumonia, which is much less frequent than the bubonic type, the sputum contains enormous numbers of bacilli; this form of plague is usually fatal.

Modes of Infection and Transmission. - Poverty and filth may be considered the two greatest contributing factors in the continuance and spread of plague. In the middle ages the hygienic condition of the whole world was identical with those found at present in China and India.

The "infectious droplets" from the pneumonic 
plague patient, the discharges from buboes, and the excreta are the sources of infective materials, which must find entrance to the body through breaks in the skin or mucous membranes to produce a plague infection.

The usual mode of infection is through an abrasion of the skin, the buboes developing in the neighborhood of the point of infection. Infection through the tonsils and air-passages may occur, but pneumonic plague is usually secondary to the infection of other tissues through abrasions.

Infection by swallowing is not supposed to occur. Aoyama points out that during the Hong Kong epidemic doctors and nurses who were in attendance upon plague-infected patients were rarely infected; neither were three hundred English soldiers who volunteered to clean and disinfect the plague pesthouses, which is strong evidence that the disease is not contracted through the alimentary tract and rarely through the air-passages.

It was long observed in many epidemics that transmission and infection did not always occur, even when healthy persons, such as doctors and nurses, were brought into close contact with plagueinfected patients.

It was also noted that epidemics of plague were 
often if not always accompanied by great mortality among rats, and investigation proved that the plague of rats and the plague of man were both due to $B$. pestis, some writers believing that plague is primarily a disease of rats and contracted from them by men. This theory led to much study of the methods whereby the infection is transferred to man. As the infection does not take place through the alimentary tract, it could not be carried by food or utensils which had been contaminated by rats, neither was it possible for every infected person to have come into direct contact with rats; but it was discovered that fleas taken from the bodies of plague-infected rats, or from rats in an infected house, and transferred to the bodies of healthy rats, would transmit plague to the latter.

The Advisory Committee of the Indian Plague Commission, in 1905, by a series of experiments, proved conclusively that rat fleas carried plague to healthy animals and to man.

The following are some of the experiments which were conducted. A series of six huts were built which only differed in the structure of their roofs. In two the roofs were made of ordinary native tiles, in which rats freely lodge; in two others flat tiles were used, in which rats live, but in which they have not such facilities for move- 
ment as in the first set, and in the third pair the roof was formed of corrugated iron. Under the roof in each case was placed a wire diaphragm, which prevented rats or their droppings having access to the hut, but which would not prevent fleas falling down on to the floor of the hut. The huts were left a sufficient time to become infected with rats, and then on the floor in each case healthy guineapigs artificially infected with plague were allowed to run about together. In the first two sets of huts to which fleas had access the healthy guinea-pigs contracted plague, while in the third set they remained unaffected, though they were freely liable to contamination by contact with the bodies and excreta of the diseased animals. In the third set of huts no infection took place as long as fleas were excluded, but when accidentally these insects obtained admission, then infection of the uninoculated animals commenced. Other experiments were also performed. In one case healthy guinea-pigs were suspended in a cage two inches above a floor on which infected and fleainfested animals were running about. Infection occurred in the cage, but if the latter were suspended at a distance above the floor higher than a flea could jump, then no infection took place. Again, in a hut in which guineapigs had died of plague, and which contained infected fleas, two cages were placed, each containing a monkey. One cage was surrounded by a zone of sticky material broader than the jump of a flea. The monkey in this cage remained unaffected, but the other monkey contracted plague. (Muir and Ritchie.) 
These experiments suggest practical measures for the control of plague. Rats, fleas, and filth being closely connected, it remains for those concerned to remove these causes. Such measures may be easily employed in Europe and America, but in China and India, whose inhabitants live in unspeakable filth, it will require generations of education to remove the conditions which so strongly favor the development and spread of the disease.

Plague in Animals. - Rats, mice, guinea pigs, and ground squirrels are very susceptible to plague, and monkeys are particularly sensitive to artificial inoculation. Rats and guinea pigs may be infected by feeding. . Dogs, swine, cattle, and horses may be inoculated artificially, but do not contract the disease under natural conditions.

As before stated, the plague of rats has been the subject of widespread investigations, which have led some observers to declare that plague is primarily a disease of rats, not man.

Protective and Curative Sera. - "Haffkine's prophylactic" serum has been used as a preventive of plague in India to a considerable extent and degree of success.

The statistics of Punjab in 1902 report that among the inoculated 1.8 per cent became infected, while 
7.7 per cent of the uninoculated contracted the disease; while the deaths among the inoculated were 23.9 per cent, and among the uninoculated 60.1 per cent.

The Yersin anti-plague serum is used for curative purposes with fairly good results.

Prophylaxis.-Besides the use of Haffkine's prophylactic serum against plague infection, the exclusion of rats, mice, and domestic pets which may harbor rat fleas, and the practice of scrupulous cleanliness both inside and outside the house, are the best preventive measures to be employed for the protection of a household. The fumigation with sulphur or formaldehyde of the cellar and basement, followed by a liberal application of whitewash to the ceilings, walls, and floors, is recommended for driving away rats and killing fleas.

It was formerly thought that the poorer classes in China and India usually contracted plague through abrasions on the feet, as they never wear shoes, but in the light of the knowledge of fleas as carriers of the plague bacillus, it is likely that the bare feet are more often bitten by fleas in the soil, in which they are found in large numbers. That the soil becomes infected in all epidemics of plague there is no doubt, and attempts are made to disinfect the soil by covering it in the immediate vicinity of dwellings with 
freshly made whitewash, which will destroy both fleas and infective materials.

When a member of a household contracts plague, it is customary to remove the patient to an isolation hospital at once, and to quarantine the house and its remaining members for ten or twelve days, at the same time cleaning and disinfecting the house and its contents to the minutest crevice.

Patients recovering from plague are kept in quarantine for four or six weeks after convalescence begins, as the bacilli are often found as late as three weeks after the beginning of convalescence.

In carrying out prophylactic measures against all infectious diseases the sources and modes of infection should be kept constantly in mind to serve as a guide. 


\section{CHAPTER XIV}

\section{ASIATIC CHOLERA. RELAPSING FEVER}

Asiatic Cholera is an acute infectious disease characterized by great intestinal irritation accompanied by profuse watery discharges called " ricewater" discharges, and by vomiting. The general symptoms include profound prostration, cold, clammy skin, cardiac depression, cramps of the muscles, and suppression of urine. Cholera is due to the Spirillum cholerce, which was discovered and described first by Koch during his investigations of cholera in Egypt in 1883.

Prior to this time little or nothing was known of the cause of cholera, although the disease existed for centuries in India, and since 1831 had been epidemic at times in all parts of Europe. In the United States cholera has been epidemic at eight different times between 1832 and 1873. 
Cholera spirilla are short, slightly curved rods having the general appearance of a comma and sometimes called "comma bacillus." The rods

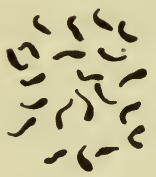
Fig. 24. - rarely found in the intestines. They usually occur singly, but may appear in pairs, curving in an opposite direction like the letter $s$. Longer forms frequently develop in cultures, but are atic cholera. are actively motile, having a single flagellum at one end only. They do not form spores, and stain readily with aniline dyes, losing their color in Gram's method.

The spirilla grow readily on all ordinary media. An alkaline reaction is necessary for all media, the spirilla being extremely sensitive to the action of acids.

At the end of twenty-four hours the colonies become visible to the naked eye, showing a round, even contour, which later becomes irregular, and a granular surface. At the end of forty-eight hours liquefaction of the gelatin occurs, resulting in a characteristic funnel-shaped depression in the colony.

Cholera spirilla are strictly aërobic organisms; they possess no great powers of resistance, being quickly killed by drying, by chemical disinfectants, 
and by $60^{\circ} \mathrm{C}$. $\left(140^{\circ} \mathrm{F}\right.$.) in ten minutes; neither do they retain their vitality for any length of time in soil or water. They may retain their vitality for several days upon the surface of fruit and vegetables, if kept in a cool, moist place. Whether there is any multiplication of cholera spirilla in impure water is still a matter of doubt, although there can be no doubt that they retain their vitality in impure water for several days, as cholera-infected drinking water is the usual source of infection.

Cholera Infection in Man. - The proof of the connection of the cholera spirillum with Asiatic cholera in man has been demonstrated several times in laboratory workers who by accident or design have become infected by the materials with which they were working; all of these instances occurring when no cholera existed in the country.

The spirilla are found in the intestines, but do not enter the blood or internal organs. The small intestines are mostly affected, the epithelium being shed, and the characteristic "rice-water" discharges containing enormous numbers of spirilla, almost pure cultures. Like typhoid fever, cholera is contracted largely through polluted drinking water, i.e. the spirilla must enter the alimentary tract, and infected drinking water is the common source. Un- 
cooked food, particularly milk, or food which has been exposed, may be infected by flies which carry the organisms upon their feet or bodies from sewers, privies, and neglected cholera discharges. Dishes and table linen may also be infected in the same way. The cholera spirilla leave the body only in the feces, and it has been demonstrated that the fecal dis-

- charges of perfectly healthy persons living in a cholera-infected district may also contain large numbers of spirilla, which is a conclusive argument in the reasons for disinfecting all bowel discharges and linen soiled with fecal matter, and for sterilizing the drinking water. The nursing methods for the prevention of infection in cholera are identical with those in typhoid fever.

The period of incubation being short, cholera epidemics are explosive in their suddenness. The last epidemic of cholera in Europe occurred in Hamburg in 1892 and was a clinical demonstration of an epidemic caused by infected drinking water. Hamburg and Altona are practically one city, although under two distinct municipal governments. Both cities obtained water from the river Elbe, but in Altona the city water supply was filtered, and in Hamburg it was not at that time, which resulted in Hamburg having 16,957 cases of cholera, 
with 8606 deaths, while Altona during the same period had 516 cases, most of them having been infected while working in Hamburg, with 316 deaths.

Since this epidemic Hamburg has established a satisfactory system of filtration; and though there has been no opportunity for proving its value in times of cholera, the death rate from typhoid fever has fallen from 34 per 100,000 to 6 per 100,000.

Cholera in Animals. - Under natural conditions animals do not contract cholera. Rabbits have been successfully inoculated by injection into the ear vein, and young rabbits have been infected through spirilla being placed upon the teats of the mother.

Intraperitoneal injections into guinea-pigs has also produced cholera, this method being often employed to test the virulence of cholera cultures.

Toxins. - For a long time there was no evidence that cholera spirilla produced toxins, as do the tetanus and diphtheria bacilli, and it was supposed that the cholera spirilla contained only an endotoxin, that is, a poison within the organism; but later investigations of Metchnikoff, Roux, and others proved that toxins are produced, and that the serum of actively immunized animals does contain an antitoxin which neutralizes the cholera toxin. 
Prophylaxis. - Vaccination against cholera has been successfully practiced in India for some years. Guinea-pigs are immunized by repeated intraperitoneal injections of small doses of spirilla until a high degree of immunity is attained. If the bloodserum from the immunized guinea-pig be injected, with a fatal dose of the virulent spirilla, into a susceptible guinea-pig, it is found that a small dose of the immune blood-serum will protect the susceptible animal against a ten times fatal dose of virulent spirilla. The immunized blood-serum dissolves (bacteriolysis) the spirilla, the phenomenon being known as "Pfeiffer's reaction." The blood-serum of an immunized animal has also an agglutinative action against the cholera spirilla, analogous to Widal's reaction in typhoid fever.

Haffkine's vaccination against cholera, which is employed so extensively in India, is carried out in accordance with these principles and has proved to be successful.

Powell gives the following statistics:-

$\begin{array}{lccc} & \text { NUMbER } & \text { CASES } & \text { DEATHS } \\ \text { Unvaccinated } & 6549 & 198 & 124 \\ \text { Vaccinated } & 5778 & 27 & 14\end{array}$

Besides vaccination for the prevention of cholera, the careful observance of quarantine, particularly 
of ships or trains coming from infected countries or districts, is of the greatest importance in preventing the spread of the disease.

When a community is threatened with an invasion of cholera, the water, milk, and other food supplies, as well as the dishes, should be freshly sterilized before each meal. No uncooked food should be used, and all food, dishes, dish towels, and table linen should be protected from flies and other insects.

All persons suffering from diarrhœa, no matter how mild the form, should be isolated, and the bowel discharges be disinfected with the same care as would be observed in a typical case of cholera.

As in typhoid fever the mild cases of cholerawhoare not confined to their beds are of more danger to a community than those who are violently ill, because in the mild cases it is thought unnecessary to disinfect the fecal discharges and the water-closets, and many fatal cases owe their origin to this neglect.

The details of nursing cholera patients, as before stated, are identical with those of typhoid fever. The disinfection of excreta and clothing soiled with excreta is especially important; the dishes used by the patient should be boiled after each meal, and refuse food should be burned.

Cholera patients are not released from quarantine 
until bacteriological examinations show that the fecal discharges are free from cholera'spirilla.

Allied Spirilla. - A number of spirilla strongly resembling $S$. cholerce have been observed in sewage and impure water especially, most of which seem to be saprophytes.

\section{RELAPSING FEVER}

Relapsing fever, as the name indicates, is a fever characterized by a number of seizures, or relapses, which occur from two to four or more times. The disease is due to Spirillum obermeieri, which was first observed by Obermeier in 1873 in the blood of patients suffering with relapsing fever.

The disease has at times prevailed in all parts of Europe, India, and the United States; but in recent years the disease rarely occurs in the United States.

$S$. obermeieri is a large spirillum with several spirals and a single flagellum at one end. It is actively motile. All attempts at artificial cultivation have so far proved unsuccessful.

- Infection occurs through inoculation; and monkeys, rats, and mice may also be infected. The disease is rarely fatal in man or animals. There are several diseases caused by similar organisms, the principal one being African tick fever, in which man is infected by means of a tick bite. 


\section{CHAPTER XV}

\section{DISEASES DUE TO PROTOZOA}

\section{Amgebic Dysentery, Malarial Fever}

Besides the infectious diseases due to the smallest form of vegetable life which we know as bacteria, there are several widespread diseases in both men and animals which are caused by animal microorganisms, known as pathogenic protozoa (sing. protozoön).

Protozoa are the smallest form of animal life, and like bacteria, are unicellular and of many species, varying in size, shape, and methods of reproduction.

In some species of protozoa the life cycle is as simple as that of bacteria, while in others it is extremely complex. A large number are parasitic upon animals and plants, and by their invasions into the bodies of men and animals are the cause of many serious maladies, especially in the tropics.

A class of protozoan parasites known as Sporozoa are nearly as widely distributed as bacteria. 


\section{Amabic Dysentery}

Dysentery is a term used to designate an inflammation of the colon, accompanied by excessive diarrhœea; but dysentery occurs in several distinct forms which are due to different organisms. Thus, several forms of dysentery are due to bacteria - Bacillus dysenteria - of which there are two or three varieties, in other words are due to vegetable organisms (bacteria); while amcbic dysentery, a chronic form usually occurring in the tropics, is caused by a protozoön known as entamœba histolytica. In amœbicdysentery large numbers of amœbæ are found in the intestinal walls, which they penetrate, causing characteristic ulcerations. The colon and rectum are most affected, although the internal organs, notably the liver, are frequently invaded, resulting in large abscesses of the liver.

The amœbæ of dysentery average about $30 \mu$ in diameter, are actively motile, and multiply by sporeformation. They possess protrusions for locomotion - pseudopodia - which they use to penetrate the mucous membranes.

Artificial cultivation of the amœbæ of dysentery has been attended with great difficulties, and has been successful only by the use of elaborate special methods. 
It is not known definitely how nor where the amœba of dysentery multiply outside of the body, although raw foods and water carry the organisms. It is said that the sand filtration of water which effectually removes the typhoid and cholera organisms does not withhold dysentery amœbæ. Monkeys in confinement contract amœbic dysentery by natural conditions, and cats and other animals have been infected by introducing the amœbæ into the rectum, and by feeding them the spores.

Amœbæ are found in the intestines of healthy persons which are called entamœba coli; these multiply by both fission and spore-formation, and are considered an entirely distinct species.

A class of protozoa known as trypanosomes cause a number of diseases common to horses, cattle, and wild animals in South Africa, as well as the terrible "sleeping sickness" among human beings.

Transmission takes place through the bites of insects: rat fleas, lice, ticks, and the "tsetse-fly" which carries the infection of "sleeping sickness." It is believed that the parasites - trypanosomes exist in the bodies of the larger wild animals, and are always transmitted to man and the domestic animals by the bites of flies or other insects. 


\section{Matiarial Fever}

Malarial fevers are characterized by periodic occurrences of chills, fever, and sweating, with a disappearance of the symptoms between the paroxysms. The intermission varies, occurring daily - quotidian; every other day - tertian; and with an interval of two days - quartan. Of the four forms of malarial fever, one, the "pernicious" type, is usually fatal and seldom occurs outside of tropical countries. Malarial fever is due to a parasite known as plasmodium malarice, or more properly hemamœba. The parasite of malaria was first observed and described by Leveran, a French army surgeon in Algiers, in 1880. Shortly after, Golgi observed that the several types of malaria were due to different malarial organisms, and that the chill always occurred when sporulation took place; that is, when a brood of young parasites entered the blood. The parasite attaches itself to the red corpuscles of man and there passes through the process of spore-formation, the duration of the process corresponding to the intermission between the paroxysms.

Before these discoveries the cause of malaria had been attributed to low marshy lands, to the rainfall, to prevailing winds, to the season, and to the drink- 
ing water; but following the work of Leveran and Golgi a great amount of research was directed to finding the mode of infection.

It was at first thought that the parasite existed in the soil and water; but all attempts to reproduce the disease through the alimentary tract or through wounds of the skin by means of soil and water were unsuccessful.

This investigation continued for several years until 1897, when Ronald Ross, an English army surgeon in India, found that malarial infection can occur only through the bite of a certain mosquito (Anopheles), and that the parasite of malaria passes through an extraordinary life cycle in which the mosquito is the definitive host and man the intermediate host. The manner in which the mosquito acquires the parasite and conveys it to man is briefly as follows: On sucking the blood of a malarial subject the parasite is taken into the stomach and intestines of the insect. It passes thence to the salivary glands, where it remains until the mosquito bites again, when through the muscular effort of sucking blood the parasite is readily injected into the tissues of the person on whom the insect is feeding.

(Abbott.)

From these discoveries the former reasons assigned as causes of the disease were easily explained, viz. 
marshy lands, rainfall, polluted water, season, and prevailing winds. Mosquitoes breed in marshy places where the amount of moisture would vary with the rainfall; their time of breeding and development coincides with the malarial season; and they are carried considerable distances by the wind.

Prophylaxis. - For generations malarial fevers have been combated with repeated doses of quinine, which is injurious and destructive to the young parasites of malaria. For this reason the quinine is given when the fever is declining, which is soon after the young broods enter the blood. Persons suffering from malarial fever should be shielded from further mosquito bites, as the insects can only become infected by sucking the blood of the malarial patient, and if there are no infected mosquitoes there will be no malarial infection for other persons.

The draining of lowlands and the application of kerosene to standing water has rid many localities of malaria by destroying the breeding places of mosquitoes; but the expense of such procedures is great, and consequently not always practical.

The screening of houses is one of the most effectual methods of preventing malarial fevers. This way shields the person suffering with the disease from further bites, and as the Anopheles is not active until 
sundown, the occupants of a well-screened house are comparatively safe from infection.

Among the many extremely interesting experiments carried on to demonstrate the proof that the Anopheles is the host of the parasite of malaria were those of the English doctors who lived for months on the Roman Campagna, where malaria has raged for centuries. These men occupied a mosquito-proof house, and while they drank the same water and mixed freely with many natives who were suffering from the disease, they did not contract it.

Another interesting experiment was made by sending mosquitoes which had bitten malarial patients, from Italy to England, where Dr. Manson permitted himself to be bitten by them and contracted a typical attack of malarial fever. 


\section{CHAPTER XVI}

INFECTIOUS DISEASES OF UNKNOWN CAUSE

Smallpox (Variola), Hydrophobia (Rabies), Scarlet Fever, Measles, Whooping Cough, Mumps, Yellow Fever, Typhus Fever, Rocky Mountain Spotted Fever, Epidemic Infantile Paralysis.

Among the common transmissible diseases are a number which have been the subjects of research and experiment continuously since the founding of the science of bacteriology, but which yet must be listed as of unknown origin.

\section{Smallpox, or Variola}

Smallpox is an acute, infectious, highly contagious, eruptive disease. The eruption passes through three stages, (1) papular, (2) vesicular, and (3) pustular, and finally heals with a scab. Like most eruptive diseases, smallpox is especially contagious during the period of desquamation. Several microorganisms, have been found in the lesions of smallpox, but none have been proved to be the cause of the disease. 
The pyogenic bacteria are nearly always found in the pustules of smallpox, and it is said that when the secondary infection is due to streptococci, the attack is nearly always fatal.

Smallpox is common to all ages, but by far the greatest number of deaths occur among young persons. The colored races are more susceptible to smallpox than the whites.

Historical medical records relate the existence of smallpox in Central Asia during the tenth century, in Europe during the twelfth century, and that it was introduced into North America by the Spaniards in the sixteenth century.

Transmission. - The modes of infection in smallpox, like the microörganism which causes it, are still questions to be answered; for years it was thought the transmission was through the air, and of course by contact, but the air-borne theory is now questioned by some of the best authorities, and no new light has been thrown on the subject.

Prophylaxis. - For the prevention of smallpox vaccination is by far the most important measure to be employed; without vaccination, isolation and disinfection can be of limited effect.

Prior to Jenner's discovery of the value of the virus 
of cowpox (vaccina), inoculation had been practiced. It had been found that inoculation by scarifying the skin and introducing a small amount of virus from a smallpox pustule would usually result in a mild attack of smallpox, with immunity from the disease in the future; but this form of the disease was as contagious as smallpox contracted in the usual way, and not infrequently was of a serious, if not fatal, type.

In 1798 Jenner published an account of his discovery that vaccination with the virus of cowpox produced only a slight local infection and conferred immunity from smallpox. Jenner had observed that milkers were often infected through abrasions upon the hands by the pustules of cowpox upon the cow's teats, and that they were henceforth immune from smallpox. The fact that vaccination not only conferred immunity for several years, but that the general symptoms produced were of the mildest character and non-contagious, led to its adoption in all civilized countries, which has resulted in stamping out the frightful epidemics of smallpox which were formerly common occurrences.

Vaccination should always be done under the strictest aseptic conditions: that serious secondary infections have often occurred through vaccination 
cannot be denied, and so long as these occur there will always be violent objectors to all vaccination among the ignorant who neither understand the principle of immunity nor the possibilities of secondary infection.

The relation of smallpox (variola) to cowpox (vaccina) is still a subject for controversy, having raged without ceasing since Jenner's discovery in 1798 .

At the present time the supply of vaccine is obtained by the continuous inoculation of calves, which are kept at the vaccine laboratories for that purpose.

\section{RABIES, OR HYDROPHOBIA}

Rabies, or hydrophobia, is an infectious disease which is communicated from one animal to another or to man by a bite. The name hydrophobia (fear of water) is a misnomer, as the subjects suffer no fear of water, but have a dread of the act of swallowing anything, which causes severe spasms of the muscles of the throat.

All attempts to discover the organism contained in the virus of hydrophobia have so far been fruitless'. That the disease is caused by a microörganism seems to be accepted as a fact, as there are many points of resemblance between the infection of rabies 
and some of the bacterial diseases, notably tetanus. Pasteur's protective inoculation serum is also regarded as another proof that hydrophobia is due to a specific microörganism, which is too small to be seen with a microscope (ultra-microscopic).

In the rabid animal and in man the virus is contained in the saliva. Infection occurs through the bite, bites upon an exposed surface such as the face and hands being usually much more serious than when the skin is covered by the clothing; in the latter case the clothing holds back the saliva. Infection may also be carried by the licking of an abraded surface by a rabid animal.

Hydrophobia occurs epidemically among wolves, dogs, sheep, cattle, and horses; but wolves and dogs are the most susceptible.

There are two forms of hydrophobia: (1) furious rabies, characterized by restlessness, and (2) dumb or paralytic rabies.

In animals the period of incubation is from three to six weeks, the first symptoms being restlessness, snapping, and tearing at all objects or persons, a peculiar change in the tone of voice, followed by spasms of the throat muscles upon attempts at swallowing, with an abundance of saliva. General 
convulsions and paralysis are speedily followed by death.

In man the period of incubation is from two weeks to six months or more, the average period being forty days. The initial symptoms in man are pain near the site of infection, with great nervous irritability, followed by the characteristic spasms of the throat muscles, delirium, general convulsions, paralysis, and death, the duration of the disease being usually from four to eight days.

Prophylaxis. - Prior to 1885 the only treatment given to persons who had been bitten by rabid animals was the cauterization and ordinary surgical care of the wounds; but Pasteur at this time made public the results of his great work in discovering a protective inoculation serum against hydrophobia. His experiments were a brilliant success, and have resulted in the establishment of Pasteur Institutes for the treatment of hydrophobia in all parts of the world.

The success of the treatment or immunization depends largely upon the time which elapses between the bite and the beginning of the treatment. It is now customary to send persons who have been bitten by rabid animals with all possible speed to the nearest Pasteur Institute for treatment. 
When any doubt exists concerning the rabid condition of the animal, it is never killed, but kept for observation, as a diagnosis after death is often impossible.

In the statistics of the Pasteur Institute of Paris it is shown that in 1886 there were 2671 persons treated, with 25 deaths; and in 1898 there were 1465 persons treated, with 3 deaths.

\section{Scarlet Fever}

Scarlet fever is an acute fever, accompanied by a diffused, vivid scarlet rash from which it derives its name, and by throat complications, varying from a simple sore throat to a serious diphtheritic infection. The organism which causes scarlet fever is still unknown, although many years of research have been devoted to the subject by bacteriologists in all parts of the world. Secondary infections of streptococci are very common in scarlet fever.

The sources of infection in scarlet fever are still disputed points, while there is probably no doubt that infectious particles are projected from the mouth and nose by the acts of sneezing and coughing, the former theory that the peeling epidermis was the chief source of danger is no longer held by the best authorities.

Rigid quarantine, with scrupulous disinfection of 
everything contained in the sick room, are the best prophylactic measures to be employed.

Measles, mumps, and whooping cough are all infectious diseases of childhood of unknown origin. In family life isolation is rarely enforced, as the diseases are so highly contagious that room quarantine is not usually effective. In hospitals, where better facilities for isolation are found, rigid quarantine is always observed.

\section{Yellow Fever}

Yellow fever is an infectious fever characterized by a high temperature, great prostration, vomiting of mucus, followed by bile (" black vomit"), diminished secretion of urine, and albuminuria. The fatalities are very high, ranging from 35 per cent to 99 per cent in different epidemics.

The disease is endemic in the West Indies, in Brazil, and in West Africa, from which it is sometimes carried into neighboring countries, resulting in terrible epidemics which are only controlled by the advent of frost.

No organism has yet been proven to be the cause of yellow fever, although there seems to be no doubt that the disease is due to an ultra-microscopic germ which is contained in the blood of the infected person. 
The disease has been reproduced by the injection of a portion of blood, taken from a yellow-fever patient, into a susceptible person.

For centuries it was supposed that the disease was carried by contact. In 1900, following the SpanishAmerican War, a United States Army Commission was appointed to investigate the cause and modes of transmission of yellow fever, which resulted in finding proof of the method of infection, although the cause is still unknown.

Several years prior to 1900, Dr. Carlos Finlay of Havana had advanced the theory that yellow-fever infection is carried by mosquitoes, and taking this theory as a basis the Commission proved without question that infection is carried only by a certain species of mosquito, Stegomyia fasciata, in the same manner as the Anopheles carries the parasite of malaria. The doctors of the Commission reared the mosquitoes from eggs, and then allowed them to bite yellow-fever patients, and later to bite non-immunes who had been quarantined and could not possibly have contracted yellow fever in any other way. Of twelve non-immunes ten contracted yellow fever.

In later experiments seven men lived for twenty days in a mosquito-proof house; these men slept in the soiled garments of yellow-fever patients, but no 
infection followed, showing conclusively that the disease can be contracted only by the bite of the mosquito, Stegomyia fasciata.

In Havana, Cuba, during the year 1900-1901, the yellow-fever cases numbered 1240 and the deaths 305. In the following year, 1901-1902, there were 31 cases and 6 deaths.

Typhus fever, which resembles Rocky Mountain spotted fever in some respects, is thought to be identical with Mexican tabardillo; it is also shown that "Brill's disease" is a form of typhus infection. The specific germ has not been isolated. The disease may be transmitted by the bite of the louse, and possibly by the bite of the flea and the bedbug.

Rocky Mountain Spotted Fever. - This disease as far as is known is confined to the Bitter Root Valley of Montana and the neighboring mountains, and is transmitted by ticks. The germ has not been isolated.

Epidemic Infantile Paralysis. - Although it has been known for fifty years that this disease is infectious and carried from one person to another by contact, presumably in the nasal discharges, the microörganism has not been isolated. 


\section{CHAPTER XVII}

BACTERIA IN AIR, SOIL, WATER, AND FOOD

THE presence of bacteria in air, in soil, in water, and in foods is constant, and under favorable conditions for their growth and multiplication may become a serious menace to health.

In air bacteria may always be found upon the floating dust, the largest number occurring in crowded dwellings and in the air nearest to the surface of the earth in cities. In the higher altitudes, as in the mountains, the number of bacteria decreases with the altitude.

It is not only when the bacteria in the air belong to the disease-producing class that they constitute a source of danger, for the action of the bacteria concerned in the process of decomposition and putrefaction may be particularly dangerous in foods, and must be especially considered in the care of foods.

The theory of "air-borne" infection boing much disputed, has largely been supplanted by the 
BACTERIA IN AIR, SOIL, WATER, AND FOOD 173 proofs of the greater frequency of "contact" infection.

In Soil. - Besides the saprophytes which grow and multiply in the soil, and are necessary to the soil and to the higher plants, there are several pathogenic bacteria which find favorable resting places in the soil, notably tetanus, and typhoid-fever bacilli, and the spirilla of Asiatic cholera.

Cultivated garden soil, which is frequently fertilized, shows the greatest number of bacteria, owing to the presence of dead organic material, and sandy soil the least. In favorable soils bacteria may be found to the depth of four or five feet in the soil.

Wherever filth of any kind, as manure, sewage, and decaying vegetation, is deposited in or upon the soil, pathogenic bacteria are usually found. Their growth and multiplication in the soil is still a disputed question, although typhoid bacilli and the spores of tetanus may survive and retain their virulence for many months in soil containing large quantities of organic matter, such as would be found in a garden. Experiments have proven, however, that in time the soil bacteria will overcome the disease-producing organisms, or in other words the soil purifies itself.

In Water. - Water outside of the laboratory is never free from bacteria, although most of them are 
harmless to man, unless present in extraordinary numbers.

The appearance of water cannot be a guide for its purity, neither are the odor or flavor any indication of its real condition. It is conceded that the only way by which the purity of water may be determined is by bacteriological examination.

Surface drainage and sewage are the most common sources of water pollution; both carry enormous quantities of organic matter, including human excreta, which is always particularly dangerous, into wells and other sources of water supply, and both are very likely to contain many pathogenic bacteria.

Polluted water carries infection by its use as drinking water, or by its use for washing dishes, or by its use for cleaning foods which are eaten without cooking, such as celery, lettuce, radishes, tomatoes, and many fruits. For domestic use, filtration with a proper filter or boiling for ten minutes are the best methods of purifying water. In large cities sand filtration is employed to free the water from bacteria; a well-managed sand filter will or should hold back 98 per cent of the bacteria.

In Food. - The bacteria which, by their activities, cause the decomposition and putrefaction of dead organic matter are to be reckoned with in every 
BACTERIA IN AIR, SOIL, WATER, AND FOOD 175

household in the care of food supplies. For this reason food is kept at a low temperature to prevent bacterial growth, and to preserve food for any length of time it is sterilized and sealed while boiling hot. Besides sterilization and low temperature, perfect cleanliness is the most important measure to be employed against the invasion of bacteria and its resulting decomposition. Unclean utensils, dish towels, and ice boxes will infect the best food materials very quickly, and are no doubt the indirect cause of many causes of food poisoning which we call "ptomain-poisoning."

Unclean methods of handling meat, fish, and milk are particularly favorable to the development of bacteria which produce highly poisonous substances.

Bacteria are found in all milk, the amount varying with the cleanliness of the cow, of the stable, of the utensils, of the milker, and all other persons who may handle it. Pathogenic bacteria are often found in milk, and may come from a diseased cow, from a diseased milker, from polluted water used upon utensils, or from insects which often carry infectious materials upon their feet and bodies; in fact, the ways of handling milk from the cow to the consumer take it through so many hands, utensils, and variations of temperature that infection through milk 
is extremely common, and at the same time it furnishes one of the most favorable media for the growth and multiplication of bacteria of all kinds.

Many large cities have established a system of milk inspection which rejects milk containing over a certain number of bacteria, thus recognizing that milk is one of the most important articles of food in common use.

Typhoid fever, diphtheria, scarlet fever, tuberculosis, and infantile diarrhœeas and gastric disorders are largely disseminated by means of impure milk.

Cleanliness is the most important measure used for controlling the infection of milk; while "Pasteurizing" by heating to $60^{\circ} \mathrm{C}$. $\left(140^{\circ} \mathrm{F}\right.$.) for twenty minutes will destroy any ordinary bacteria which milk may contain.

The action of all bacteria upon food materials is not however to its detriment; in many articles of food, such as butter, cheese, and other milk products, vinegars, wines, etc., the activities of certain bacteria are necessary for their flavor or aroma.

In several industries, as the tanning of hides for leather, and in the preparation of flax for linen, bacterial activity forms an important part of the process. 


\section{INDEX}

Acid, production of, 11, 44 .

Acid-proof bacteria, 87.

Actinomyces, 102.

Actinomycosis, 102.

Adaptability of bacteria, 30 .

Aërobes, 29.

Agar, 25.

Agglutinins, 65 .

Alexin, 60.

Alkali, production of, 44 .

Anaërobes, 29.

Animal inoculation, 26.

Anopheles, 159.

Anthrax, 104.

Antibodies, 65.

Antiseptics, 34.

Antitoxin, 57, 121, 132.

Asiatic cholera, 147.

Attenuation, 56.

Autoclave, 21.

Bacillus, 9.

anthracis, 104.

botulinus, 134 .

chauvei, 133.

coli, 108.

diphtheriæ, 117.

influenzæ, 134.

Klebs-Löffler, 117.

Koch-Weeks, 137.

lepræ, 97.

mallei, 100.

pestis, 137.

pneumoniæ, 71 .

psittacosis, 108.

tetani, 126.

tuberculosis, 86.

typhosus, 109.

Welchii, 133.

Bacteremia, 49.

Bacteria, adaptability of, 30 . and disease, 46. chemical composition of, 13 .

discovery of, 1.

effects of chemicals upon, 33 .

effects produced by, 43 .

in soil, $32,173$.

methods of study, 15 .

structure and development, 9, 10

Black death, 137.

Bovine tuberculosis, 89.

Bubonic plague, 137.

Carbolic acid, 36.

Carbol-soap, 38.

Cholera, 147.

Coccus, 9.

Colonies, 12.

Colon-typhoid bacilli group, 108.

Copper sulphate, 36.

Corrosive sublimate, 36 .

Crenosol, 37.

Creolin, 37.

Culture media, 19, 25.

tubes, 24.

Diphtheria, 117.

antitoxin, 57, 121.

Diplococcus pneumoniæ, 71 .

Disinfectants, 34, 40.

Dysentery, 155.

Endotoxins, 45.

Entamœba histolytica, 156.

Enteritis, 108.

Enzymes, 43.

Epidemic cerebro-spinal meningitis: 74.

Farcy, 101.

Fermentation, 44.

Flagella, 9.

Food, for bacteria, 30 .

Foot-and-mouth disease, 47. 
Formaldehyde, 39 .

Fränkel's pneumococcus, 71 .

Gas production, 44 .

Gelatin, 18.

Glanders, 100.

Glassware, 23.

Gonococcus, 76.

Gonorrhœea, 76.

Hay bacillus, 10.

Hydrophobia, 165.

Immunity, 54. active, 55 .

passive, 55.

Inflammation, 66.

Influenza, 134.

Infusoria, 3.

Involution forms, 9 .

Klebs-Löffler bacillus, 117.

Koch-Weeks bacillus, 137.

Leprosy, 97.

Light, 28.

Lysol, 37.

Malaria, 158.

Malignant edema, 133. pustule, 106.

Mallein, 102.

Measles, 169

Meningitis, 74 .

Meningococcus, 74 .

Microscopic methods, 26.

Milk, as a culture medium, 113.

Mixed infections, 50.

Moisture, effects of, 29.

Morphology, of bacteria, 7 .

Motility, 9.

Nitrifying bacteria, 32 .

Nucleus, 9.

Opsonic index, 62.

Opsonins, 62.

Otitis media, 68.

Oxygen, 29.

Parasites, 30.

Phagocytosis, 61.

Phosphorescence, 43.
Photogenic bacteria, 43.

Pigment, 44.

Plague, 137.

Plasmodium malariæ, 158.

Pneumococcus, 71.

Pneumonia, 66, 71.

Potassium permanganate, 35 .

Preservation of foods, 174 .

Protozoa, 155.

Pseudo-diphtheria bacillus, 125.

Ptomains, 44.

Pure culture, methods of obtain ing, 5, 18.

Putrefaction, 43.

Pyemia, 67.

Rabies, 165.

Relapsing fever, 154.

Saprophytes, 31 .

Sarcinæ, 10.

Scarlet fever, 168.

Septicæmia, 49, 67.

Sleeping sickness, 157.

Smallpox, 162.

Soap, 37.

Spirillum, 9.

choleræ, 147.

obermeieri, 154.

Spirochæta pallida, 81 .

Spontaneous generation, 4.

Spores, 11.

Sporozoa, 155.

Staining, 25.

Staphylococcus, 67.

albus, 67.

aureus, 67.

Sterilization, 20.

by heat, 20 .

by chemicals, 20 .

discontinuous, 21.

Sterilizer, hot air, 20.

Arnold's, 22.

Streptococcus, 68.

Sulphur dioxide, 35 .

Suppuration, 66.

Susceptibility, 54.

Syphilis, 80.

Tanning, 176.

Temperature relations, 27.

Tetanus, 126. 
Thermal death point, 28 .

Thermogenic bacteria, 43.

Tick, 157.

Toxæmia, 49.

Toxins, 44, 120.

Transmission of infection, 51 .

Treponema pallidum, 81 .

Trypanosomes, 157.

Tsetse-fly disease, 157.

Tuberculin, 96.

Tuberculosis, 85 .

Typhoid fever, 108.
Ulcerative endocarditis, 68.

Vaccination, 116, 152, 163.

Venereal diseases, 76.

Virulence, 48, 66.

Whooping cough, 169.

Widal reaction, 65, 115.

Yellow fever, 169. 

Advice to Consumptives. Home Treatment, . After-Care, and Prevention

\author{
BY NOEL DEAN BARDSWELL, M.D. \\ MEDICAL SUPERINTENDENT, KING EDWARD VII SANATORIUM \\ Cloth, 148 pp., index, 12mo, \$o.75
}

The after-care of the consumptive on leaving the sanatorium is of the highest importance, and just the knowledge that is required for this care by an expert of the first rank will be. found in this convenient little volume.

Nursing the Insane

BY CLARA BARRUS, M.D.

Cloth, 409 pp., index, 8vo, $\$ 2.00$

The author of this very important book is the woman assistant-physician in the State Homeopathic Hospital for the Insane at Middletown, N.Y. It is addressed primarily to the special nurse, and unites with minute directions for the care of persons whose minds, as well as their bodies, are diseased, an explanation of the reason for each thing recommended. To physicians the book is important as marking the great advance which has taken place in the last few years in the whole subject of treating insane patients.

\title{
Confessio Medici
}

$$
\text { Cloth, gilt top, I58 pp., I2mo, \$I.25 }
$$

"There is nothing sensational about this book. . . It is just a series of talks by a man who has seen much and thought much,"-Express (Buffalo).

The Conquest of Nerves

By J. W. COURTNEY, M.D.

$$
\text { Cloth, gilt top, } 209 \text { pp., index, I2mo, \$1.25 }
$$

A book of sensible, practical advice with regard to the fundamental principles of mental healing and the applications of these principles that can safely be made by every person for himself. From the best possible standpoint - that of a broad-minded, experienced physician - Dr. Courtney takes up this principle and discusses it.

\section{The Healthy Baby: The Care and Feeding of}

\section{Infants in Sickness and in Health}

\section{BY ROGER H. DENNETT, M.D.}

INSTRUCTOR IN DISEASES OF CHILDREN IN THE NEW YORK POST-GRADUATE MEDICAL SCHOOL, ASSISTANT ATTENDING PHYSICIAN TO THE BABIES' WARDS IN THE NEW YORK POST-GRADUATE HOSPITAL; CHIEF OF CLINIC IN THE POST-GRADUATE DISPENSARY FOR CHILDREN; FELLOW OF THE NEW YORK ACADEMY OF MEDICINE

$$
\text { Cloth, } 235 \text { pp., index, I2mo, \$1.00 }
$$

Dr. Dennett is a well-known physician in New York City and is also a writer of reputation. What he has to say, therefore, on such subjects as appetite, clothing, the bath, exercise, discipline, nervousness, fever, the throat, the teeth, milk, and mixing and care of the food, and food for traveling, is certain to secure wide attention. Physicians can well recommend this book to mothers. 


\section{A Laboratory Hand-book for Dietetics}

\section{BY MARY SWARTZ ROSE, PH.D.,}

ASSISTANT PROFESSOR DEPARTMENT OF NUTRITION, TEACHERS COLLEGE, COLUMBIA UNIVERSITY

$$
\text { Cloth, I27 pp., index, I2mo, \$I.Io }
$$

This work is the outcome of several years of remarkably successful teaching. It explains the problems involved in the calculation of food values and food requirements, and the construction dietaries. It also furnishes reference tables giving food values for the roo-caloric portion, for the gram, ounce and pound, which will minimize the labor involved in such work without limiting the dietary study to a few food requirements. Such data have been included as seem most useful for determining the amount of food for any normal individual under varying conditions of age and activity. As the work is designed to be a laboratory notebook, as well as a manual for calculations, ample space has been allowed for convenient writing.

\section{Anaesthetics and Their Administration}

\section{A Text-Book for Medical and Dental Practitioners and Students}

\section{By SIR FREDERIC HEWITT,}

ANESTHETIST TO HIS MAJESTY THE KING, AND TO THE HOSPITALS IN LONDON

$$
\text { Cloth, 8vo, } 676 \text { pp., with } 71 \text { illustrations, index, } \$ 5.00
$$

The present edition differs considerably from its predecessors. In the first place, its publication has been rendered imperatively necessary by the extraordinary changes that have recently taken place in the practice of anæsthesia - changes so revolutionary in their character that large sections of the book have had to be completely rewritten. In the second place, it contains two wholly new chapters - added after much deliberation - one on local and regional anasthesia, and the other on the medico-legal aspects of surgical anæsthesia in general.

\section{The Sexual Life of the Child}

\section{BY DR. ALBERT MOLL.}

TRANSLATED FROM THE GERMAN BY DR. EDEN PAUL, WITH AN INTRODUCTION BY EDWARD L. THORNDIKE, PROFESSOR OF EDUCATIONAL PSYCHOLOGY, TEACHERS COLLEGE, COLUMBIA UNIVERSITY

$$
\text { Cloth, } 339 \text { pp., index, I2mo, \$I.75 }
$$

The Medical Times says: "After reading a great variety of trash on the subject of sexual education of the boys and girls of this generation, it is a pleasure to have the subject taken up in a frank, open, dignified manner by Dr. Moll. He leads one through the mazes of the sexual development of the child, and so cleverly analyzes its real feelings that one instinctively feels one's self well qualified to interpret child psychology and to apply the lessons gained therefrom."

\section{The Care of the Body}

By R. S. WOODWORTH,

PROFESSOR IN COLUMBIA UNIVERSITY

$$
\text { Cloth, } 359 \text { pp., index, 12mo, \$1.50 }
$$

The blood, the circulation, breathing, food, digestion, wastes and their removal, diet, bodily heat, the work of the body, the ear, the eye, nerve and brain, work, rest, and recreation, indulgences, the cycle of life and disease, are among the different topics which the author takes up.

\section{THE MACMILLAN COMPANY




\section{Materia Medica for Nurses}

By A. S. BLUMGaRTEN, M.D.

INSTRUCTOR IN MATERIA MEDICA AT THE GERMAN HOSPITAL TRAINING SCHOOL FOR NURSES, NEW YORK.

8vo, ill.

This book is unique, as it is planned along lines not before attempted. It is in plain, simple English, intensely interesting in style, and is written along strictly pedagogic lines. It therefore contains clear, concise instruction throughout. Stress has been laid upon teaching facts, not words, with the result that, while thoroughly scientific, the book is free from the technical terminology in which seems to lie the fault of so many text-books for nurses.

It will assist and train the nurse in the observation of the effects of drugs as produced upon actual patients in the wards. The physiological action is particularly arranged to facilitate the retention of the facts presented. A special feature will be found in an original and very elaborate chapter on "Solutions." It enables the nurse to handle any problem in the calculation and administration of a required dose of a drug, or to make up any required solution. There is also a chapter on "Prescription Reading," and there are numerous tables such as "Saturation Points," "Comparative Action of Various Drugs," etc., scattered throughout the text. It also contains all the nerw and non-official remedies in common use.

THE MACMILLAN COMPANY Publishers 
Primary Nursing Technique for First Year Pupil Nurses By ISABEL MCISAAC.

$$
\text { Cloth, I2mo, } 197 \text { pp., \$1.25 }
$$

A thoroughly honest book for nurses starting on their course of study. It is written with the one object in view of inculcating in the minds of its readers the fact that an accurate knowledge of the human body is the first essential to successful nursing.

\section{Hygiene for Nurses}

By ISABEL MCISAAC.

$$
\text { Cloth, I2mo, } 208 \text { pp., \$1.25 }
$$

The pages of this book are full of just the information that every woman in charge of souls and bodies needs. The chapters on food, ventilation, sewage, causes and dissemination of disease, household, personal and school hygiene, the hygiene of occupation, disinfection, etc., are all of the most vital interest and should be taken to heart by every one.

\section{Text-Book of Anatomy and Physiology for Nurses}

\section{By DIANA C. KIMBER.}

FORMERLY ASSISTANT SUPERINTENDENT, NEW YORK CITY TRAINING SCHOOL FOR NURSES, BLACKWELL'S ISLAND, N.Y.

Third edition revised by Caroline E. Gray, R.N., Assistant Superintendent, New York City Training School for Nurses.

$$
\text { Cloth, } 8 v o, 438 \text { pp., ill., \$2.50 }
$$

"From her long experience in teaching classes the author knows exactly what nurses need and how much can be reasonably given them in the short space of two years' time, and for the assistance of the inexperienced teacher her book is arranged in lessons covering the first or junior year. The subjects are presented with sincerity and distinction, and illustrated by cuts and plates of unusual merit." - The Trained Nurse.

\section{Home Nursing}

$$
\begin{aligned}
& \text { By ISABEL MACDONALD. } \\
& \text { Cloth, } 326 \text { pp., I2mo, \$o.80 }
\end{aligned}
$$

Miss MacDonald, in her Preface to this admirable and most useful book on Home Nursing, expresses her belief that " there is room for a work written in simple language and showing more fully than is possible in a lecture how to alleviate pain and discomfort, how to avoid pitfalls and mistakes, and how to help in saving valuable lives in times of sickness and danger."

\section{District Nursing}

BY MABEL JACQUES.

With an Introduction by Dr. John H. Pryor.

Cloth, I2mo, $\$ 1.00$ by mail $\$ 1.08$

The writer has given us a book that is practical and useful, and one which will prove a great help to all who take an active, personal share in social advance.

\section{THE MACMILLAN COMPANY}

\section{Publishers}




\section{The Treatment of Fractures by Mobolization and Massage}

\section{BY JAMES B. MENNELL,}

HOUSE SURGEON AND CASUALTY ASSISTANT, ST. THOMAS' HOSPITAL, LONDON, WITH AN INTRODUCTION BY DR. LUCAS-CHAMPONNIĖRE, CHIRURGIEN HONORAIRE DE L'HOTEL DIEU, MEMBRE DE L'ACADEMIE DE MEDICINE, PRESIDENT DE LA SOCIETE INTERNATIONALE DE CHIRURGIE, ETC.

$$
\text { Cloth, } 8 v 0,458 \text { pp., ill., } \$ 5.00
$$

Dr. Mennell has made his work a practical, rather than a pathological, treatment of fractures by methods which, although well known on the Continent, have as yet been little used in America and England.

Dr. Mennell's success in this method of treatment of fractures has been marked and his experience has been ample. His ideas are revolutionary but are worthy of very serious consideration, and we would strongly urge every physician who has occasion to reduce fractures to read this book.

\section{Mind and Health}

$$
\begin{aligned}
& \text { By EDWARD E. WEAVER, PH.D. } \\
& \text { Cloth, } 500 \text { pp., I2mo, } \$ 2.00
\end{aligned}
$$

This treatise is an attempt to embody some of the latest results of the psychological study of the influence of mental states upon health. After a thorough psychological discussion, a painstaking examination is made of various systems of healing of a religious character from the standpoint of present-day scientific mental healing. Both the strong points and weaknesses of these systems are pointed out.

\section{The People's Medical Guide}

Points for the Patient, Notes for the Nurse, Matter for the Medical Adviser, Succor for the Sufferer, Precepts for the Public.

$$
\begin{aligned}
& \text { By JOHN GRIMSHAW, M.D. } \\
& \text { B.s. (Lond.), D.P.H. (СAmв.), M.R c.s. (ENG.), втc. } \\
& \text { Cloth, } 839 \text { pp., index, glossary, ill., } 8 v o, \$ 3.00
\end{aligned}
$$

A medical guide for the people, thoroughly modern in matter and tone, embracing all the remarkable advances of the last decade. Besides constituting a plea for a reform in medical education, this book is an exposition of the different branches of medical work and social reform.

\section{Biological Aspects of Human Problems}

\section{BY CHRISTIAN A. HERTER, M.D.}

LATE PROFESSOR OF PHARMACOLOGY AND THERAPEUTICS IN COLUMBIA UNIVERSITY

$$
\text { Cloth, } 344 \text { pp., I2mo., \$I.50 }
$$

This work gives the personal convictions of a foremost authority on the far-reaching effects of Biology. Dr. Herter first discusses in what respects the animal body may be regarded as a mechanism, next he treats of the nature of the self-preservative and sexual instincts which appear to be the most fundamental of all instinctive qualities in living protoplasm. Following this the various instincts of human nature, such as those which relate to imitation, affection, love of beauty, the awe of the powerful and unintelligible, are taken up, while finally the tendencies in development in education, literature, music, art, business, politics and science, are considered. There has been no saner exposition of the essential duties of life.

\section{THE MACMILLAN COMPANY}


"We have no hesitation in saying that this work will live as one of the greatest biographies in the English language." - The Daily Chronicle, London.

\title{
The Life of Florence Nightingale
}

\section{By SIR EDWARD COOK}

\author{
With Photogravure Portraits
}

Two volumes. Cloth, $8 v 0, \$ 7.50$

carriage extra

"This book," says the author in his Introductory remarks to this notable biography, "is not a history of the Crimean War, nor of nursing, nor of Indian administration. Something on all these matters will be found in it ; but only so much of detail as was necessary to place Miss Nightingale's work in its true light and to exhibit her characteristic methods. So, also, many other persons will pass across the stage-persons drawn from many different classes, occupations, walks in life; but the book does not aim at giving a detailed picture of 'Miss Nightingale's circle.' Her relations, her friends, her acquaintances, her correspondents only concern us here in so far as their dealings with her affected her work, or illustrate her character."

The biography is in two volumes and is divided into seven Parts. Part I tells the story of Florence Nightingale's early years and her early aspirations for a life of active usefulness. Part II is devoted to the Crimean War, where it was as Administrator and Reformer rather than as the Ministering Angel the Lady with the Lamp - that her peculiar powers were shown. Part III portrays her laying her plans for the health of the British Soldier - the period of her close coöperation with Sidney Herbert. Part IV describes, as its main themes, the work she did as Hospital Reformer and the Founder of Modern Nursing. Part V deals with a new interest in her life and a new sphere of her work. Her efforts on behalf of the British Soldier at home led to a like attempt for the army in India. Then gradually she was drawn into other questions, till she became a keen Indian reformer all along the line. Part VI continues this subject, and introduces another sphere in which her influence had important significance, namely, the reform of the Workhouse Nursing; and as one thing led to another it will be seen that Florence Nightingale deserves also to be remembered as a Poor Law Reformer. Part VII comprises the last thirty-eight years of her life - a period which, though it has admitted of more summary treatment, was full of interest. It deals with her literary work and her studies in Plato and Christian Mystics. An endeavor is made to portray her as the "Mother-Chief" (as she was called) of the nurses. It describes other of her projects and realizations, and so brings the long and wonderful life to a close.

It should be pointed out that for the purposes of this work Sir Edward Cook has had access to the family papers, and has therefore been able to prepare the first full and authentic record of Florence Nightingale's character and career. The volumes are rendered additionally attractive by the inclusion of several interesting portraits.

"A masterly biography which not only puts into a permanent record her whole-souled devotion and humanity, but relates the history of one of the greatest and most fruitful movements of modern time. For as Sir Edward well says, her nursing mission in the Crimean War was only the starting point. ... He has put the essence of saintliness into good literature and sober history."- The Pall Mall Gazette.

"A noble biography." - The Daily News, London.

\section{THE MACMILLAN COMPANY}



1

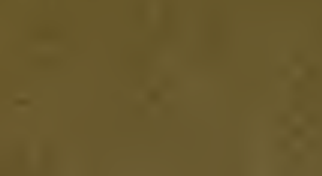

$\sqrt{2}+2$

I

단

8

a .

1

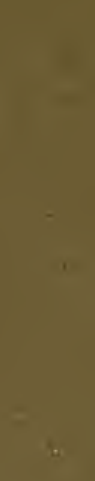




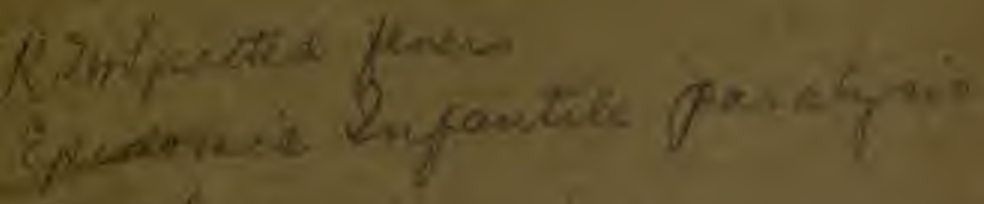

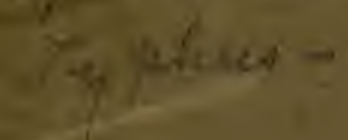


